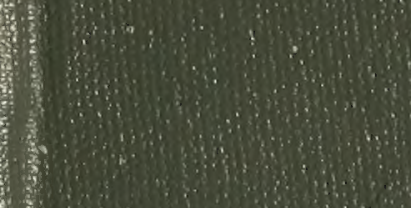

1.7.

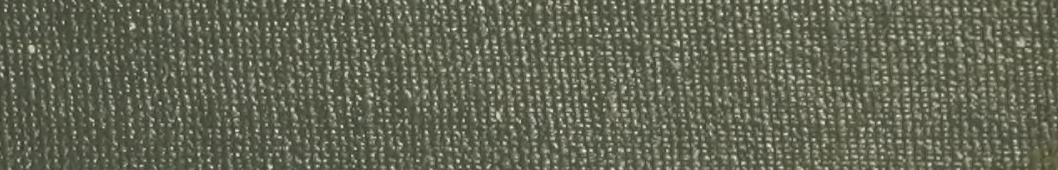

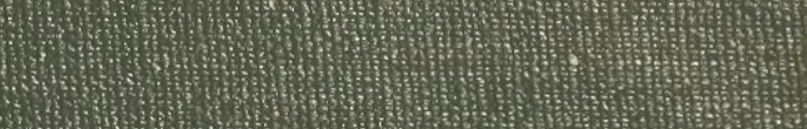

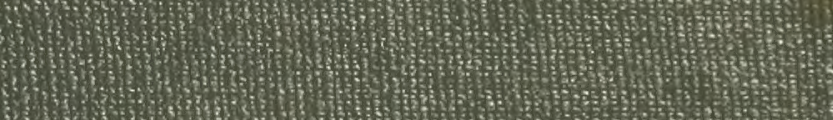

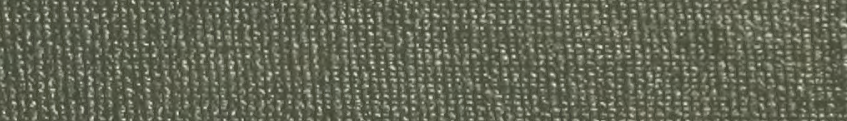
W.7.

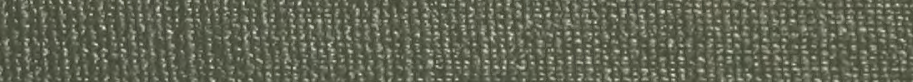

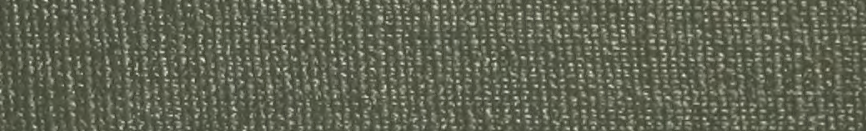

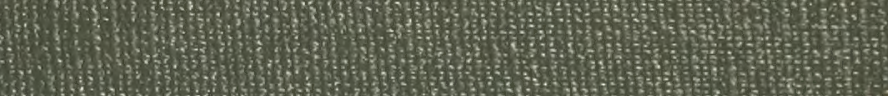
-

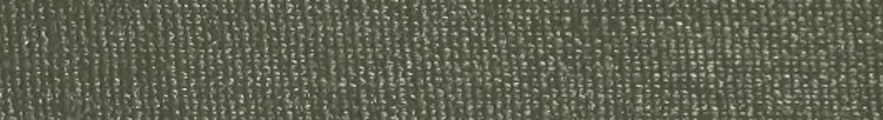
Q 3. WHY W.W

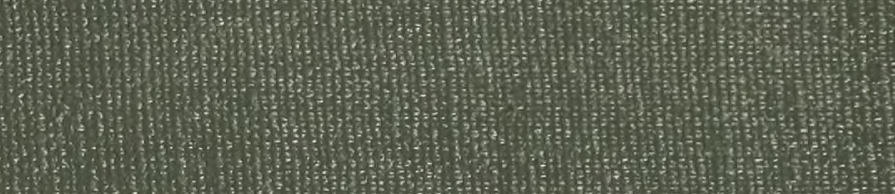

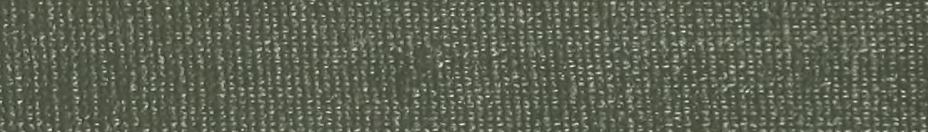
H.WWX) W. WWWWWXW

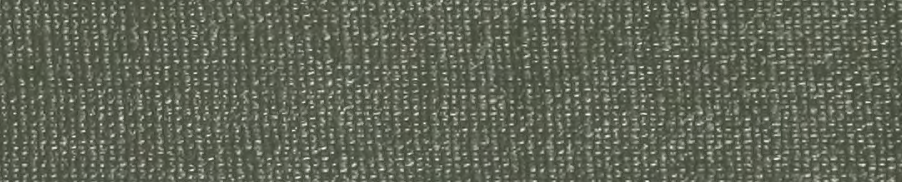
2. W

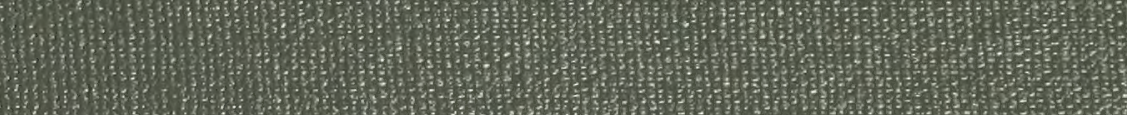

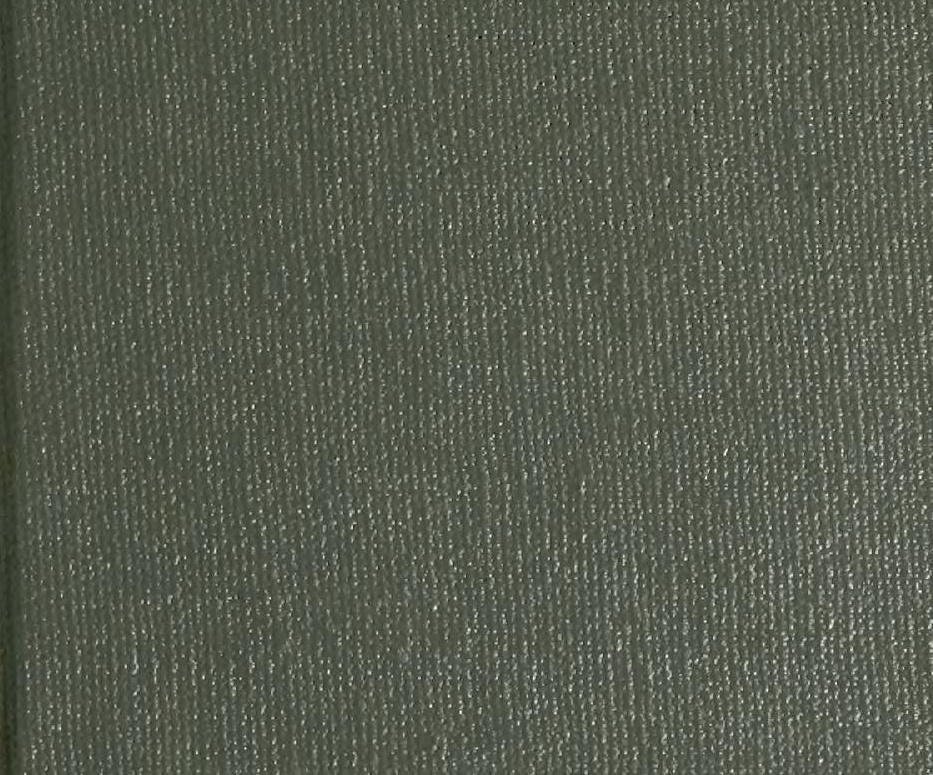
Wh: W.mWm) WWX W

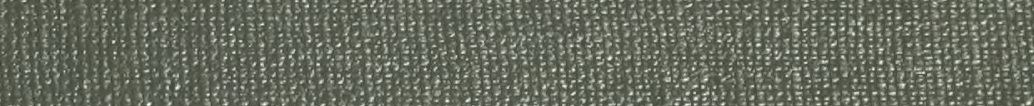
XXm

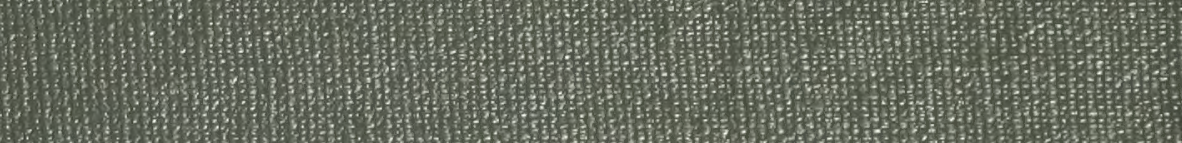
3.7. 2. 2.7.

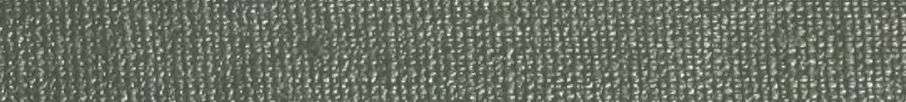





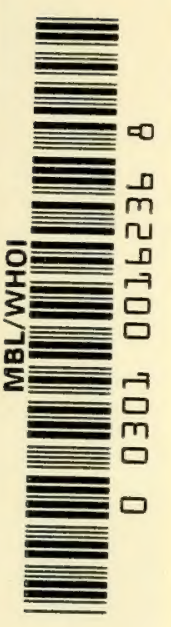







\section{OCLC \# 1037527}

\section{DIE

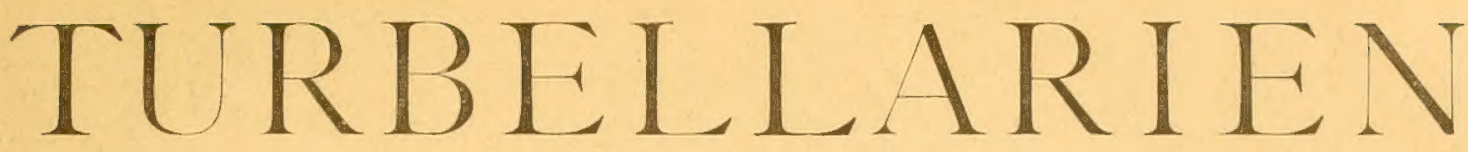 \\ ALS \\ PARISITEN UND WIRTE \\ VON \\ L. V. GRAFF}

BEARBEITET MIT UNTERSTÜTZUNG DER KAISERL. AKADEMIE DER WISSENSCHAFTEN IN WIEN AUS DEM LEGATE WEDL

HERAUSGEGEBEN ALS

FESTSCHRIFT DER K. K. KARL-FRANZENS-UNIVERSIT'ÄT' IN GRAZ FÜR DAS JAHR 1902

MIT 1 TEXT-FIGUR UND 3 TAFELN
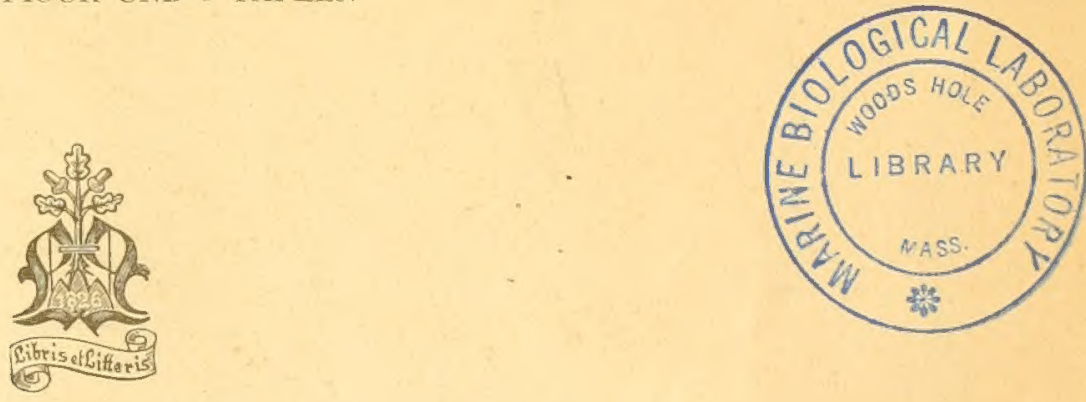

GRAZ

LEUSCHNER \& LUBENSKY'S UNIVERSITÄTS-BUCHHANDLUNG 1903 



\section{INHALT.}

Vorwort $\quad$ Seite

Neue Untersuchungen ... . . . . . . . . . . . . . . . . . . . I

Byrsophlebs nana (Laidlaw) . . . . . . . . . . . . . . . . . I

Provortex tellinae Graff. . . . . . . . . . . . . . . . . . 8

Graffilla buccinicola fames, . . . . . . . . . . . . . . . . . 10

Syndesmis echinorum Frangois . . . . . . . . . . . . . . . . . I9

Genostomatidae nov, fam. . . . . . . . . . . . . . . . . . . 2 I

Genostoma tergestinum (Calandr.) . ... . . . . . . . . . . . . . 22

- marsiliense (Calandr.) . . . . . . . . . . . . . . . . . . . . 24

Urastoma cyprinae (Graff) . . . . . . . . . . . . . . 25

Die bisher bekannt gewordenen parasitischen Turbellarien . . . . . . . . . . . . . 29

Acoela . . . . . . . . . . . . . . . . . . . . . . . . . 29 29

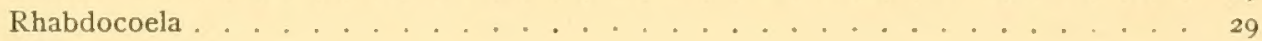

Alloeocoela . . . . . . . . . . . . . . . . . . . . . . 36

Tricladida . . . . . . . . . . . . . . . . . . . . 37

Polycladida . . . . . . . . . . . . . . . . . . . . 38

Der Einfluß des Parasitismus auf den Bau der Turbellarien . . . . . . . . . . . . . . 4I

Freilebende und parasitische Plathelminthen . . . . . . . . . . . . . . . . . . . . . . . 47

Verzeichnis der Turbellarien -Wirte . . . . . . . . . . . . . . . . . . 50

Die Parasiten der Turbellarien . . . . . . . . . . . . . . . . . . . . . . 53

Symbiotische Algen . . . . . . . . . . . . . . . . . . 53

Krystalloide . . . . . . . . . . . . . . . . . . . . . 56

Bakterien und fragliche Protozoen . . . . . . . . . . . . . . . . 58

Sporozoa . . . . . . . . . . . . . . . . . . . . . . . . . . 59

Ciliata . . . . . . . . . . . . . . . . . . . . . . . 62

Orthonectida . . . . . . . . . . . . . . . . . . 63

Trematodes . . . . . . . . . . . . . . . . . . . . . . 63

Nematodes . . . . . . . . . . . . . . . . . . . . . . . . 64

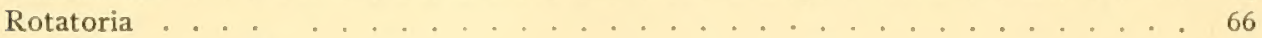

Erklärung der Tafeln I-III .................... . . . . . . . . . 74 



\section{VORWORT.}

In den Lehrbüchern der Zoologie werden noch immer die Turbellarien als „freilebende": Plattwürmer den ,parasitischen" Gruppen der Trematodes und Cestodes gegenübergestellt und damit der Beweis dafür erbracht, daß die Kenntnis von der weiten Verbreitung des Parasitismus in der erstgenannten Abteilung der Plattwürmer trotz der schon vor Jahren von Max Brau n ${ }^{1}$ ) gegebenen Zusammenstellung noch nicht Gemeingut der Fachgenossen geworden ist. Und doch verdienen die bisher schon vorliegenden Mitteilungen über die Organisation der parasitischen Turbellarien eine doppelte Aufmerksamkeit angesichts der nie bezweifelten Tatsache, daß Trematoden und Cestoden v́on den Turbellarien abstammen und daß bei den parasitischen Formen der letzteren dỉe Aufklärung zu suchen sei für den Weg, welcher von freilebenden Formen zu so extremen Anpassungen geführt hat, wie sie uns der Bau und die Entwicklungsgeschichte der Trematoden und Cestoden darbieten.

In dieser Überzeugung habe ich während der, mir durch die kaiserliche Akademie der Wissenschaften in Wien ermöglichten Studienreisen des letzten Jahres mein HauptAugenmerk auf die parasitischen Turbellarien gerichtet und gern die Gelegenheit ergriffen, den diese betreffenden Teil meiner Studien zum Thema der vorliegenden Festschrift zu wählen.

Es schien mir passend, dabei auch die Rolle der Turbellarien als Wirte darzustellen und damit die Aufmerksamkeit auf die, bisher in der Literatur meist ganz übersehenen, zahlreichen Parasiten derselben zu lenken.

Ich benütze diesen Anlaß, um dem hohen k. k. Ministerium für Kultus und Unterricht, der hohen kaiserlichen Akademie der Wissenschaften und den Schiffahrtsgesellschaften des "Österreichischen Lloyd" und der "Adria" für die Förderung meiner Reisezwecke, den Direktionen der biologischen Stationen in Bergen, Alexandrowsk, Neapel und Triest sowie allen den Freunden und Kollegen, welche mich bei meinen Arbeiten mit Material und Auskünften unterstützten, herzlichsten Dank zu sagen.

1) M. Braun, Über parasitische Strudelwürmer. Zusammenfassender Bericht. Centralbl. f. Bakteriologie und Parasitenkunde, I. Jahrg., II, Bd., Jena 1887, pag. 452-457, 478-484. - Nachtrag, ebendas., V. Bd. 1889 , pag. $4 \mathrm{I}-44$. 
Für in dieser Arbeit verwertete Original-Mitteilungen bin ich ganz besonders verpflichtet den Herren: J. Kunstler (S. 9), A. Luther (S.2I u. 56), R. T. Leiper (S. 29), B. Wahl (S. 33), R. v. Stummer-Traunfels (S. 38), Ed. Graeffe (S. 40), S. Prowazek und F. Schaudinn (S. 6I).

Die umfangreiche Literatur habe ich nicht im einzelnen zitiert, sondern überall da, wo bereits Publikationen mit genauen Literaturangaben vorliegen, erstere angeführt und in der Regel nur jene Arbeiten dazu genannt, welche seither erschienen sind, so daß danach der Leser trotzdem einen vollständigen Literatur-Nachweis erhält. Wie in meinen bisherigen Publikationen, so bediene ich mich auch hier bei Verweisungen auf die zitierten Werke der Bezeichnungen pag., tab., fig. und textfig., während S., Taf, Fig. und Textfig. die Seiten, Tafeln und Figuren der vorliegenden Schrift bezeichnen.

In der Nomenklatur folge ich den, vom V. Internationalen Zoologen-Kongresse festgestellten Regeln.

Der befreundeten Firma Werner \& Winter in Frankfurt a. M. danke ich für die vorzügliche Wiedergabe meiner Zeichnungen und der $\mathrm{k}$. $\mathrm{k}$. Universitäts-Buchdruckerei "Styria" für die schöne typographische Ausstattung dieser Schrift. 


\title{
Neue Untersuchungen.
}

\author{
Byrsophlebs nana (Laidlaw).
}

Taf. III, Fig. $1-24$.

Durch wiederholte Sendungen der zoologischen Station Neapel war ich in der Lage, diese von Goodrich und Laidlaw ${ }^{1}$ ) zum ersten Male untersuchte Form genauer zu studieren. Sie lebt als Ektoparasit auf Nephthys scolopendroides Chiaje, u. zw. besonders zwischen den Ruderlappen und an diesen selbst angeheftet, so daß man am besten tut, sie durch einen starken Wasserstrom mit der Pipette von dem Wirte abzulösen oder die, bei den energischen Bewegungen der Wirte abgeworfenen Individuen im Glasteller zu sammeln. Bei dem Mangel von Augen und irgend welchen Pigments sind diese Tiere außerordentlich pelluzid und nicht leicht zu sehen, dagegen fallen sie bei der Abtötung des Wirtes mit schwachem Alkohol oder mit Sublimat ab und es zeigt sich dann, in welch enormer Zahl der Parasit vorhanden ist. So bekam ich im Jänner und Februar von I4 Nephthys zusammen 59 und von 6 Nephthys 129 Exemplare desselben.

Im ausgestreckten Zustande (Fig. I) ist der Körper fadenförmig und erinnert mit seinem fein ausgezogenen Vorderende und der allmählichen Verbreiterung nach hinten an Monoceliden. Der vor dem Munde gelegene „Rüssel" macht im Kriechen gut ein Drittel der Gesamtlänge aus; er ist außerordentlich kontraktil, wird nach allen Seiten tastend ausgestreckt und ich füge zu den schon von Goodrich (1. c. fig. 2) gegebenen Abbildungen noch die Darstellung (Fig. S) der eigentümlichen Gestalt, welche entsteht, wenn das Tier bei Kontraktion des postoralen Abschnittes mit dem Kaudalanhange (ca) verankert ist und den präoralen Teil $(R)$ tastend nach hinten krümmt. Bei der Mehrzahl der abgetöteten Exemplare erscheint der Rüssel dicht vor dem Munde um $45^{\circ}$, oft aber um mehr als $90^{\circ}$ abgeknickt (s. Goodrich, fig. 2, a). Der Kaudalanhang ist beim Kriechen (Fig. I) durch eine seichte Einschnürung als spatelförmige Platte abgesetzt, an der einige Querfurchen zu sehen sind. Letztere sind bei starker Kontraktion (Fig. 2) auch am Hinterleibe wahrzunehmen; der sonst abgeplattete Kaudalanhang setzt sich dann durch eine Ringfurche (*) scharf ab und nimmt bei der Anheftung, je nachdem man ihn bloß von oben (Fig. 3 u. 5) oder auch von hinten zu sehen bekommt (Fig. 4, 6, 7), mannigfache Formen an, bei welchen die hervortretenden Warzen die Punkte der Festheftung vermittels Klebzellen bezeichnen. Die eigentümlichen Papillen, welche besonders auf dem Rüssel, aber auch auf dem übrigen Körper bei der Kontraktion zum Vorschein

1) F. F. Laidlaw, Typhlorhynchus nanus: a New Rhabdocoele, Quart. Journ. Micr. Sc., N. Ser. vol. 45 , London 1902, pag. 637-652, tab. 35 .

v. Graff, Turbellarien als Parasiten. 
kommen, entstelın dadurch, daß das Epithel der starken Muskelkontraktion nicht folgen kann und daher nach außen vorgetrieben wird, ähnlich wie man dies auch bei Syndesmis echinonm (s. unten S. 20) beobachten kann. Diese warzige Erhebung des Epithels (ep) ist umso leichter, als dessen Zusammenhang mit dem Hautmuskelschlauche (hm) ein sehr lockerer ist, wie man an Schnitten sehen kann, welche oft eine Trennung der beiden Schichten des Integumentes auf kleinere oder größere Strecken (Fig. 13, I5, I7, I8) darbieten. Im Leben meist nicht viel über I $m m$ (selten bis $2 m m$ ) lang und in der Gegend des Geschlechtsporus die größte Breite von nahezu 0.2 mm erreichend, kontrahiert sich das Tier auf weniger als die Hälfte seiner Länge. Der Rüssel wird dabei viel stärker als der postorale Abschnitt verkürzt und bildet dann einen ca. ein Siebtel der Gesamtlänge ausmachenden konischen Zapfen, der durch eine dicht vor dem Munde gelegene ringförmige Einschnürung vom Reste des Körpers abgesetzt ist, wie dies in Laidlaws fig. I dargestellt erscheint.

Schon Laidlaw hat die vollständige Bewimperung des Körpers sowie den Mangel von Zellgrenzen und die Spärlichkeit der Kerne in der Epithelialschicht hervorgehoben. Am frischen, lebenden Objekte ist dieselbe am postoralen Abschnitte o०or mm hoch, sinkt aber am Schwanzanhange und noch melır am Rüssel auf o*0o8 $m$, während die Cilien (ci) etwa halb so lang sind, als das Integument dick ist. Die Kerne (epk) sind meist in größeren Intervallen anzutreffen, nur selten - wie im Schwanzanhange (Fig. 24) findet man deren mehrere beisammen. Ihr Chromatin besteht aus auffallend groben Kügelchen und Laidlaws „clusters of nuclei" scheinen den Häufchen von Chromatinkugeln eines einzigen Kernes zu entsprechen. Diese Kerne liegen meist flach in der Basis der Epithelialschicht; wo das Epithel sich in Papillen erhebt (Fig. 24), da sind sie auch rundlich oder oval und senkrecht zur Fläche gestellt anzutreffen (epk I). Dies läßt auf eine sehr weiche Konsistenz der Kerne und Verschiebbarkeit ihrer Chromatinkügelchen schließen. Schon am lebenden Objekte und noch besser an tingierten Präparaten sieht man das Plasma der Epithelialschicht in seiner ganzen Dicke von feinen Streifen durchsetzt (Fig. IO, ep). Laidlaw hat dieselben für Rhabditen genommen, indessen glaube ich diese, in Flächenschnitten (Fig. I4, ep) als dunkle Pünktchen erscheinende Zeichnung für den Ausdruck der Plasmastruktur halten zu müssen, nachdem es mir niemals gelungen ist, aus dem lebenden Objekte diese angeblichen Rhabditen zu isolieren. Der Hautmuskelschlauch (Fig. I4, hm) besteht aus sehr kräftigen, bandartigen inneren Längsmuskeln (Fig. IO, lm) und einer gleichmäßig angeordneten Lage feiner äußerer Ringfasern ( $\mathrm{rm})$. Dazu kommen diagonal gekreuzte, voneinander weit entfernte Fasern, welche zwischen den anderen beiden Schichten liegen (Fig. I4). Auf dem Rande und der Ventralfläche des Schwanzanhanges finden sich die zur Festheftung dienenden Klebzellen markiert durch auffallende Kerne (Fig. IO, k). Die sie enthaltenden Stellen der Epithelialschicht sind an Schnittpräparaten cilienlos und tiefer unter die Oberfläche in eine Aussackung des Hautmuskelschlauches (hm) eingesenkt; das Chromatin der Kerne besteht aus einem größeren Haufen von Kugeln als sonst und von letzteren führen feine Chromatinfäden zu kleineren, dicht unter der Klebfläche (klz) liegenden Kügelchen - eine Gestaltung des Kernes, die mit der sekretorischen Funktion dieser Stellen des Epithels in Beziehung stehn dürfte.

Der M und (Fig. I u. 23, o) liegt an der Basis des Rüssels auf der Ventralfläche; er kann durch einen Sphinkter von kräftigen Ringfasern (sph) verschlossen und durch feine 
Radiärfasern (mr) dilatiert werden. Da das Epithel des Mundrandes sich direkt in das cilienlose und der Kerne völlig entbelırende Pharynxepithel fortsetzt und niemals mit einer Ringfalte auf die Außenwand des Pharynx übergreift, so fehlt hier der sonst so weit verbreitete, als Pharyngealtasche bezeichnete Vorraum. Aber auch in Bezug auf den Bau des Phary $\mathbf{n}$ weicht vorliegende Spezies von allen bekannten Rhabdocoela dadurch ab, daß die sogenannten Pharyngealzellen nicht gleichmäßig rings um das Lumen des Pharynx verteilt sind, sondern der Hauptmasse nach in einem kropfartigen, ventralen Blindsacke (phzs) angehäuft erscheinen. Dieses Verhältnis frappiert zunächst in Quetschpräparaten (Fig. I), an welchen man vergeblich nach dem Lumen sucht, welches durch die bräunliche, von hellen Kernen durchsetzte Masse der Pharyngealzellen zum Darme ziehen soll, bis man erkennt, daß der Sack blind endet und das Pharynxlumen über ihm nach hinten zu dem als Ösophagus (Fig. 23, oe) zu bezeichnenden verengten Darmteile zieht, von welchem ein präösophagealer dorsaler Blindsack sich in den Rüssel fortsetzt, um erst vor dem Gehirne zu enden (Fig. I, da I). Querschnitte durch den distalen Teil des Pharynx zeigen nichts besonders Auffallendes. Wir sehen an denselben (Fig. I4) eine innere Muskularis (mmi) bestehend aus einer unter der Epithelialschicht (phep) angebrachten Lage feiner Längs- und darauffolgender ebensolcher Ringfasern. Diese innere Muskularis schlägt sich direkt auf die Außenwand des Pharynx um, wo also die Längsfasern außen und die Ringfasern innen liegen. Nur sind hier die Längsfasern viel kräftiger und es treten zu ihnen vom ganzen Umkreise her radiäre Muskeln ( $\mathrm{mr}, \mathrm{mr}_{\mathrm{I}}$ ), welche, von der ventralen Leibeswand entspringend, zur Festheftung des Pharynx sowie zu seiner und des Mundes Dilatation dienen. Zwischen innerer und äußerer Muskularis spannen sich die Radiärfasern (Fig. I4 u. 23, rdm) aus, die meist schief vom Rücken zum Bauche verlaufen und daher in auf die Plaryngealachse senkrechten Querschnitten je näher zur Achse des Pharynx, desto mehr quer durchschnitten erscheinen $\left(\mathrm{rdm}_{\mathrm{I}}\right)$. Zwischen den Radiärfasern sind die Pharyngealzellen mit ihren Kernen (phz) eingelagert und während dieselben in der vorderen Wand des Pharynx nicht zahlreicher sind, als sonst bei Mesostomiden, erscheint sowohl ihre Zahl wie ihre Größe enorm vermehrt in dem ventralen Pharyngealzellensack (Fig. I5, I6 u. 23, phzs), der sich überdies, je näher seinem blinden Ende, desto mehr durch eine Abschwächung seiner Muskularis (mm) und den Mangel an Radiärfasern auszeichnet. Wenn die Pharyngealzellen der Mesostomiden wirklich eine Art elastisches Gewebe darstellen, welches durch seine, auf passivem Wege erfolgende, Expansion den durch die Aktion der Muskularis und der Radiärfasern kontrahierten Pharynx wieder rasch ausdehnt und derart ein intensives Pumpen mit möglichst geringem Kraftaufwande ermöglicht, so ist der Pharyngealzellensack vom Byrsophlebs nana als ein diese Altion erheblich unterstützendes, spezifisches Organ anzusehen, namentlich wenn man berücksichtigt, daß neben dem Schwanzanhange tatsächlich auch der Pharynx zur Festheftung auf der Unterlage benützt wird und daß die vorliegende Turbellarie wahrscheinlich ein Blutsauger ist, da weder Laidlaw noch ich jemals irgend welche Nahrungsobjekte in ihrem Darme gefunden haben.

Der beschriebene Bau der Pharynx hat zur Folge, daß auf Quetschpräparaten (Fig. I) nur das distale Ende des Pharynx muskulös zu sein scheint. Besonders wenn das Objekt kontrahiert ist, spannen sich die an das distale Ende des Pharynx herantretenden Retraktoren (mr) straff quer zur Seite aus: die Pharynxspitze erscheint als eine Scheibe, deren mittlere Durchbohrung - der Mund - zunächst von einem hellen 
Saume und dann von den radiären Fortsätzen der Retraktoren umgeben ist. Der helle muskelfreie Saum ist die epitheliale Umrandung des Mundes. Vor dem Pharynx findet sich ein, den Binnenraum des Rüssels von jenem des Rumpfes abgrenzendes, muslkulöses Diaphragma. Dasselbe wird hergestellt teils durch die zum distalen Ende des Pharynx konvergierenden Dilatatoren (mr), teils durch die vor dem Pharynx liegenden Muskeln. Letztere erscheinen, insoweit als sie vom ventralen Halbbogen des Integumentes an die Vorderwand des Pharynx herantreten (Fig. 23, mdi), als Protraktoren, insoweit sie jedoch von der dorsalen Leibeswand kommen $\left(\right.$ mdi $\left._{1}\right)$, als Retraktoren desselben. Erstere werden bei ihrer Verkürzung die Spitze des Pharynx nach hinten, letztere im gleichen Falle dieselbe nach vorn richten. Diese Muskeln sind es, welche bei heftigen Kontraktionen des Körpers die an der Vorderwand des Pharynx verlaufende ringförmige Einschnürung bewerkstelligen. Das Diaphragma bildet natürlich keinen vollständigen Abschluß gegen den Rüssel, wie ja aus der Tatsache hervorgeht, daß ein Darmblindsack in den Rüssel eintritt. Auch kann man beobachten, wie in Quetschpräparaten bei zunehmender Kompression des Körpers die zu Seiten des Pharynx liegenden Speicheldrüsen (Fig. I, spd) schließlich zwischen den radiären Muskeln hindurch in die Rüsselbasis gedrängt werden.

Der Darm (da) füllt den von den übrigen Organen freigelassenen Raum fast vollständig aus. Im Leben ist er durch die in seiner Wandung enthaltenen grünlichgelblichen Kügelchen zu verfolgen, aber auch an Schnitten sind die charakteristischen, bald schwachgefärbten, bald ungefärbten Kügelchen und das zarte Plasmagerüst sowie die großen runden Kerne (dak) mit dem hellen, einen punktförmigen Nucleololus einschließenden Kernkörperchen meist ein sicheres Mittel, ihn von dem umgebenden Mesenchym zu unterscheiden, obgleich eine, ihn scharf von letzterem abgrenzende Tunica propria fehlt. Am weitesten erscheint er in der Region zwischen Pharynx und dem männlichen Kopulations-Organ, wo man auch stets sein Lumen wahrnimmt (Fig. I u. I 7). Dagegen mangelt dasselbe in dem, über den Kopulations-Organen bis zur Basis des Schwanzanhanges nach hinten.(Fig. 24) sowie meist auch in dem präoralen, nach vorn abgehenden Endstücke. Doch erkennt man in dem Fig. 12 abgebildeten Schnitte durch das Gehirn ein zentrales Darmlumen. Als Ös ophagus (Fig. I5, I6, 23, oe) bezeichne ich den engen Teil des Darmrohres, welcher, über dem Pharyngealzellensack liegend, durch diesen von unten und durch die Speicheldrüsen (spd) von den Seiten her eingeengt wird. Im Bau von den übrigen Teilen des Darmes nicht verschieden, wird dieser Ösophagus anatomisch bloß durch die Aufnahme der Ausfülrungsgänge der Speicheldrüsen charakterisiert. Letztere sind zum Teile schon von Laidlaw erkannt worden. Indessen handelt es sich nicht um „a few unicellular glands" (pag. 643), sondern um zwei große Büschel im lebenden Zustande sehr heller, feinkörniger, birnförmiger und langgestielter Drüsen, welche die Seitenteile des Körpers in ganzer Länge des Pharynx erfüllen (Fig. I, spd). Ihre Granula färben sich in Hematoxylin-Eosin hellviolett, in ihren $0.006 \mathrm{~mm}$ breiten runden Kernen ist das Chromatin in einer Randzone angehäuft, welcher der große Nucleolus anliegt, während der zentrale Teil der Kerne wenig Chromatinkörnchen enthält, so daß der Nucleolus von einer halbmondförmigen hellen Zone umgeben 'erscheint.

Im Beginne des letzten Siebtels des (gestreckten) Körpers finden sich die beiden Geschlechtsöffnungen (Fig. I, $\sigma^{\top}$ u. 우), die weibliche dicht hinter der männlichen. Sie werden im Leben oft papillenartig vorgestreckt, namentlich die männliche, und dieses Spiel 
wird durch je einen kräftigen Sphinkter und ein System radiär von den Öffnungen aus strahlender, als Dilatatoren und Retraktoren wirkender Muskelfasern unterstützt. Zwei langgestreckte Dotterstöcke (Fig. I, I6-I8, 24, do) nehmen die Seiten des Körpers ein, vom Pharyngealzellensack angefangen bis zur Höhe der weiblichen Geschlechtsöffnung (q), woselbst sie quer zum Atrium femininum konvergieren. Sie sind fast in ganzer Länge gleich breit und mit dicht aufeinanderfolgenden ringförmigen Einschnürungen versehen, die umso tiefer eingreifen und die seitliche Begrenzung der Dotterstöcke in aufeinanderfolgende Läppchen zerfällen, je stärker der Körper kontrahiert ist. Die jüngsten, noch keine Dotterkugeln enthaltenden Zellen gehören hauptsächlich der lateralen Rinde an (Fig. I7, do II), während nach innen von diesen die Übergänge (do ${ }_{1}$ zu den medialen, ganz von Dotterkugeln erfüllten Zellen (do) zu sehen sind. Der Keimstock (Fig. I u. 24, ks) ist unpaar, von einer feinen Muskularis umhüllt und die aus dem blinden Ende $\left(\mathrm{ks}_{\mathrm{I}}\right)$ hervordrängenden Keimzellen erscheinen in Schnitten distal vorgewölbt und durch Lücken voneinander getrennt, welche offenbar eine Folge der Konservierung sind, da man von ihnen am lebenden Objekte nichts wahrnimmt. Wie schon Laidlaw konstatierte, ist das distale Ende des Keimstockes am meisten aufgetrieben und dient als Receptacu'lum seminis (Fig. 24, rs). Der Ovidukt mündet von oben und vorn her in das, bloß durch den distalen Teil des in Fig. 24 gezeichneten weiblichen Kanals of repräsentierte Atrium, während der Rest dieses dorsal blind endenden Kanals die Bursa seminalis vorstellt. Diese ist von Laidlaw (pag. 645) ganz richtig als ein von hinten nach vorn komprimierter Sack beschrieben worden, welcher auf seiner kaudalen Wand ein Divertikel trägt, in welchem der Chitinanhang ( $\mathrm{ch}_{1}$ ) eingeschlossen ist. Die Wandung der Bursa ist zuinnerst von einer dünnen, cilien- und kernlosen Fortsetzung der integumentalen Epithelialschicht ausgekleidet, auf welche eine sehr kräftige, tiefrot tingierte, scheinbar homogene Schicht folgt, welche Laidlaw als „chitinoid lining substance“ (pag. 645) bezeichnet, die ich aber für eine innere Längsmuskelschicht halte, der dann außen zahlreiche Ringfasern anliegen. Diese Muskularis umschließt den Chitinanhang vollständig, so daß derselbe keine Kommunikation nach dem Mesenchym besitzt. Die Form des Chitinanhanges wechselt hier ebenso wie bei dem gleichen Organ der Gattungen Proxenetes und Iyporhynchus. Meist erscheint er als ein 0.012 bis $0.016 \mathrm{~mm}$ langes, fein geringeltes, gerades oder schwach gekrümmtes Röhrchen (Fig. 9, c), einmal fand ich ihn sehr kurz und aus zwei, durch eine Einschnürung getrennten Stücken besteliend (b) und ein anderes Mal saß ein solches eingeschnürtes Röhrchen einem viel weiteren basalen Ringe auf (a). Wenn Laidlaw angibt, daß die Wandung der Bursa seminalis „merges quite gradually with the protoplasm of the parenchyma", so wird dieser Anschein dadurch hervorgerufen, daß ebenso wie zu dem Atrium femininum, so auch zur Wand der Bursa von allen Seiten Muskelfasern und Ausführungsgänge von Drüsen konvergieren. Den Kranz der atrialen Drüsen und Muskeln sieht man an Quetschpräparaten (Fig. I, 우) ganz deutlich, die tiefen Schichten derselben erscheinen auf Schnitten als ein, die Umgebung der Bursa erfüllendes Geflecht von Muskeln und Sekretfäden, in das einzelne Drüsenzellen eingebettet erscheinen (Fig. 24, mg). Noch viel mannigfacher und zahlreicher sind die zum männlichen Apparate gehörigen Drüsen.

Die beiden $\mathrm{Hoden}$ (Fig I, te) sind außerordentlich klein, indem sie zusammen nicht mehr Raum einnehmen als der Pharynx. Sie liegen ein Stück vor letzterem dem 
seitlichen Integumente an als längsovale, helle Körper, unterhalb des präösophagealen Darmastes. Bei Verkürzung und entsprechender Verbreiterung des Rüssels (vgl. Laidlaw, fig. I) werden sie rundlich und rücken vom Integumente ab. In meinem Querschnitte (Fig. I3) berühren sich die Hoden in der Mittellinie und zeigen eine kernführende Tunica propria. Auch mir ist es nicht gelungen, die Vasa deferentia in ihrem ganzen Verlaufe zu verfolgen. Ich sah sie erst dort, wo sie die, bald kugel-oder birnförmigen (Fig. I, vd ${ }_{1}$, bald gestreckt-schlauchförmigen, als „falsche Samenblasen" zu bezeichnenden Anschwellungen bilden, die voneinander getrennt in das blinde Ende des KopulationsOrgans einmünden. Die falschen Samenblasen sollen nach Laidlaw (p. 647) ,chitinouslike walls" besitzen, ich fand sie von einer aus feinen Ring- und Längsfasern bestehenden Muskularis bekleidet, gleichwie die distalen Enden der Vasa deferentia (Fig. I8, vd). Die Mündungen der letzteren sind umgeben von den zahlreichen Ausführungsgängen mächtiger Drüsenbüschel, welche bisweilen doppelt so umfangreich sind als in dem Fig. I, dr abgebildeten Falle. Unter diesen Drüsen lassen sich zweierlei Arten durch Tinktion und Beschaffenheit des Sekretes unterscheiden, die ich als Körnerdrüsen und Schleimdrüsen bezeichnen will. Erstere kennzeichnen sich durch ihr, aus glänzenden Körnern bestehendes eosinophiles Sekret (Fig. I $\$$ u. 24, edr), welches auch innerhalb des Kopulations-Organs (Fig. I9 u. 24, kr) seine Beschaffenheit nicht ändert und sich dadurch auffallend von dem Sekret der Schleimdrüsen unterscheidet. Letztere (Fig. Is u. 24, dr) gleicluen in Form und Tinktion den Speicheldrüsen, ihre hellvioletten Sekretgranula werden innerhalb des Kopulations-Organs noch heller und fließen zu Strängen (Fig. 19 u. 24, s) zusammen. In den zitierten Quer- und Längsschnitten des KopulationsOrgans sieht man, daß die akzessorischen Sekrete sich weder untereinander noch mit den Spermatozoen ( $\mathrm{sp}$ ) mischen, obgleich ich mit Sicherheit keine Membran nachweisen konnte, welche Sekret- und Spermareservoir (Samenblase) voneinander trennte. Nur im distalen Teile des Penis tritt ein Kanal (Fig. 19, 20, 24, dre) auf, welcher, dicht an den Spermaballen verlaufend, das Sekret in den clitinösen Penis (ch) zu führen scheint. Doch ist es möglich, daß die Wandung dieses Kanals ebenso wie die homogene Umhüllung der Spermamasse, wie sie in Fig. 20 zu sehen ist, bloß durch flüssiges Sekret gebildet ist. Was die wabige Masse im oberen Teile des Kopulations-Organs (Fig. I9, v) bcdeutet, ist mir ebenfalls unklar geblieben; ihre hellen Räume sind von, aus eosinophilen Körnchen gebildeten, Fäden geschieden und es handelt sich hier vielleicht bloß um schaumige Verteilung einer Portion des anliegenden Körnersekretes.

Das Kopulations-Organ ist von einer kräftigen Muskularis ( $\mathrm{mm}$ ) aus äußeren Längsund inneren Ringfasern gebildet, wozu als innerste Schicht noch eine weitere lockere Lage von Längsfasern (mu) hinzukommt. Die Form des chitinösen Penis ist von Goodrich (1. c. fig. 6, a u. b) so vortrefflich dargestellt worden, daß ich nichts weiter hinzufügen kann. Ich bemerke bloß, daß der basale Teil des Penis umgeben ist von birnförmigen cyanophilen Zellen (Fig. 22, cdr), deren Stiele ( $\mathrm{cdr}_{\mathrm{I}}$ ) zu der Chintinmembran konvergieren, die den eingezogenen Penis umgibt und aus welcher die in Längsreihen angeordneten kleinen Stacheln entspringen. Es handelt sich, da ja die Stacheln solid sind und keinerlei Durchbohrungen derselben oder ihrer basalen Membran nachzuweisen sind, in den erwähnten cyanophilen Zellen wahrscheinlich nicht um Drüsen, sondern um die in das umgebende Mesenchym versenkten Matrixzellen dieser Chitingebilde. Dagegen ist das Atrium masculinum reich ausgestattet mit Atriumdrüsen (Fig. 22 u. 24, adr), welche 
sich von den früher erwähnten eosinophilen akzessorischen Drüsen des Kopulations-Organs bloß durch ihre geringere Größe unterscheiden. Ihre Ausführungsgänge ( $\operatorname{adr}_{\mathrm{I}}$ ) münden in der Atriumwandung. Die aus der Samenblase isolierten reifen Spermatozoen sind feine, geschlängelte Fäden von 0.26 bis 0.28 mm Länge.

Das Gehirn liegt über dem Vorderende des präoralen Darmblindsackes, etwas linter der Mitte des ausgestreckten Rüssels. Am lebenden Objekte erkennt man die beiden, durch eine breite Querbrücke verbundenen Hälften des Gehirns (Fig. I, g), deren jede sich sowohl nach vorn als nach hinten in einen Nerv fortsetzt. Auf dem Querschnitte durch die Gehirnmitte (Fig. I2) erscheint die zentrale, von stärkeren Fasern durchsetzte Punktsubstanz von den Kernen der Ganglienzellen überrindet, welche namentlich an den vier Ecken sich in größerer Anzahl anhäufen. Von diesen Ecken gehn nun vier Nerven nach vorn, zwei dorsale (Fig. II, nd) und zwei ventrale (nv), die an ihrem Ursprunge als reichlich mit Ganglienzellen versehene Gehirnlappen erscheinen, im weiteren Verlaufe aber nur vereinzelte Kerne aufweisen. Nach hinten findet man nur zwei, den beiden unteren Ecken des Querschnittes entsprechende Gehirnlappen, aus welchen die Längsnervenstämme des Körpers entspringen, welche ich nur bis hinter die Hoden verfolgen konnte (Fig. I 3, nI).

Das Mesenchym ist überaus schwach entivickelt, da der Leibesraum vom Darm und den verschiedenen Drüsen fast vollständig ausgefüllt ist, bis auf einen geringen Raum unter dem Integumente. Hier findet man zarte Bindegewebsfasern mit aufliegenden feinen Körnchen (Fig. I6 u. I \&, bg) und stellenweise dazu ovale Kerne (bgk) mit spärlichen Plasmaresten. Stärker entfaltet ist dieses grofmaschige Bindegewebe dagegen in der vor den Hoden gelegenen Region des Rüssels (Fig. I I u. I2, bg, bg I). Im terminalen Teile des Rüssels treten zu den Bindegewebsfasern noch zahlreiche Längsmuskelfasern (Fig. I, Rm), doch konnte ich in deren Verteilung keine bestimmte Regel erkennen.

Von Exkretions-Organen habe ich nichts gesehen.

Laidlaw (p. 649) betont mit Recht bei Erörterung der Frage, ob die vorliegende Form zur Familie der Mesostomatidae oder zu jener der Proboscidae zu stellen sei, daß die Entscheidung lediglich von der Auffassung des sogenannten Rüssels abhänge. Und da er denselben gleichwertig hält dem Rüssel der Proboscidengattung Psendorhynchus, so statuiert er für unsere Turbellarie eine neue Gattung Typhlorhynchus der Proboscidae. Meiner Ansicht nach soll der Name „Rüssel“ (Proboscis) bloß dort angewendet werden, wo ein Teil des Vorderkörpers in toto ausschließlich für die Tastfunktion umgestaltet erscheint, wie dies bei dem Probosciden-Rüssel mit Muskelzapfen und Scheide sowie bei dem Mikrostomidengenus Rhynchoscolex der Fall ist, wo zwar eine Scheide fehlt, aber der mit Muskelzapfen und terminalen Tastpapillen ausgestattete Rüssel weder den Darm, noch das Nervensystem, noch auch irgend einen Teil des Geschlechts-Apparates einschließt, demnach exklusive der Tastfunktion dient. Im Gegensatze dazu soll meines Erachtens nicht von einem „Rüssel" gesprochen werden, wenn es sich - wie bei Mesostoma rostratum (Müll.) und noch mehr bei Byrsophlebs nana - bloß um besondere Kontraktilität des Vorderkörpers handelt, olne daß dieser (Darm, Hoden und Nervensystem einschließende) kontraktile Teil in seiner ganzen Ausdelınung der Tastfunktion angepaßt wäre. Von diesem Gesichtspunkte aus fällt auch das Vorderende von Fsezdorhynchus nicht ganz unter meine Definition des Rüssels, weil dasselbe trotz des Mangels der Cilien und der Bedeckung mit Tasthaaren auch das vordere Ende des 
Darmes in seine Basis einschließt. Und wenn ich trotzdem Pseudorhynchus bei den Probosciden als Ausgangsgruppe eingereiht habe, so geschah dies in der Erwägung, daß der echte Proboscidenrüssel sich aus einem ähnlichen Vorstadium entwickelt haben muß, wie es im Vorderende von Pseudor. bifidus (M'Int.) repräsentiert ist und weil die übrige Organisation dieser Spezies (besonders des Geschlechts-Apparates) die Annahme unterstützt, daß es sich hier um eine Ausgangsform für die typischen Proboscidae handelt.

Nichts von alledem kann für die vorliegende Form behauptet werden. Ihr kontraktiler Vorderkörper ist von dem typischen Proboscidenrüssel weiter entfernt, als selbst das Vorderende von Mes, rostratum. Auch ist die Kontraktilität - Empfindlichkeit und weite Vorstreckbarkeit - des Vorderkörpers bei Byrsophlebs nana wahrscheinlich ein bloßes Mittel zur Wiederauffindung des Wirtes, wenn durch dessen heftige Bewegungen der Parasit abgeworfen wurde, also eine sekundäre Anpassung an die parasitische Lebensweise, gleich der Haftscheibe des Hinterendes und vielleicht auch der Ausbildung des Pharyngealzellensackes (s. oben S. 3). Deshalb scheinen mir diese Charaktere auch nicht geeignet, ein eigenes Genus darauf zu begründen, und ich ziehe diese Form zur Gattung Byrsophlebs, deren Diagnose vollständig auf sie paßt, indem sie heute lauten muß: Mesostomatidae mit einem Keimstock und davon getrennten Dotterstöcken, mit zwei Geschlechtsöffnungen, die männliche vor der weiblichen gelegen, ohne ventrale Hautgrube.

\section{Provortex tellinae Graff.}

R. Leuckart hat I $868^{\text {) }}$ ) über eine, von ihm in Neapel untersuchte "Vortexartige Turbellarie aus dem Darme von Tellina ${ }^{*}$ berichtet und diese Notiz später ${ }^{2}$ ) ergänzt. Danach handelt es sich um ein $2 \mathrm{~mm}$ langes Tier mit zwei Augen, deren jedes drei kleine Linsen besitzt. „Eierstöcke, Dotterstock und Uterus ließen sich ebenso scharf und deutlich erkennen wie die Hoden. Im Uterus war vielleicht ein halbes Dutzend Eikapseln mit je zwei Embryonen im Innern zu unterscheiden, die in der Nähe des vorderen Leibesendes schon mit Augen versehen waren und ganz dieselben Verhältnisse zeigten, wie M. Schultze sie in seiner bekannten Monographie von Vort. balticus beschrieben hat." L. schließt aus dem Vorhandensein der Augen, daß diese Turbellarie "schwerlich einen stationären Schmarotzer darstellen dürfte". Da Leuckart offenbar zwei Keimstöcke gesehen hatte, mußte $\mathrm{ich}^{3}$ ) in diesem Tiere einen Vertreter des von mir aufgestellten Gen. Provortex vermuten.

Mit dem von Leuckart beschriebenen Parasiten ist wahrscheinlich identisch die von J. Kunstler schon I 882 gefundene, aber erst I $888^{4}$ ) beschriebene „Planaire dans

1) R. Leuckart, Bericht üb. d. Leist. i. d. Naturg. d. nied. Tiere w. d. J. $8866-1867$. Arch. f. Naturg., 33. Jahrg., II. Bd., Berlin I867 (1868), pag. 292.

2) R. Leuckart, Bericht etc. w. d. J.1876-1879. Arch. f. Naturg., 44. Jahrg., II. Bd., Berlin 1878 (1882), pag. 66t.

3) L. v. Graff, Monographie der Turbellarien, I. Rhabdocoelida, Leipzig I882, pag. 348.

4) J. Kunstler, Sur de nouveaux vers remarquables. Compte rendu Acad. Sc. Paris, tome ro6, Paris 1888, pag. 553-554. 
l'intestin du Solen vagina". Da Herr Kunstler so freundlich war, mir eine, bisher nur in sehr unvollkommener Weise reproduzierte ${ }^{1}$ ) Handzeichnung zur Verfügung zu stellen, so bin ich in der Lage, die vorläufige Mitteilung des Genannten zu ergänzen. Der Körper des Solen-Parasiten ist $2 \mathrm{~mm}$ lang, an beiden Enden abgestumpft, aber vorn breiter als an dem allmählich verjüngten Hinterende, ganz mit Cilien bedeckt, welche am Vorderende kürzer sein sollen. Nicht weit vom Vorderende liegen zwei große, schwarze, mit ihren großen Linsen seitwärts gerichtete Augen, voneinander fast doppelt so weit entfernt als vom Seitenrande. Unter dem Epithel eine dichte gelblichweiße Parenchymschicht, das übrige Parenchym ist blasig und farblos. Zwischen den Augen liegt der im Ende des ersten Fünftels des Körpers (als Rosette gezeichnete) Pharynx "il est suivie d'un tube digestif peu distinct, allongée, simple". Das Gehirn findet sich als quere zweilappige Nasse dicht hinter dem Pharynx und entsendet nach vorn zu den Augen sowie nach hinten jederseits einen Nerv. Von Geschlechts-Organen erwähnt Kunstler die im mütterlichen Körper sich entwickelnden Eier, Hoden („des vésicules remplies de spermatozoïdes se voient dans le même parenchyme") und jederseits "des trainées allongées paraissant être de glandes accessoires de l'appareil reproducteur". Aus der mir vorliegenden Zeichnung ist noch folgendes zu ersehen. Zunächst die am Ende des zweiten Fünftels des Körpers liegende, von einer Rosette einzelliger Drüsen umgebene Geschlechtsöffnung. Dann eine vor der letzteren angebrachte rundliche Blase (Vesicula seminalis des nicht erkannten männlichen Kopulations-Organs?) und sieben ovale, je zwei Embryonen enthaltende Kokons, von denen drei vor und vier hinter der Geschlechtsöffnung verteilt sind und welche in der Gestalt völlig mit jenen des Provortex balticus (M. Schultze) übereinstimmen. Dicht hinter dem Gehirn, den seitlichen Raum zwischen diesem und der Geschlechtsöffnung einnehmend, zwei von kleinen runden Zellen erfüllte ovale Organe, welche wahrscheinlich den Hoden entsprechen. Sie setzen sich in der Zeichnung direkt fort in große, geldrollenförmig angeordnete Zellen, die beiden Keimstöcke, und hinter diesen, bis nahezu an das Schwanzende reichend, liegen die im letzten Körperdrittel sich verästelnden „traînées allongées“, welche nichts anderes sind als Dotterstöcke. Schließlich zeichnet Kunstler im Vorderende zerstreut spindelförmige Zellen, welche von Pharynx und Augen radiär zur Körperspitze ausstrahlen und in denen ich Stirndrüsen vermute.

Dieser Solen-Parasit ist keine Mesostomide, da der Pharynx vor dem Darme angebracht ist, was bei Mesostomiden niemals vorkommt, sondern eine Vorticide und gehört aller Wahrscheinlichkeit nach zu dem Gen. Provortex.

Ich habe in Tellinen von Neapel und Solen von Triest vergeblich nach diesem Darmparasiten gesucht. Nach den mitgeteilten Angaben von Leuckart und Kunstler ist eine Verweclsslung mit dem von mir bei dieser Gelegenheit an den Kiemen von Solen gefundenen Urastoma cyprinae ( $\mathrm{G} \mathrm{r}$ a f $)$ ) ausgeschlossen. Dagegen ist es fraglich, auf welche Form sich eine hier anzuführende Bemerkung von Vaillant) beziehen dürfte.

1) P. Busquet, Les Etres vivants: Organisation - Évolution, Paris 1899, pag. I35, fig. I18 Promesostum (du Solen) (d'après Kunstler). - Der Name soll natürlich Promesostomm lauten!

2) L. Vaillant, Histoire nat. des Annelés marins et d'eau douce, tome III, I. partie. Paris I889, pag. 663: „c'est à ce dernier genre (Provortex) que je crois devoir rapporter un Rhabdocoelien, dont je doit connaissance à mon collègue et ami M. le professeur Balbiani, comme trouvé dans les mêmes circonstances (dans l'intestin) chez le Solen vaginu Lin. à Villers-sur-Mer". 
Von den übrigen Vertretern des Gen. Provortex würde sich P. tellinne durch die relative Größe der weiblichen Geschlechtsdrüsen, besonders der Dotterstöcke und die verästelte Gestalt der letzteren unterscheiden.

\title{
Graffilla buccinicola James.
}

\author{
Taf. I u. Taf. II, Fig. I - II.
}

Von fünf wälırend meines Aufenthaltes in Alexandrowsk gedregten Fusus antiquns waren zwei mit diesem, zuerst von Jameson ${ }^{1}$ ) beschriebenen Parasiten behaftet, u. zw. enthielt der eine Fusus deren 24, der andere I5 Exemplare. Sie waren größtenteils an der Niere mit dem Pharynx festgesaugt, einige auch zwischen den Kiemenblättchen. Das größte Exemplar hatte ausgestreckt eine Länge von $4^{\circ} 5$ und eine größte Breite von etwas über $1.5 \mathrm{~mm}$, das kleinste war $\mathrm{I}^{\circ} 6 \mathrm{~mm}$ lang. Völlig gestreckt erschien ihr Körper fast drehrund, nur wenig breiter als hoch, mit rasch und fein zugespitzten Enden, doch änderte sich die Form durch seitliche Krümmungen und träge fortschreitende Kontraktionen und lokale Einschnürungen noch mehr als bei den Gattungsgenossen, wie aus Taf. I, Fig. I hervorgeht, woselbst ich die an einem großen (a) und einem kleinen (b) Individuum binnen einiger Minuten beobachteten Gestaltänderungen dargestellt habe. Der größte Teil des Körpers erschien strohgelb bis cremefarbig und nur die Spitzen sowie eine schmale Randzone waren durchscheinend, wobei die opake gelbe Partie dem Verbreitungsbezirke der Geschlechtsdrüsen entspricht. Diese Tiere sind in Quetschpräparaten schwer zu untersuchen, da sie leicht zerreißen und bei größeren Exemplaren zudem der Dotterstock alle übrigen Organe verdeckt; was auf diese Weise zu sehen ist, hat Jameson dargestellt, wogegen mir eine genauere Darstellung der anatomischen Verhältnisse übrig blieb. Dabei kam mir außerordentlich $z u$ statten die bei der vorliegenden Form beispiellos scharf differenzierende Wirkung der HämatoxylinEosin-Tinktion, weshalb ich die Schnitte in den durch letztere erzielten Farbentönen dargestellt habe.

Integument. Der Körper erscheint im Leben farblos und man bemerkt im Quetschpräparate bloß feinpunktierte rundliche Tüpfel über die Oberfläche zerstreut - offenbar die von Jameson (pag. 170) erwähnten "groups of olive brown pigment granules" welche bei Druck zwischen den Epithelzellen hervorquellen und wahrscheinlich identisch sind mit den Schleimtropfen (Taf. I, Fig. I4, sl), welche auf Schnittpräparaten da und dort dem Integumente anhaften. Doch kann ich nicht sagen, woher dieselben stammen, da es hier keine durch Ausführungsgänge mit der Haut verbundene Drüsenzellen gibt, wie aus der Darstellung des Parenchymgewebes hervorgelın wird. Die Cilien erscheinen schon am lebenden und noch mehr am konservierten Objekte außerordentlich kräftig, aber nicht so dicht gestellt wie sonst. Im Leben sind sie so lang wie das Epithel hoch ist und man kann sie bei ihren langsamen Bewegungen einzeln voneinander unterscheiden. An Schnitten erscheinen sie mehr oder weniger eingezogen und dementsprechend an ihrer Spitze verdickt (Taf. I, Fig. I, ci, ci $i_{1}$ ), während ihre Basis zu einem

1) H. L. Jameson, Additional Notes on the Turbellaria of the L. M. B. C. District. Trans. L'pool Biol, Soc, vol. XI, Liverpool I897, pag. 169. 
Bulbus (Fußstück) angeschwollen ist. Stäbchenförmige Körper fehlen und im optischen Querschnitte der lebenden Objekte werden solche vorgetäuscht durch die hellen, spindelförmigen Lücken zwischen den einzelnen Epithelzellen, welche dieser Lücken wegen auch nur lose zusammenhalten und bei Druck sich leicht ablösen und auseinanderfallen. Die unregelmäßig-polygonalen Epithelzellen sind im konservierten Objekte (Taf. I, Fig. I4) bis 0.012 mm hoch und höchstens ebenso breit, doch sind die meisten schmäler und schlanker. In unserer Tinktion ist die ca. ein Drittel der Zellhöhe ausmachende Randschicht (r) rot gefärbt, besonders ihre verdichtete tiefrote kutikulare Randpartie (c) Jameson meint wahrscheinlich die ganze Randschicht mit seiner "cuticular layer" —, die Randschicht geht ziemlich unvermittelt über in die tiefblau gefärbte Mittelschicht (d), wåhrend der aus zahlreichen feinen Füß̧chen bestehende Basalteil (f) der Epithelzellen hellviolett erscheint. Die hellen runden Kerne mit ihren Kernkörperchen liegen stets in der Mittelschicht, meist etwas näher der Basis als der freien Fläche der Zellen. Die Interzellularlücken (v) nchmen hauptsächlich die Mittelschicht des Epithels ein und greifen selten in die Randschicht über.

Der Hautmuskelschlauch weist eine einfache Lage von äußeren Ring-(rm) und inneren Längsfasern $(1 \mathrm{~m})$ auf.

Darm und Pharynx. Der Darm ist ein einfacher Sack, dessen Umrisse jene des ganzen Körpers wiederholen. Er läßt das Schwanzende frei und nimmt so ziemlich die Mitte des Querschnittes ein, aus welcher er bloß durch die Kopulationsorgane etwas nach oben gedrängt wird. Bei jungen Tieren fast halb so breit wie der Körper (Taf. II, Fig. I - 7, da), geht er mit der Entwicklung der weiblichen Geschlechtsdrüsen auf weniger als ein Drittel der Leibesbreite zurück und erfährt eine seitliche Kompression (Taf. I). Zugleich verändert sich die histologische Beschaffenheit seines Epithels. Bei jungen Individuen kann man deutlich die einzelnen Darmzellen unterscheiden (Taf. II, Fig. II, dz), zwischen welchen sogenannte „Körnerkolben" (kz) eingestreut sind, und es ist an solchen auch der schon von Jameson (tab. VI, fig. 8) gezeichnete Ösophagus (oe) zu erkennen, dessen Zellen durch geringere Größe und ein dichtes, nicht vakuolisiertes Plasma sich von jenen des eigentlichen Darmsackes unterscheiden. Dagegen ist bei größeren Individuen (von ca. 2 mm Länge an) das Darmlumen zwar ebenfalls erhalten, das Epithel jedoch, von der Basis bis zur freien Fläche, in ein aus derberen und zarteren Balken gebildetes spongiöses Vakuolensystem aufgelöst, das in seinen Lücken nur spärliche Plasmareste neben den, dem Gebälke anliegenden Kügelchen und Körnchen enthält. In der Nähe der Muskularis (dm) - welche in allen Lebensaltern den Darm vom Parenchym und den umgebenden Geschlechtsdrüsen scharf abgrenzt - finden sich zwar noch die hellen runden Kerne der Epithelzellen zerstreut, aber eine Abgrenzung der Zelleiber voneinander ist nicht mehr möglich. Daß trotzdem der Darm noch funktioniert, ist dadurch erwiesen, daß man häufig Fetzen des Nierenepithels der Schnecke in seinem Lumen vorfindet.

Der relativ kleine (sieh bei Jameson) Pharynx ist ein typischer Vorticidenpharynx mit reichlich ausgebildeten Radiärmuskeln ( $\mathrm{rdm}$ ) und kleinen Pharyngealzellen (phz).

Vom Nervensystem habe auch ich nicht mehr als das Gehirn (Taf. I, Fig. 4 und Taf. II, Fig. 7, g) gesehen, dessen undeutlich zweilappige Masse dicht hinter dem Pharynx quer über dem Darmanfange liegt. Die zentrale, tiefrot-tingierte Fasermasse ist von einer Rinde hellroter Ganglienzellen (ga) umgeben, die sich durch runde, violett gefärbte 
Kerne deutlich von Bindegewebszellen unterscheiden. Im übrigen macht das Gehirn durch seine geringe Größe, seine wenig ausgeprägte Zweiteilung und Gestalt sowie die lockere Anordnung des Ganglienzellenbelages hier noch mehr als bei den nächstverwandten Formen ${ }^{1}$ ) den Eindruck eines in Redulstion begriffenen Organs. Die beiden Augen, welche nach $\mathrm{J}$ ameson in die Gehirnsubstanz eingebettet sind, habe ich an den in Alexandrowsk frisch untersuchten Exemplaren nicht gesehen, auch finde ich in meinen Präparaten keine Spur derselben.

Geschlechts-Apparat. Jameson (pag. I7I) hat schon auf den sukzessiven Hermaphroditismus dieser Spezies hingewiesen. Sie ist protandrisch, aber es beginnen sich die weiblichen Geschlechtsdrüsen sowie die Bursa seminalis (von Jameson als „Receptaculum seminis" bezeichnet) schon frülizeitig anzulegen, wie daraus hervorgeht, daß der genannte Beobachter die männlichen Organe bei Individuen von I bis I $\$$ mm als "generally predominant" bezeichnet. Die kleinsten von mir auf Schnittserien untersuchten Exemplare waren solche von $1^{\circ} 6 \mathrm{~mm}$ (konserviert $0.9 \mathrm{~mm}$ ) Länge; sie zeigen neben vollentwickelten Hoden (Taf. II, Fig. 3-7, te) bereits die Anlagen der Dotter- und Keimstöcke (do und lis) sowie der Bursa seminalis, sind aber physiologisch Männchen, da sich die Ovidukte (Taf. I,

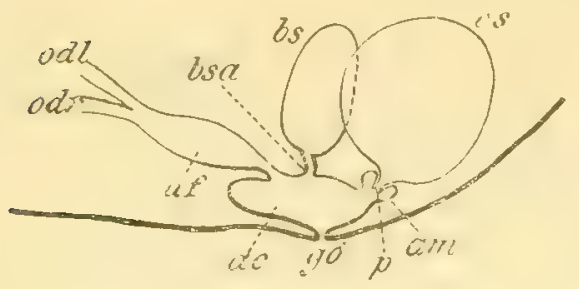

Schema des Kopulations-Apparates.

of Atrium femininum, ac Atrium genitale commune, "2m Atrium masculinum, bs Bursa seminalis, bsa Stiel derselben, oll linker und odr rechter Keim-Dottergang, Penis, os Vesicula seminalis. Fig. 7, od) erst nach erlangter Reife der weiblichen Geschlechtsdrüsen ausbilden. In weiblich reifen Exemplaren finden sich zwar nur mehr spärliche Reste der Hoden (Taf. I, Fig. $S$ bis IO, te), aber im Gegensatze zu Jameson muß ich bemerken, daß auch bei meinem größten Exemplare (lebend $4^{\circ} 5 \mathrm{~mm}$, konserviert $3 \mathrm{~mm}$ lang) Penis und Samenblase (vs) wie bei dem Taf. II, Fig. $5-7$ abgebildeten erhalten waren. Bei solchen Individuen - Jameson hat überhaupt keine in voller weiblicher Reife befindlichen Exemplare vor sich gehabt - ist demnach das Atrium genitale vollständig ausgebildet und die Topographie des ganzen Kopulations-Apparates zu übersehen. Ich werde zuerst diesen beschreiben und dann erst die Geschlechtsdrüsen. Die Geschlechtsöffnung (Taf. I, Fig. 6, gö) liegt etwas hinter dem Pharynx und ist mit einem kräftigen Sphinkter ausgestattet. Das Atrium genitale (Textfigur, ac) ist ein länglicher Sack, etwa doppelt so lang als breit, der in der Region der Geschlechtsöffnung am breitesten ist und sich nach beiden Enden verengt. Sein hinterer Schenkel ist etwas länger als der vordere. Von diesem Atrium commune ist am Vorderende durch eine seichte Einschnürung ein Vorraum, Atrium masculinum (am), abgetrennt, in dessen Grunde der kurze konische Penis hineinragt, welchem die mächtige Samenblase (vs) anhängt. In die Decke des Atrium mündet, fast direkt über dem Geschlechtsporus, ein dickwandiger Kanal (bsa), der Stiel der Bursa seminalis (bs), ein Stück hinter diesem das als weiblicher Genitalkanal dienende Atrium femininum (af) aus. Dasselbe ist bei voller Ausbildung bauchig aufgetrieben und allmählich nach hinten verengt, um sich schließlich in die quer seitlich abgehenden beiden

1) L. B ö hmig, Unters, üb. rhabd. Turbellarien, I. Das Genus Graffilla v. Ihering., Z. f. wiss. Zool., XLIII, Bd., Leipzig 1886, pag. 290. - F. Schmidt, Graffilla Brauni n. sp., Arch. f. Naturg., 52. Jahrg., I. Bd., Berlin 1886, pag. 304 . 
Keim-Dottergänge (odl u. odr - vgl. auch Taf. I, Fig. 7) zu gabeln. Im frühesten männlichen Stadium ist der Penis schief von hinten und oben nach vorn und unten gerichtet und die Samenblase liegt 'ganz oder größtenteils hinter der Geschlechtsöffnung, wie aus J amesons Abbildung (tab. VI, fig. S) hervorgeht, woselbst das hintere Divertikel des Atrium commune (rs) noch sehr wenig ausgebildet ist. Mit dem Eintritte der weiblichen Reife wachsen die Schalendrüsen, die Bursa seminalis und der weibliche Genitalkanal sprossen dorsal aus dem an Größe zunehmenden Atrium commune und so wird der Penis nach vorn gedrängt. Die Samenblase legt sich dann zumeist in einem von vorn nach hinten aufsteigenden Bogen über das ganze Atrium, während die Bursa seminalis nicht, wie in obigem Schema, senkrecht steht, sondern seitlich zur Ventralseite herabsinkt (Taf. I, Fig. 6 u. 7). In das Atrium commune münden zweierlei Drüsen, die sich nicht bloß in ihrem Bau und Verhalten gegen Farbstoffe, sondern auch durch die Zeit ihres Auftretens unterscheiden: die männlichen Körnerdrüsen und die weiblichen Schalendrüsen. Erstere (Taf. II, Fig. I -4 u. 8, kdr) sind nur während der männlichen Periode vorhanden und wurden von Jameson schon an seinem jüngsten Exemplare (tab. V, fig. 3, s. gl.) beobachtet, aber in der Tafelerklärung als "salivary (?) glands“ bezeichnet. Es sind langgestreckte, birnförmige Drüsen, deren runde, helle, mit einer scharfbegrenzten Membran versehene und bis o.o I mm breite Kerne ein violettes Kernkörperchen von o*0 I mm Breite einschließen. Das feinkörnige Plasma dieser Drüsen enthält zahlreiche Vakuolen und glänzende helle Sekretkörnchen (etwa halb so groß wie das Kernkörperchen), die sich namentlich in den Ausführungsgängen dicht zusammendrängen. Die Drüsenleiber sind dorsal zu Seiten des Anfangsteiles des Darmes sowie über und zu beiden Seiten der Samenblase (Fig. I, 2, 3, S) angehäuft und münden in den distalen Teil der Samenblase sowie in das Atrium, bis zu der Stelle, an welcher von letzterem die Bursa seminalis abzweigt. Die hintere Aussackung des Atrium ist bei meinen kleinsten Individuen noch wenig umfangreich, aber schon allseits umgeben von Schalendrüsen, welche, obgleich noch sehr klein, doch schon mit ihren Ausführungsgängen an der Atriumwand haften (Taf. II, Fig. 4 u. 5, sdr). In dem noch jüngeren Stadium Jamesons (tab. VI, fig. S) scheinen Schalendrüsen überhaupt noch nicht angelegt gewesen zu sein. In voller weiblicher Reife bilden diese Drüsen zwei seitliche Haufen (Taf. II, Fig. $6-S$, sdr u. sdr 1 ) unterhalb der Keim und Dotterstöcke, wozu noch ein drittes medianes Büschel kommt, déssen Zellen den Raum einnehmen, welcher zwischen der Ventralfäche des Darmes und den beiden, zum Atrium herabsteigenden seitlichen Ästen des Dotterstockes frei bleibt. Die Ausführungsgänge des unpaaren Büschels treten von hinten her, die der beiden seitlichen von rechts und links an das Atrium femininum, das auf diese Weise in seinem ganzen Verlaufe zum Schalendrüsengang wird, während keine einzige dieser Drüsen in das Atrium commune mündet. Wie aus den Abbildungen hervorgeht, sind die ausgebildeten Schalendrüsen größer und derber als die männlichen Körnerdrüsen. Ihre Kerne gleichen denen der letzteren, aber ihr Plasma entbehrt der Vakuolen und ist dicht erfüllt von den, eine satt-weinrote Tinktion annehmenden Selretkörnchen.

Zum feineren Bau der Kopulations-Organe sei folgendes bemerkt. Das Atrium commune wird in seiner Lage befestigt durch Muskeln, welche von dem ventralen Integumente gegen dasselbe radiär ausstrahlen - die von hinten kommenden sind in Taf. I, Fig. 7 bei ma quer durchschnitten - sowie von der. Darmmuskularis herabziehen (Fig. 8, m). Dazu kommt eine Verstärkung des auf das Atrium sich fortsetzenden Haut- 
muskelschlauches, die besonders am Stiele der Bursa seminalis (Fig. 6 , bsa) sowie an dieser selbst (bs) auffällt. In ihrer ersten Anlage (Taf. II, Fig. Io) besitzt die Bursa eine äußere Längs- und eine einfache innere Ringfaserschicht, doch kommt im ausgebildeten Zustande noch eine mehrschichtige äußere Ringfaserlage hinzu. Das Epithel des Atrium und seiner Adnexe entbehrt der Cilien. Das Atrium commune und femininum ist von kleinen kubischen Zellen ausgekleidet, die eine gleichmäßig rötliche Tinktion annehmen. In der jugendlichen Bursa seminalis beobachtet man große kubische Zellen mit runden Kernen und Schollen eines feinkörnigen Sekrets (s), das wahrscheinliclı von dem Epithel selbst geliefert wird. Die ausgebildete Bursa (Taf. II, Fig. 6, bs) ist ein gestreckt-ovales Organ von $0^{\circ} 37$ mm Länge, das mittels eines kurzen zylindrischen Röhrchens an der dorsalen Wand des Atrium commune angeheftet ist und sich quer nach außen wendet, gegen das blinde Ende allmählich bis zu einer Breite von $0^{\circ} \mathrm{I} 3 \mathrm{~mm}$ anschwellend. Zum großen Teile von Schalendrüsen umlagert, ist die Bursa in weiblich reifen Individuen fast ganz von Sperma (sp) erfüllt, während vom Epithel zwar noch die Kerne, aber nicht mehr die Zellgrenzen erkennbar sind. Das Atrium masculinum sowie die Samenblase (Taf. II, Fig.9) sind von einem Plattenepithel ausgekleidet mit ovalen Kérnen (k) und wenig deutlichen Zellgrenzen. Die Muskularis der Samenblase zeigt im Gegensatze zur jungen Bursa eine starke innere Ring- (rm) und eine aus schütter gestellten zarten Fasern bestehende äußere Längsschicht $(\mathrm{Im})$. Der Penis ist ein kurzes, zur Spitze etwas verjüngtes, muskulöses Röhrchen. Jameson hat es im ausgestreckten Zustande nach einem Quetschpräparate abgebildet (tab. VI, fig. I3) und danach besäße dasselbe drei erhöhte Ringleisten, von welchen nach vorn und hinten feine Fältchen oder Zähnchen abgehn. Diese Ringleisten sind auch an den Schnittpräparaten erkennbar, sie scheinen hier aus einer Reihe von Körnchen oder Knötchen (Anschwellungen von Muskelfasern?) zu bestehn.

Die Geschlechtsdrüsen sind viel umfangreicher, als man nach Jamesons Beschreibung vermuten könnte. Vor allem gilt dies von den Hoden, welche nach seiner Darstellung zwei ovale kleine Organe (kleiner als die Samenblasel) darstellen, zu Seiten des Darmes gleich hinter der Samenblase gelegen. In den von mir untersuchten kleinsten Tieren erstrecken sich die Hoden über die Hälfte der Gesamtlänge des Körpers. ${ }^{1}$ ) Im Ende des zweiten Körperdrittels mit ihrer dem Darme jederseits anliegenden Spitze beginnend, wachsen sie rasch zu kompakten Massen (Taf. II, Fig. 4 u. 5, te) heran, welche die Seitenteile des Körpers fast ganz ausfüllen und dorsal häufig durch Querkommissuren (Fig. 5 u. 8) verbunden sind. Schon in diesem kompakten Teile der Hoden finden sich vielfach kleinere und größere Lücken (Taf. I, Fig. 4-6, tel), deren Zahl und Weite nach vorn zunimmt. Aber erst im Ende des zweiten Drittels lösen sich die Hoden in ein aus feineren und gröberen Ästen bestehendes Netzwerk auf, welches den ganzen Darm umspinnt (Fig. 6) und immer feiner werdend, schließlich in die dem Hinterende des Darmes anliegende Zellenmasse (Fig. 7, bgz) übergeht. Diese besteht in jungen Tieren größtenteils aus Zellen, die sich in nichts von den Bindegewebszellen, wie ich sie (Taf. I, Fig. I4, bgz) abgebildet habe, unterscheiden, und in ihr sind andere Zellen eingebettet, welche alle Übergänge darbieten zu der charakteristischen Gestalt

1) In der aus 196 Schnitten bestehenden Serie, welcher die Figuren $1-6$ der Tafel II entnommen sind, beginnen die Hoden im 63. und enden im 163 . Querschnitte. 
der, je weiter nach vorn desto unzweifelhafter als solche erkennbaren, Hoden-, Keimund Dotterzellen. Die erste Veränderung, durch welche die Geschlechtszellen sich als solche erkennen lassen, besteht in einer dunkleren, violetten Färbung des Plasma, die von dem Auftreten cyanophiler Körnchen herrührt. Die jüngsten, offenbar durch Teilung solcher Zellen entstandenen Hodenzellen sind etwa halb so groß (ca. 0.004 bis $0.006 \mathrm{~mm}$ ), in ihren, von tiefblauen Körnchen erfülten, entsprechend kleineren Kernen ist das Kernkörperchen verschwunden, ihr Plasma ist noch dunkler geworden. Sie wachsen auf O०OI bis 0*OI 2 heran und ihr bis 0*006 mm breiter Kern erhält wieder eine dünne Membran, die einen hellen Kernsaft und in diesem eine geringe Anzahl (6- Io) kleiner Chromatinkugeln erkennen läßt, während das Zellplasma hell rötlichviolett geworden ist. Aus der Teilung dieser Spermatocyten gehn dann die 0.004 bis $0.006 \mathrm{~mm}$ breiten runden, hellroten Spermatiden hervor mit ihren scharfbegrenzten ca. $0^{\circ} 002 \mathrm{~mm}$ breiten Kernen. Die reifen Spermatozoen (Taf. I, Fig. I') sind $0^{\circ} 6$ mm lange, äußerst träge schwingende Fäden mit einem spindelförmigen Kopfe. Die in das Hinterende der Samenblase getrennt einmündende Vasa deferentia hat schon Jameson beschrieben, ihr Verhältnis zu den Hoden, ven deren ventraler Kante sie entspringen, ist aus Taf. II, Fig. 4, vd ersichtlich.

Der Dotterstock wird von Jameson (pag. 173) als ein, den Darm vom Gehirn an bis zum Hinterende umschließendes Netzwerk beschrieben. Auf Schnitten durch das weibliche reife Tier ( $\mathrm{Taf}, \mathrm{I}$, do) bildet er eine lückenlose Scheide um den Darm in dessen, hinter den Kopulations-Organen gelegenem Abschnitte. Im Schwanzende schon hinter dem Darm aus einzelnen, die Mitte des Querschnittes einnehmenden Läppchen bestehend, wird er in der Umgebung des Darmes (Fig. I2) kompakt und füllt fast den ganzen Leibesraum aus (Fig. I I); erst im Ende des zweiten Drittels der Körperlänge (Fig. Io u. 9) beginnen die Keimstöcke (ks) und weiter vorn auch das blasige Bindegewebe $(z)$ ihn seitlich vom Integumente abzudrängen, während die Schalendrüsen und Kopulations-Organe (Fig. 6-S) auf der ventralen Seite des Darmes eine Bresche in den Dotterstock legen. Von da an wird er netzartig und gewährt auf Querschnitten das in Jamesons fig. 9 gezeichnete Bild, ${ }^{1}$ ) während einzelne Läppchen bis in die Nähe des Gehirns reichen. Die beiden Ausführungsgänge, deren Verhältnis zum Atrium schon oben beschrieben wurde (s. Textfigur), lassen eine ursprünglich paarige Anlage des Dotterstockes vermuten und ich hebe hier gegen Jameson unter Hinweis auf Fig. 7 nur nochmals hervor, daß Keim- und Dotterstöcke gemeinsam durch dieselben Kanäle (od) ihre Produkte in das Atrium entsenden. Der Dotterstock wird von Bindegewebe umhüllt, das, in denselben eindringend, seine Zellen in größere und kleinere Läppchen gruppiert, zwischen welchen häufig enge Spalträume oder auch Lücken (Fig. 8), ähnlich jenen der Hoden, frei bleiben. Die reifen Dotterzellen sind ca. $00^{\circ} \mathrm{O} 4 \mathrm{~mm}$ breit, durch gegenseitigen Druck polygonal abgeplattet und enthalten einen violett gefärbten, runden Kern von 0.005 mm Durchmesser mit dicker Membran und einem großen, tiefblauen Kernkörperchen, so daß sich derselbe bloß durch die Färbung von dem Kerne der indifferenten Zellen des Hinterendes des Körpers unterscheidet. Das Plasma der ausgebildeten Dotterzellen ist grobkörnig, hellpurpurn tingiert und erfüllt von den intensiv gelbrot gefärbten Dotterkugeln, die zwar in der Größe variieren, aber im allgemeinen nicht viel mehr als halb

1) Doch liegen auch hier die Dotterstock-Läppchen unmittelbar der Darmwand an und sind nicht im Parenchym eingebettet, wie es nach Jamesons Abbildung scheinen könnte. 
so breit sind wie die Kerne der Dotterzellen. In den jungen Läppchen des Dotterstockes, wie sie sich hinter dem Darme und bisweilen auch weiter vorn zwischen reifen Dotterzellen eingekeilt (Taf. I, Fig. I I, 12 u. Taf. II, Fig. I-6, do) vorfinden, sind die Zellen tiefviolett gefärbt und nicht viel größer als die Kerne der reifen Dotterzellen, die Kerne lalb so groß als letztere, aber mit einem deutlichen Kernkörperchen versehen.

Die Keimstöcke hatten bei meinem kleinsten Exemplare die Form kurzer zylindrischer Schläuche und waren nicht länger als bei irgend einer unserer freilebenden Vorticiden. Etwas weiter entwickelt, im Beginne der Schlängelung, stellt sie Jamesons fig. 4 dar, wobei aber die nach aufwärts gehenden hinteren Fortsätze der beiden Keimstöcke durch die Quetschung im Winkel nach vorn abgebogen erscheinen. Bei dem auf Taf. I dargestellten Individuum sind die Keimstöcke aber viel umfangreicher. Sie stellen Stränge von geldrollenartig aufgereihten Zellen dar, die in ihrem ausführenden Abschnitte (Fig. 7, ks) rundlich oder eiförmig erscheinen, aber weiter nach hinten so aufeinanderdrücken, daß die einzelnen Zellen abgeplattet sind und ihre größte Breite an der Stelle haben, wo der eingelagerte Kern eine weitere Abplattung verhindert (Fig. 9). Vom Ovidukt (od) unterhalb der Dotterstöcke schief nach außen und oben ziehend, beginnen die Keimstöcke - stets den Dotterstöcken dicht angeschmiegt - zwischen letzteren und dem blasigen Bindegewebe und vom Beginne der zweiten Körperhälfte, wo das blasige Bindegewebe schwindet, zwischen den Dotterstöcken und dem Integumente (Fig. 9) in dichtgedrängten auf- und abgehenden Sclllingen die Seiten des Körpers einzunehmen. Im Anfange des letzten Drittels (Fig. 10) wird die bisher streng zylindrische Anreihung der Keimzellen unregelmäßig, es schieben sich junge, unreife Keimzellen (ksil) ein und im Beginne des letzten Körperviertels (Fig. I , ks) endet die Kontinuität des Keimstockes und man findet von da an nur mehr einzelne unreife Keimzellen hie und da dem Dotterstocke anliegend, bis hinein in die oben erwähnte indifferente Zellenmasse am Hinterende des Darmes. In dieser finde ich sowohl bei den weiblich reifen wie bei den kleinsten männlich reifen Individuen einzelne $0^{\circ} 024 \mathrm{~mm}$ breite, rundliche Keimzellen mit hell-bläulichviolettem Plasma und o.008 mm messenden Kernen, deren großes Kernkörperchen aber eine tiefrote Färbung besitzt. Es scheinen also die Keimzellen wie die Dotter- und Hodenzellen auch noch während der Geschlechtsreife hier neu gebildet zu werden, um im Bedarfsfalle von da nach vorn gegen den Kopulations-Apparat zu wandern und in den Verband der Geschlechtsdrüsen zu treten. Die reifen Keimzellen in den ausführenden Abschnitten erreichen einen größten Durchmesser von $0^{\prime} I$ I $m$, ihr von groben Körnern durchsetztes Plasma ist dunkelviolett, der ovale $0.024 \mathrm{~mm}$ lange Kern fleischfarbig, das runde $0.006 \mathrm{~mm}$ breite Kernkörperchen schwärzlich-purpurn tingiert.

Parenchymgewebe. Der von den übrigen Organen freigelassene Leibesraum wird von einem Gewebe ausgefüllt, das sich bei der vorliegenden Spezies schärfer als bei irgend einer andern der parasitischen Turbellarien in zwei Formen differenziert: das retikuläre und das blasige Bindegewebe.

Das retikuläre Bindegewebe ist, wenn auch stellenweise in einer nur dünnen Lage, unter dem Integumente des ganzen Körpers verbreitet, bildet ausschließlich das Parenchym der zweiten Körperhälfte und nimmt außerdem einen größeren Raum in der dorsalen Partie des Vorderendes über dem Gehirn und dem Pharynx ein. Es besteht (Taf. II, Fig. 14) aus einem Maschenwerke von zarten, feingranulierten Bindegewebsfasern (bgf), die sich deutlich von den Muskelfasern (mp) unterscheiden. Die letzteren sind 
homogen, färben sich tiefrot und bilden, untereinander anastomosierend, ein ähnliches spongiöses Netz wie die Bindegewebsfasern. In den Lücken finden sich zweierlei Zellen: kleine, überall zahlreich vorkommende Bindegewebszellen (bgz) und vielfach größere Zellen (Z), die überall nur vereinzelt vorkommen ( $\mathrm{Z}$ auf Taf. I, Fig. 4, 5, Taf. II, Fig. 2-S) und durch ihre wechselnde Gestalt die Vermutung erwecken, daß sie sich frei im Bindegewebe herumtreiben, weshalb ich sie als „amöboide Zellen" bezeichnen will.

Die Bindegewebszellen haben ein feinkörniges, hellrot tingiertes Plasma, das mit dem bindegewebigen Retikulum durch Fortsätze kommuniziert. Sie sind in größerer Masse am Hinterende des Darmes (s. o.) angehäuft, wo sie, in die Maschen des muskulösen Netzes eingebettet, rundlich-polygonale Formen annehmen. Die Breite dieser Zellen beträgt ca. O'OI5 mm, ihre hellen, mit einer feinen Membran und einem punktförmigen Nucleolus versehenen Kerne sind zumeist 0.006 mm breit und kugelrund. Dagegen werden die amöboiden Zellen zwei- bis dreimal so groß, sie sind zwar verschiedentlich in stumpfe, breite Lappen ausgezogen, doch fehlen ihnen die feinen Verbindungsfäden mit dem Retikulum, ihr Plasma ist dunkler und enthält bald mehr, bald weniger blau-konturierte Bläschen oder Körnchen, ihre ovalen Kerne erreichen einen größten Durchmesser von $0.012 m m$ und besitzen eine starke Membran und einen bläschenförmigen großen Nucleolus.

Das Bindegewebe verdichtet sich in der Umgebung der Geschlechtsdrüsen und bildet zusammenhängende Membranen, welche dieselben umhüllen und in den Hoden und die Dotterstöcke eindringend, diese Organe in Läppchen zerspalten.

Das blasige Bindegewebe findet sich bloß in der vorderen Körperhälfte. ${ }^{1}$ ) Im Ende dieser oder im Beginne der zweiten Hälfte treten seitlich und unter den Geschlechtsdrüsen, zwischen diesen und der schmalen Randschicht retikulären Bindegewebes einzelne Zellen ( $Z$, auf, welche, von einer Membran umgeben, einen feinkörnigen, hellgrauen Inhalt besitzen. Ihre Zahl wächst nacl vorn in dem Maße, als die Geschlechtsdrüsen an Umfang abnehmen und vor den Kopulations-Organen (Taf. I, Fig. 3, 4, Taf. II, Fig. I, 2) erfüllen sie fast den ganzen Leibesraum. Bei jungen Individuen sind sie kleiner (Taf. II) als bei ausgewachsenen, weiblich reifen (Taf. I), bei welchen manche dieser Zellen einen größten Durchmesser von $0^{*} 2 \mathrm{~mm}$ und mehr besitzen. Sie sind eingebettet in die Lücken eines spongiösen Gerüstes, welches aus zweierlei Elementen besteht: einer sehr fein granulierten, sich hellrot tingierenden Membran (Taf. I, Fig. I3, bgm) und tiefrot tingierten Muskelfasern (m), welche der Membran anliegen oder in sie eingebettet sind. In der Membran finden sich rundlich-ovale Kerne (bgk), die sich in nichts von den Kernen der Bindegewebszellen des retikulären Bindegewebes unterscheiden, und das ganze System dieser, die Zellen trennenden Membranen scheint eine bloße Modifikation des retikulären Bindegewebes und des in ihm gelegenen muskulösen Retikulums zu sein. Die Zellen selbst besitzen viel größere Kerne ( $\mathrm{zk}_{\mathrm{k}} \mathrm{u} . \mathrm{zk}_{\mathrm{l}}$ ) als das sie trennende Gerüste, die Kerne sind an den Rand der Zellen gedrängt und erinnern in Form und Größe an die Kerne der amöboiden Zellen; nicht selten aber besitzen diese Kerne unregelnäßige Umrisse (Fig. 4, zk), als ob auch sie amöboide Fortsätze bildeten. Das Merkwürdigste an den Zellen ist aber

1) Bei dem weiblichen Tiere (Taf. I) zeigt die aus 307 Schnitten bestehende Serie die letzte Spur des blasigen Bindegewebes im 151. Schnitte, die Serie durch das männliche Exemplar (Taf. II, Fig. I-6), aus 196 Schnitten bestehend, im 106. Schnitte. 
ihr wechselndes Verhalten gegen Farbstoffe, welches ich in Fig. 13 in der Weise illustriert habe, daß ich alle mir wichtig scheinenden Arten der Tinktion aus mehreren Schnitten in diese Figur eingetragen habe. In den hinteren Partien des zelligen Bindegewebes finden sich neben vereinzelten gelblichen Zellen $(Z)$ meist hellgraue $\left(Z_{t}\right)$ und man erkennt schon hier, daß es sich um dunklere Körnchen handelt, die in einer homogenen Grundsubstanz suspendiert sind. Weiter vorn begegnet man solchen Zellen $\left(Z_{2}\right)$, in denen die Grundsubstanz schwachrötlich, die Körnchen aber dunkler geworden sind. Die Körnchen färben sich dann rot $\left(Z_{3}\right)$ und werden massenhafter $\left(Z_{4}\right)$, während hie und da Zellen $\left(Z_{5}\right)$ auftreten, bei denen die Grundsubstanz einen hellblauen Ton annimmt, während die Körnchen sich zum Teile die rote Farbe bewahren und zu dichteren Häufchen und Strängen (er) gruppieren, zum Teile aber eine blaue Färbung (cy) erhalten haben. Schließlich treten - zuerst in der Höhe des Atrium genitale unter dem Integumente der Dorsalfläche - ganz blaue Zellen (Fig. $3-S$ u. ${ }_{13}, Z_{6}$ ) auf, die in einer blauvioletten Grundsubstanz schwarzblaue Körnchen führen, während ihr Kern (ZK I) rötlich, ihr Nucleolus aber gleichfalls schwarzblau tingiert erscheint. Diese blauen Zellen sind bald heller und mehr violett, bald in toto tief schwarzblau und die dorsale Hälfte der Querschnitte aus der Gegend des Gehirns und des Pharynx enthält fast bloß solche blaue Bindegewebszellen. Neben diesen Zellen finden sich aber auch Anhäufungen von Körnchen und feine Stränge von solchen zwischen den Septen des blasigen Bindegewebes - weiter hinten rot, näher dem Vorderende blau gefärbte - und diese Stränge (bgl , bgl II) werden besonders auffallend dort, wo die blauen Zellen angehäuft sind. In der Gegend über dem Atrium (Fig. 6 u. S) bilden die Körnchen feine Äderchen, weiter vorn erscheinen sie als gleichweite, rot konturierte Kanäle (Fig. 3-5) und es scheint, ${ }^{1}$ ) als ob einer oder mehrere dieser Kanäle in die Pharyngealtasche mündeten, um hier ihren Inhalt zu ergießen (Fig. 3, ex). Ein Blick auf Fig. I 3 lehrt, daß sowohl die erythrophilen (bgl) als auch die cyanophilen Körnchenstränge $\left(\mathrm{bgl}_{1}\right)$ in den Lücken zwischen den Bindegewebs-Membranen benachbarter Zellen verlaufen.

Ich halte das als "blasiges Bindegewebe" beschriebene System von Zellen für einen Exkretions-Apparat, umsomehr, als ich nichts sonst gefunden habe, was auf einen solchen zu beziehen wäre, und mir nicht vorstellen kann, welcher Teil des Körpers der Graffilla buccinicoli von Jameson als "excretory tubes" beschrieben worden ist. ${ }^{2}$ ) Die eigentlichen Exkretophoren ${ }^{3}$ ) sind wahrscheinlich jene großen, im ganzen Körper verteilten „amöboiden Zellen“, welche sich mit Exkretionsstoffen beladen und dann zu den Zellen des blasigen Bindegewebes werden, indem sie vom Rande sich an dasselbe ansetzen und in dessen Gerüstwerk eindringen -- wie man denn vielfach am äußeren Rande dieses Gewebes eine Anhäufung ganz kleiner Blasenzellen vorfindet (Taf. I, Fig. 3, zz). Sie nehmen an Größe zu und rücken in dem Maße vor, als am Vorderende des Körpers

I) Ich bin nämlich nicht ganz sicher, ob es sich hier nicht etwa um eine Zcrreißung des Gewebes handelt, durch wclche dic blauen Körnchenballen in die Pharyngealtasche gelangt sind.

$\left.{ }^{2}\right)$ L. C. pag. 173: "Underneath the epidermis is the same extraordinary system of supposed excretory tubes that has been observed in other species of the same genus. They ramify and anastomose all over the dorsal surface in a most complex manncr; and as in the other members of this genus, no flame cells are visible. On either side of the body, running from anterior to posterior end is a larger tubule, which presents a slight dilatation about the middle of its length."

3) Vgl. A. Graf, Hirudineenstudien. Nova Acta Acad. Leop.-Car., Bd. LXXII, Nr. 2, Halle 1899, pag. 3 I Iff 
(Fig. 3 u. 4) ein Zerfall der Blasenzellen und eine Ausfuhr der dadurch frei gewordenen Exkretballen (Fig. 2, cyb) auf dem Wege der Gewebelücken nach der Pharyngealtasche stattfindet. Vielleicht spielt bei dem Transporte der Exkretionsstoffe nach vorn neben der aktiven Bewegung der Blasenzellen auch die Strömung der Exkretionsstoffe von Zelle zu Zelle eine Rolle, wobei von hinten nach vorn die Konzentration der Auswurfstoffe zunähme, welche in dem verschiedenen Verhalten gegen Farbstoffe - erst gelblich, dann grau, dann rot und schließlich blau - ihren Ausdruck findet. ${ }^{1}$ )

\section{Syndesmis echinorum François.}

Taf, II, Fig, I4.

Die zuerst von Silliman²) aufgestellte Gattung Syndesmis enthält nur diese eine, weit verbreitete Spezies, welche wiederholt ${ }^{3}$ ) und am eingehendsten von Russo untersucht worden ist. Ich habe sie auch in Bergen und Alexandrowsk gefunden.

Völlig ausgebreitet (Fig. I4, a) kriecht das Tier überaus langsam und hat dann eine blattförmige Gestalt, vorn abgerundet, bis zum Beginn des zweiten Körperdrittels allmählich verbreitert und hinten zu einem stumpfen Schwänzchen verschmälert. Der Bauch ist dann flach und der Rücken schwach gewölbt. Doch vollziehen sich träge Kontraktionen, welche den Leib strecken und das Schwanzende fein ausziehen (Fig. 14, b); das Vorderende kann eingezogen, die Körpermitte verbreitert werden und so kommen Gestalten zu stande, welche an ähnliche von mirt) abgebildete Formzustände von Graffilla muricicola erimnern. Auch werden oft die Seitenränder načh oben umgeschlagen und der flache Leib dütenartig spiral eingerollt, so daß er Spindelgestalt erlangt. Dies ermöglicht es dem Tiere, sich zwischen den Kotballen im Darme des Wirtes hindurchzuzwängen. An Durchsichtigleit wetteifert diese Spezies mit 1lesost. elurenbergi: der Darm schimmert auf schwarzem Grunde als hellgelber Medianstreif durch, das Parenchym ist jederseits des Darmes gelbrötlich (hämoglobinfärbig), welche Farbe gegen den Rand des Körpers immer heller und nur unterbrochen wird durch zwei längliche orange Flecken, die Dotterstöcke.

1) Nach diesem Erklärungsversuche seicn noch einige Worte den eigentümlichen kanalartigen Streifen (fa) gewidmet, welche sich in der Schnitserie (Taf. I) abgebildet finden. Ich habe sie nur bei diesem großen, in voller weiblicher Reife befindlichen Tiere gefunden, während in drei anderen Serien (durch ein anderes großes, weiblich reifes Tier und zwei kleine, männlich reife Exemplare) keine Spur davon zu beobachten war. Schon dieser Umstand ließ vermuten, daß es sich um Kunstprodukte handle. Eine genaue Prüfung ergab, daß tatsächlich nichts anderes vorliegt, als feine Fältchen, die sich in dem zarten blasigen Bindegewebe, sei es schon vor dem Schneiden bei der Konservierung, sei cs erst während des Aufklebens der Schnitte auf den Objektträger, gebildet haben. pag. 1087

2) W. A. Silliman, Sur un nouveau type de Turbellariés. C.-R. Ac. Sci. Paris, vol. 93, I88I,

i) Ph. François, Sur le Syndesmis, nouveau type de Turbellariés. C.-R. Ac. Sci. Paris, vol, 103, I886, pag. 752. - L. Cuénot, Commensaux et Parasites des Echinodermes, 2. note. Revue biol. Nord de la France, tome V, Lille I892/93, pag. Ir. - A. Russo, Sulla Morphologia del Syndesmis echinorum François., Ric. Lab. Anat. Roma, vol. 5, I\$95, pag. 43-68, tab. 5 u. 6. - A. E. Sh ipley, On some Parasites found in Echinus esculentus L., Quart. Journ. Micr. Sc., N. Ser, vol. 44, London 1901, pag. $28 \mathrm{I}-290$, tab. Is.

4) Graff, Monogr. Turbell., I., tab. XIV, fig. I, b. 
In Bezug auf die Anatomie will ich hier nur einige Bemerkungen anführen, ohne auf die erst noch zu bearbeitende Histologie dieses Tieres genauer einzugehn. Die Epithelzellen verhalten sich sehr merkwürdig. Überall, wo eine Delınung bei der Krümmung des Körpers stattfindet, flachen sie sich ab, wo dagegen eine Pressung erfolgt, springen sie als mehr weniger hohe Papillen an der Oberfläche hervor. Eine und dieselbe Körperstelle zeigt also ganz verschieden gestaltete Epithelzellen, je nachdem sie konvex oder konkav ist, Rücken und Bauch zeigen die eine oder die andere Form, je nachdem die Körperränder nach oben oder nach unten eingeschlagen sind. Das Parenchym hat den gleichen Bau wie jenes von Graffilla muricicola. Rhabditen und Hautdrüsen fehlen und das von $\mathrm{Russo}$ zu letzteren gerechnete ventrale Drüsenbüschel (1. c. pag. 5 8 ) führt in das Atrium femininum ("camera commune"). Russo und ebenso auch Shipley beschreiben den Darm als einen gestreckten Kanal mit glatten Seitenrändern. Indessen erscheint er so bloß an Quetschpräparaten ${ }^{1}$ ) und bei ungequetschten Tieren erkennt man deutlich die kurzen, warzenförmigen, jederseits ca. I6 seitlichen Divertikel, welche hinter dem Ösophagus beginnen und bis nahe an das hintere Darmende reichen. Der Dotterstock hat nicht selten jederseits bis über 20 aus dem Dottergange parallel abgehende Äste, die sich gegen den Körperrand weiterverästeln und hier vielfach miteinander netzartig anastomosieren. Der Penis ist bei Russo (fig. I) verhältnismäßjig zu groß gezeichnet, doch ist im allgemeinen seine Darstellung des Geschlechts-Apparates viel genauer und eingehender als die (viel später publizierte) Shipleys. Das wichtigste Kapitel aus seiner Monographie ist jenes, welches den weiblichen Kopulations-Apparat behandelt. Das von Russo als „receptaculum seminis" bezeichnete Organ ist im Sinne meiner Nomenklatur ${ }^{2}$ ) eine Bursa seminalis. Dieselbe entspringt mittels eines kurzen Stieles von dem trichterförmig erweiterten Anfangsteile des, die Ausführungsgänge der Keim- und Dotterstöcke aufnehmenden Ductus communis. Dieser von Russo als "camera commune" - der Ausdruck "Atrium femininum" wäre richtiger - bezeichnete Raum setzt sich als enges Rohr nach hinten fort, um neben dem einfachen Uterus in das Atrium commune zu münden. Die besondere Eigentümlichkeit des Geschlechtsapparates von Synd, echinom besteht aber darin, daß die Bursa seminalis nach Russo nicht blind endet, sondern von ihrem birnförmig aufgetriebenen Fundus sich in einen von Papillen ausgekleideten Kanal fortsetzt, welcher separat (auf der, der Uterus-Einmündung gegenüber liegenden Seite des Penis) in das Atrium mündet. Dieser Kanal wird von den bisherigen Autoren als Vagina bezeichnet, da er, ähnlich wie die Vagina bei Trematoden und Cestoden, als Begattungskanal dienen dürfte. Von speziellem Interesse ist Russos Beobachtung, daß die Vagina nicht immer vom Fundus, sondern oft von der Seite der Bursa - ja bisweilen sogar direkt von der "camera commune" — abgeht

1) Die Tiere sind so zart, daß sie beim Quetschen sich fast auf die doppelte Größe ausdehnen, die Geschlechtsdrüsen (namentlich die Hoden, wie in Russos Zeichnung tab. 5, fig. I) sich verbreitern und die Darmdivertikel verstreichen.

2) Graff, Monogr. Turbell, I., pag. 146. - Bei dieser Gelegenheit sei bemerkt, daß Russos Darstellung der Entwicklung der weiblichen Geschlechtsdrüsen vollständig mit der von mir (1.c.pag.130) vertretenen Ansicht übercinstimmt, wonach die getrennten Keim- und Dotterstöcke durch Differenzierung aus ursprünglich einheitlichen weiblichen Drüsen (,Ovarien") sich herausgebildet haben. Russo hat mich offenbar mißverstanden, da er mir imputiert, „un' origine diversa del germigeno e del vitellogena “ vertreten $z$ haben. 
(1. c. pag. 50). Dieser Umstand erscheint als ein wichtiger Beleg für seine Auffassung, daß wir es in dieser Vagina mit einer sekundären Bildung zu tun haben (pag. 62). Durch sie ist die Schwierigkeit der Begattung und Befruchtung der Eier kompensiert, welche sich aus der, wahrscheinlich durch die Vergrößerung und Verästelung der weiblichen Geschlechtsdrüsen bedingten Herausbildung des langen Ductus communis ergeben hatte.

$\mathrm{Zu}$ den schon bisher bekannten Wirten und Fundorten dieses Parasiten kann ich weiter nennen: Sphaerechimus granularis A. Ag. (I I solche von Windnäspollen auf Sartorö enthielten 8 Parasiten) bei Bergen, Strongylocentrotus dröbacchensis (Müll.) bei Alexandrowsk (2I solche enthielten Io Parasiten). Herr Magister A. Luther fand ${ }^{1}$ ) Ostern dieses Jahres diesen Parasiten massenhaft bei Triest. Wie Russo denselben ,abbondantamente" bloß in Echiniden von der Secca della Gaiola bei Neapel fand, so sind auch bei Triest nur die See-Igel bestimmter Lokalitäten infiziert. Bei Triest lieferten 30 Exemplare Echinus microtuberculatus Blv. und 22 Strongylocentrotus lividus Brdt. gar keinen, 5 Sphacrchinns gramularis A. Ag. bloß 5 Parasiten, 6-Sphaerechinus granularis von Punta di Salvore, Pirano und den Brionischen Inseln brachten gar keinen, dagegen enthielten sämtliche bei Umago gefischten Exemplare des letztgenannten See-Igels zahlreiche Syndesmis - je zwischen I9 und I33 Stück -, u. zw. in allen Teilen des Darmes mit Ausnahme des Ösophagus, am zahlreichsten jedoch im Enddarme. Ich fand die Parasiten oft dicht von Schleim umhüllt und rate, beim Sammeln den herauspräparierten Darm nicht mit der Schere zu zerschneiden, sondern mit Pinzetten zu zerreißen und dann auszuspülen.

\section{Genostomatidae nov. fam.}

Nach meiner Auffassung müssen die beiden, von Dörler aufgestellten und bisher bloß parasitische Formen umfassenden Genera Genostoma und Urastoma zu einer von den Vorticiden zu trennenden besonderen Familie vereinigt werden. Dieselbe wäre folgendermaßen zu charakterisieren:

Hermaphroditische Rhabdocoela, deren Geschlechts-Apparat in die Pharyngealtasche mündet, so daß der (das Hinterende des Körpers einnehmende) Mund zugleich als Geschlechtsöffnung dient. Mit einem am Hinterende des Darmes angebrachten Pharyndoliformis, dessen Spitze nach hinten gerichtet ist. Mit Keim-Dotterstöcken oder paarigen, von den Dotterstöcken getrennten Keimstöcken und parigen kompakten Hoden. Weibliche Hilfsapparate und Uterus fehlen.

Die beiden hiehergehörigen Gattungen nähern sich einerseits in der Größe und Stellung des Pharynx sowie durch die Lage der Mundöffnung der Gattung Opistomum O. Schm., andrerseits schließen sich im Bau der weiblichen Geschlechtsdrüsen Genostoma an Maxia mihi, ${ }^{2}$ ) Urastoma dagegen an Provortex Graff an.

1) Nach mündlicher Mitteilung.

2) Das von mir 1882 (Monogr. Turbell., I., pag. 344) aufgestellte Genus Schullziu ist, wie mir Herr Prof, v. Mährenthal mitteilt, schon seit $\$ 876$ vergeben. Ich schlage daher für dasselbe den Namen Maxia vor. 
Genostoma Dörler. ${ }^{1}$ ) Genostomatidae mit Keim-Dotterstöcken und mit einer bewimperten Kriechsohle, außerhalb welcher das Cilienkleid fehlt.

\section{Genostoma tergestinum (Calandr.). $\left.{ }^{2}\right)$}

Taf. III, Fig. $25-30$.

Ich habe diese und die folgende Spezies im Laufe des Jänner und Februar untersucht und kann auf Grund derselben Repiachoffs und Dörlers Darstellungen ergänzen. Auf Nebalia bipes von Triest ist Gen. tergestimun häufiger als Gen. marsiliense. Beide leben im Schalenraume, meist an der Innenwand des Schalenpanzers. An ihrem hyalinen farblosen Körper sieht man bloß den Darm mit hell-gelblichgrünlichem Ton durchscheinen und bei auffallendem Lichte sich kreidigweiß abheben. Gen. marsiliense ist noch hyaliner als Gen, tergestinum und fällt - von der Penisform und der Lage der Hoden abgesehen - besonders durch die glänzenden Penis- und Speicheldrüsen und den Kranz von Selkretpfropfen an der Pharyngealbasis auf. Jedoch kann man an noch nicht geschlechtsreifen Tieren in Zweifel geraten, welche der beiden Spezies vorliegt. Hat das Auge einmal die charakteristischen Merkmale erfaßt, so wird man etwa in jeder zehnten Nebalia ein, selten zwei Exemplare der Parasiten finden und auch bisweilen im Wasser solche entdecken, welche sich auf die Füße des Wirtes verirt und von denselben hinausgeschleudert wurden.

Meine größten Exemplare von Gen. tergestimum hatten ausgestreclzt kriechend nur wenig über $0^{\circ} 51 m m$ Länge, während Dörler konservierte Exemplare von ca. $0.6 \mathrm{~mm}$ vorlagen. Der Körper ist im Leben dorsal konvex, ventral in der Breite der Krieclsohle abgeflacht und bewegt sich sehr rasch, bald gleichmäßig kriechend, bald spannerartig schreitend. Im Kriechen ist das tastende Vorderende (Fig. 25) etwas verbreitert und seitlich mehrweniger stark ausgeladen, hinter demselben ist die schmalste Stelle des Körpers, von welcher an eine langsame Verbreiterung bis in das letzte Viertel stattfindet, während das Hinterende quer abgestutzt ist. Bisweilen kontrahiert sich bloß das Hinterende bei gleichzeitiger stärkerer Verbreiterung, wodann der Körper eine flaschenförmige Gestalt erlangt. Das ungequetschte Tier ist zierlich quergeringelt durch, an den Seiten des Körpers mehrweniger scharf markierte, ziemlich regelmäßig aufeinanderfolgende Einschnitte. Doch ist keine denselben entsprechende Anordnung des Hautmuskelschlauches zu beobachten. Die im Verhältnis zu den Längsfasern sehr feinen und dicht aufeinanderfolgenden Ringfasern bilden vielmehr eine ganz kontinuierliche einfache Schicht.

Die ventrale Fläche der vorderen Verbreiterung trägt eine querovale, wulstig umrandete Sauggrube (ss), an welcher die zahlreichen, im ersten Körperdrittel ent-

1) A. Dörler, Neue und wenig bekannte rhabdocoele Turbellarien. Z. f. wiss. Zool., Bd. LXVIII, Leipzig 1900, pag. 20.

2) W. Repiachoff, Über eine neue an Nebalien lebende Turbellarie, Zool. Anz., VII. Jahrg., Leipzig 1884, pag. 717. - S. Calandruccio, Anatomia e sistematica di duc specie nuove di Turbellaric. Atti Accad. Gioenia di Sc. Nat. in Catania, ser. 4. ${ }^{\text {, }}$ vol. X, Mem. 16, Catania 1897, pag. 17 (tauft Repiachoffs Turbellarie Hypotrickina tergestina). - Dörle r, 1. c. pag. 21, tab. II, fig. 8- 2 (Genostona terges(imum). 
haltenen Drüsen (Fig. 27, sad) ausmünden, so daß dieselbe doppelt zur Anheftung geeignet erscheint. Die hintere Anheftung wird bei der spannenden Fortbewegung durch den Pharynx bewerkstelligt. Der Unfang der Sauggrube wechselt beständig, ihr bewimperter Vorderrand schiebt sich bisweilen freiwillig bei den tastenden Bewegungen, namentlich aber bei plötzlicher heftiger Kontraktion und infolge von Quetschung unter dem Vorderende hervor (Fig. 26, ss), während sie sich verbreitert (s. den hintern Rand ss der Saugscheibe in Fig. 26). Bei starker Quetschung wird auch das Sekret der Drüsen der Saugscheibe tropfenweise herausgepreßt. Abgesehen von dieser wulstigen Umgrenzung der Saugscheibe, welche mit dem vorderen Ende des ventralen Cilienfeldes (Fig. 25, cif) zusammenfällt, habe ich keinerlei, das letztere begrenzende Falte oder Furche (Repiachoff) wahrgenommen. Die Kriechsohle ist vielmelı bloß durch das Aufhören der Cilienbekleidung (Fig. 27, ci-ci) von der übrigen, mit einer glänzenden Cuticula überzogenen Körperoberfläche abgegrenzt, die allerdings bisweilen in der unmittelbaren Umgebung des Cilienfeldes von diesem hell absticht.

Der Pharynx ist bei Gen.tergestimum massiver als bei Gen. marsiliense und seine Form åndert beståndig während des oft sehr lebhaften Spieles von Ausstreckung und Zusammenziehung, Vorstoß und Retraktion. Bald konisch (wie in Fig. 25, ph), bald zylindrisch mit ausgreifenden freien Rändern, wie ein Trikladenpharynx (Fig. 26), hat er doch den Bau des typischen Pharynx doliiformis. Die Zurückziehung des Pharynx besorgen zwei, seitlich vom Integumente im Anfange des letzten Körperviertels entspringende Retraktoren (Fig. 25, rph), die nach hinten konvergieren und mit dem größten Teile ihrer Fasern in den Pharynx eintreten, mit einem kleineren Teile aber auf der Pharyngealtasche (pht) verstreichen. Der Darm nimmt beim ungequetschten Tiere etwa das dritte und vierte Fünftel des Körpers ein und ist hier gestreckt und schmal mit drei, seltener zwei Paaren seitlicher stumpfer Divertikel versehen (Fig. 25-27, da). Er nimmt fast die ganze Höhe des Querschnittes (Fig. 27) ein und ist beiderseits von dorsoventralen Leibesmuskeln ( $\mathrm{dvm}$ ) begleitet. Die divertikellose ovale Form, wie sie in der von Dörler (tab. II, fig. 8) reproduzierten Zeichnung Böhmigs dem Darme zukommt, habe ich nie gesehen und vermute, daß dieselbe auf sehr starke Quetschung zurückzuführen sei. Im Lumen des Darmes fanden sich bei der Schnittserie, welcher Fig. 27 entnommen ist, frei im Darmlumen liegende Gregarinen $(G)$, deren ovaler Körper einen Längsdurchmesser von $0^{\circ} \mathrm{O} 2 \mathrm{~mm}$ besaß und einen hellen Kern mit großem Kernkörperchen einschloß.

Zu Seiten des vorderen Darmendes liegen die beiden, verhältnismäßig großen Hoden (Fig. 26, te) und die Art, wie die einzelnen Spermatidenhäufchen sich voneinander absetzen, erweckt manchmal die Erinnerung an die zerstreuten Hodenfollikel der Alloeocoelen. Indessen überzeugt man sich bẹi genauerem Zusehen von dem Vorhandensein einer Tunica propria, welche sich auf die Vasa deferentia fortsetzt. Letztere liegen in den Seitenteilen des Körpers (Fig. 27, vd), von den, zwischen ihnen und dem Darme eingekeilten Keimdotterstöcken (do) durch dorsoventrale Muskelzüge getrennt, ${ }^{1}$ ) und fallen durch ihre Weite auf. In geschlechtsreifen Exemplaren (Fig. 26) sind die Vasa deferentia von mächtigen Spermamassen erfüllt, welche die Wandung derselben

1) Wenn Repiachoff (1. c. p. 718, Anm. 3) die Dotterstöcke zuäußerst, die „Hoden" dagegen zwischen letzteren und dem Darme liegen läßt, so handelt es sich hier offenbar um eine Verwechslung der beiden Organe. 
unregelmäßig ausbuchten, und bei starker Quetschung verstreichen diese Ausbuchtungen und es entsteht das Bild der von Dörler (1. c. pag. 23) beschriebenen, mit stumpfen Lappen versehenen seitlichen „Blasen“. Im übrigen kann ich der Darstellung, welche der genannte Autor vom Geschlechts-Apparate gegeben hat, nur noch einige Bemerkungen über das Kopulations-Organ hinzufügen. Die „verdickte Partie“ ist der von Körnersekret-Ballen ausgekleidete Bulbus penis und der Chitinstachel (ch) des letzteren variiert in der Form. Bald ist er ein gleichmäßig zur Spitze zulaufender Kegelmantel (Fig. 28, a), dessen Öffnung aber nicht die Spitze einnimmt, sondern etwas linter derselben auf der Ventralseite (bei $b_{l}$ ) liegt, bald schwillt der Chitinstachel vor der Spitze wie eine Lanzenspitze an (c).

Die beiden rätselhaften, in ihrer Form an Segmental-Organe erinnernden Gebilde habe ich bei allen geschlechtsreifen Exemplaren dieser Spezies gefunden, u. zw. immer hinter dem ersten Paare der Darmdivertikel (Fig. 25 u. 26, x). Das ganze Rohr hat ca. $0.05 \mathrm{~mm}$ Länge und die ovale Anschwellung (Fig. 30, e) nimmt so ziemlich die Mitte ein. Die Art der Krümmung wechselt sehr (vgl. Fig. 25, 26, 29, 30), doch scheint der engere Teil des Rohres, dessen Öffnung sich in radiär ausstrahlende feine Fasern verliert (pr), stets näher dem Darme zu liegen, wogegen das weitere Ende (di) von letzterem abgekehrt erscheint. Die Gestalt dieser distalen Mündung ist meist die in Fig. 30 abgebildete, aber bisweilen ist sie zu einem deutlich abgesetzten Trichter oder Teller (Fig. 29) verbreitert. Auch die Form und die Zahl der die Rosette des distalen Endes bildenden „kugeligen Zellen" (Dörler, pag. 24) wechselt nicht bloß bei verschiedenen Individuen, sondern auch bei den beiderseitigen Organen desselben Tieres von 2 bis 9 (Fig. 29, a) und manchmal fehlen sie ganz und an ihrer Stelle findet sich bloß eine kugelige Anhäufung (b, der (auch das Lumen des Rohres ausfüllenden) feinkörnigen, plasmatischen Substanz.

\section{Genostoma marsiliense (Calandr.). ${ }^{1}$ )}

Taf. III, Fig. 3r.

Im allgemeinen etwas kleiner als Gen. tergestimum - Dörler gibt $0.38 \mathrm{~mm}$ als größte Länge des lebenden ausgestreckten Tieres an - ist sie auch in der Gestalt abweichend, wie ein Blick auf unsere Abbildung lehrt. Das seitlich nicht ausgebuchtete Vorderende setzt sich in gleicher Breite auf den Körper fort, welcher im Leben sich nach hinten nicht verbreitert, sondern nach einer seichten Einschnürung am Beginne des letzten Viertels eine rasche Verjüngung erfährt. Die Querringelung ist hier nur durch eine seichte Einkerbung der Seitenränder angedeutet und erreicht niemals die Ausprägung wie bei Gen.tergestinum. Die bewimperte Kriechsohle ist wie bei letzterer Spezies gestaltet und auch eine Saugscheibe vorhanden, welche mit ihrem Vorderrande sich bisweilen als „Hautfalte" (ss) vorschiebt, wie ich gegen Dörler (1. c. pag. 25) bemerken muß. Dagegen ist der, die Saugscheibe umrahmende Wulst viel weniger deutlich. Vor dem Gehirn (g) sieht man die Drüsen der Saugscheibe (sad) eingefaßt von zum Vorderende ziehenden Muskelfasern (ms). Die außerhalb dieser liegenden, sogenannten „stäbchen-

1) Repiachoff, Noch eine an Nebalien lebende Turbellaric. Zool. Anz, XI. Jahrg., 1\$88, pag. 141. - Calandruccio, 1. c. (Hypotrichina marsiliensis). - Dörler, 1. c. pag. 25, tab. II, fig. 13-I5 (Genostonsa marsiliense). 
förmigen Gebilde" (rh) scheinen mir nichts anderes zu sein als Insertionspunkte weiterer, zum Vorderrande der Saugscheibe ziehender Muskelbündel (mrh). Der Darm (da) gibt kein brauchbares Unterscheidungsmerkmal gegen die andere Spezies ab, ebensowenig die Lage der, von mir ebenfalls als terminal befundenen Mundöffnung (o). Dagegen finde ich den Pharynx (ph) wesentlich kleiner und seine beiderseitigen Büschel von Speicheldrüsen, namentlich aber die, an der Pharyngealbasis als glänzende Perlen aufgestauten Selzretpfröpfchen derselben (spp) sind ebenso auffallend wie die, bei der klaren Durchsichtigkeit dieser Spezies sofort in die Augen springenden, akzessorischen Drüsen des männlichen Geschlechts-Apparates (vgl. Dörler, l. c. tab. II, fig. I3).

Die beiden Hoden (te) liegen weit hinten, im Ende des dritten Körperviertels, dicht vor dem Keimstocke (ks), und die Vasa deferentia sind hier demnach sehr kurz. Die Samenblase (vs) findet sich bald vor (s. bei D örler), bald hinter dem Penis und diese Lagerung fand ich viel häufiger als jene. Der Bulbus penis ist kugelig und von wurstformigen Kornsekretmassen ausgekleidet (pe), seine Spitze besteht aus einem kurzen, muskulösen und keinerlei Chitinbildung aufweisenden Röhrchen, das in das Innere des Bulbus zurückgezogen werden kann, wie dies bei Dörler dargestellt ist. Die beiden Dotterstöclie (do) sind rosenkranzförmig eingeschnürte schlanke Schläuche, die sich bis gegen das vordere Darmende erstrecken, hinter den Hoden miteinander verschmelzen und nach hinten einen unpaaren medianen Lappen bilden, den Keimstock (ks). Doch fand ich meist auch einige junge Keimzellen $\left(\mathrm{ks}_{\mathrm{I}}\right)$ weiter vorn, im Ende des rechten dotterbereitenden Schenkels der weiblichen Geschlechtsdrüse. Überhaupt sah ich weder bei Gen. nucrsiliense noch bei Gen. tergestinum den Keimstock so scharf vom dotterbereitenden Abschnitte geschieden, wie dies bei Dörler gezeichnet ist, indem die Keimzellenlager gleichsam in Dottermasse eingebettet sind, welche letztere alle Lücken zwischen den sich ablösenden Keimzellen ausfüllt.

Wie meine Vorgänger, so habe auch ich bei dieser Spezies niemals eine Spur der rätselhaften Organe vorgefunden, und was Repiach off (1. c. pag. 143) mit den angeblich in der Gehirngegend ausmündenden ,zwei ziemlich langen, nach abwärts ziehenden Blindsäcken" meint, ist mir nicht klar geworden.

Urastoma Dörler. Genostomatidae mit zwei Keimstöcken und $z$ wei von denselben getrennten Dotterstöcken, mit vollständigem Cilien. kleide.

\section{Urastoma cyprinae (Graff).}

Taf, II, Fig.12-13.

Diese Spezies, für welche Dörler1) das Genus Urastoma schuf, wurde von W. Faussek und H. Sabussow bei Solowetzk auf und zwischen den Kiemen von Mytulis edulis L. gefunden und von dem letztgenannten ${ }^{2}$ ) infolge einer falschen Auf-

1) Dörler, 1. c. pag. 27-33, tab. III, fig. I-8 (Urastoma fansseki).

2) H. Sabussow, Mitteilungen üb. Turbellarien-Studien, II. Zur Kenntnis des Körperbaues von Enterostoma mytiti v. Graff., Zool. Anz., XXIII. Jahrg, Leipzig 1900, pag. 256-263. - H. Sabussow, Beobacht, üb. d. Turbellarien d. Inseln von Solowetzk. Arbeiten (Trudi) d, Naturf. Ges, b. d. Univ. Kasan, Bd. XXXIV, Heft 4, Kasan 1900 (russisch mit deutschem Auszuge), pag. r89 u. 198, tab. 1I, fig. 22 - 30. 
fassung des Pharynx als Enterostoma mytili zu den Alloeocoelen gestellt. Indessen war sowohl diese Zuteilung als auch die Speziesbezeichnung falsch, da die von mir ${ }^{1}$ ) unter dem gleichen Namen angeführte Form aus dem Sund nicht zwei, sondern vier Augen besitzt und dadurch ohne weiteres von der vorliegenden Spezies zu unterscheiden ist. Dagegen überzeugte ich mich im Laufe der vorliegenden Arbeit davon, daß der von mir als Acmostoma cyprina ${ }^{2}$ ) beschriebene Parasit von Cyprina islandica L. mit Dörlers Urastoma fansseki identisch ist. Die Beschreibung der ersteren paßt vollständig auf letztere in allen wesentlichen Punkten, mit Ausnahme des Pharynx und der Mundstellung. Diese Differenz ist jedoch damit zu erklären, daß ich die, zu jener Zeit noch nicht bekannt gewesene, Stirndrüse für den Pharynx gehalten hatte, ähnlich wie dies damals allgemein bei verschiedenen Acoelen geschehen war. ${ }^{3}$ )

Dörler hat bloß konserviertes Material untersucht und Sabussow liat es ebenfalls unterlassen, die Gestalt und Organisation nach dem lebenden Objekte genauer darzustellen. Diese Lücke in unserer Kenntnis kann ich ausfüllen, nachdem ich selbst zahlreiche lebende Exemplare dieses Tieres untersucht habe. Es lebt im Mantelraume verschiedener Muscheln, zwischen den Kiemen lebhaft umherschwimmend oder auf denselben festgeheftet, auf welchen sich der Parasit als weißes Pünktchen abhebt, wenn man die Kiemenblätter über einem schwarzen Grunde untersucht. Fast die Hälfte aller in Alexandrowsk untersuchten Miesmuscheln war mit diesen Parasiten beliaftet, manche enthielten deren mehr als vierzig Stück. Während die Muscheln nach einem achtzehnstündigen Aufenthalte im Trockenen größtenteils noch lebten, waren die darin enthaltenen Parasiten sämtlich schon abgestorben. Lebend aus der Muschel in reines Seewasser gesetzt, bleiben letztere ebensolange frisch wie die nichtparasitischen Verwandten, dagegen fällt ihr ausgesprochener negativer Heliotropismus auf - sie sammeln sich im Gefäß sofort an der dem Lichte abgewendeten Seite.

Die größten Exemplare haben eine Länge von 0.75- I $\mathrm{mm}$ und erreichen in der Körpermitte eine Breite, welche nicht ganz ein Dritteil der Länge beträgt. Nach den abgerundeten Enden verjüngt sich der Körper ein wenig, doch ist das Schwanzende etwas breiter als das Vorderende. Die ganze Körperoberfläche ist mit einem Pelz feiner und dichtgestellter Cilien bekleidet, deren Länge gleich ist der Dicke der Epithelialschicht. In letzterer finden sich kleine, glanzlose Pseudorhabditen (vgl. Subussow, Zool. Anz. pag. 257). Dem freien Auge weißlich, erscheint die Farbe im auffallenden Lichte bei schwacher Vergrößerung (Taf, II, Fig. I2) hellgelb mit grauen Fleckchen. Die gelbe Farbe wird bedingt durch runde oder ovale, bis $0.024 \mathrm{~mm}$ lange Parenchymzellen (Fig. 13, pi), die eine scliwefelgelbe Flüssigkeit mit feinen Körnchen enthalten. Solcher Pigmentzellen sind in der Regel 30 bis 40 über den Rücken zerstreut, doch variiert ihre Zahl und damit auch die Intensität des gelben Farbentons. Nicht selten kommen Exemplare vor, die nur wenige ( 3 bis 5 ) gelbe Zellen und diese bloß vor den Augen enthalten. Die graue Fleckung wird in erster Linie bewirkt durch birnförmige Hautdrüsen (hdr),

1) L. v. Graff, Monogr. Turbell,, I., Leipzig 1882, pag. 403.

2) Ebendas. pag. $3 S_{4}$.

3) Die Hoffnung, durch nochmalige Untersuchung der Kieler Cyprina-Parasiten jeden Zweifel an der Identität der genannten Formen ausschließen zu können, scheiterte leider an dem Umstande, daß dic mir von Herrn Prof. Dr. K. Brandt gütigst gesandten Cyprinen unser Institut so spät erreichten, daß von den Turbellarien licine Spur mehr zu finden war. 
die, doppelt so groß als die gelben Zellen, einen hellen Kern und grobkörniges Plasma besitzen, welches im durchfallenden Lichte meist einen gelblichgrauen oder bräunlichen Ton darbietet. Ihr feiner Ausführungsgang ist am Integumente angelieftet, wie man am besten an Quetschpräparaten sieht, bei denen Pharynx und Darm durch den Mund ausgestoßen sind und wo bei wechselndem Drucke diese Drüsen, unter Dehnung ihres Ausführungsganges, hin- und hergeworfen werden. Von den Hautdrüsen durch ihre schlanke Gestalt und ihr feinkörniges Plasma unterschieden sind die, am Vorderende (jedoch ohne scharfe Begrenzung des Mündungsfeldes) ausmündenden Stirndrüsen (sd), welche als ovales Paket den Raum zwischen der Körperspitze und dem Gehirn einnehmen.

Der weite, unregelmäßig gelappte, gelbliche Darm (da) erstreckt sich bis nahe an das Vorderende und enthält niemals irgendwelche Nahrungsobjekte. Der verhältnismäßig kleine Pharynx (ph) ist, wie schon Dörler (pag. 30) nachgewiesen und wie auch aus Sabussows fig. 26 hervorgeht, ein echter Pharynx doliformis. Das querausgezogene Gehirn (g) bildet jederseits eine. Anschwellung, welche ein Auge trägt. Die beiden Augen sind voneinander etwas weiter entfernt als vom Seitenrande des Körpers. Sie liegen nahezu am Ende des ersten Fünftels der Körperlänge, doch variiert diese Lage sehr je nach dem Kontralktionszustande des, oft stark eingezogenen Vorderendes. Der Pigmentbecher der Augen ist aus groben, braunen bis schwarzen, Kügelchen zusammengesetzt und hat meist Nierenform, mit nach außen gerichteter Konkavität und bis drei "Linsen" in letzterer. Manchmal bildet das Augenpigment einen rundlichen Haufen mit kurzen Fortsätzen an seiner Peripherie, auch habe ich einmal eine dreilappige Form desselben beobachtet.

Die Hoden (te) fand ich, Dörlers Darstellung entsprechend, als zwei längliche Massen entwickelt, welche seitlich hinter dem Gehirn beginnen und bis in den Anfang der zweiten Körperhälfte reichen. Vom muskulösen Penis (pe) mit seiner Samenblase (vs) sei nur das eine bemerkt, daß ich, im Gegensatze zu den Befunden an konservierten Objekten, am lebenden Tiere die proximale Masse alzzessorischen Drüsensekrets ( $\mathrm{s}_{1}$ ) viel gröber granuliert fand als das, in radiären Schollen verteilte, distale Selret (su), welches ein fast homogenes, fettglänzendes Aussehen darbot. Die Keimstöcke (ks) sind von oben her natürlich nur zum Teile zu sehen, dagegen überblickt man deutlich das Verhältnis des männlichen Genitalkanals (gc) zum Mund (o) sowie - am besten bei auffallendem Lichte - die Form des Dotterstockes. Er hebt sich, auf dunklem Grunde betrachtet, von dem hellgelblichen Darme dadurch ab, daß die durchsichtigen und daher dunklen Dotterkiggelchen hell umrandet sind, und indem man diese verfolgt, zeigt es sich, daß der Dotterstock aus geweihartig verästelten zylindrischen Strängen besteht, die vielfach miteinander anastomosieren, so daß sie stellenweise ein engmaschiges Netz bilden. Die reifen Spermatozoen sind ca. $O^{\circ} I m m$ lange geschlängelte Fäden, die sich hinten rasch zu einer feinen Spitze verschmälern, während sich ihr Vorderende in eine längere (ca. ein Fünftel der Gesamtlänge ausmachende) feine Geißel auszieht.

Auf der Suche nach dem Darmparasiten von Solen vagina (s. o. S. 9) habe ich mir im Laufe eines Jahres einige Hunderte Exemplare dieser Muschel von der zoologischen Station in Triest senden lassen, ohne im Darme etwas anderes als Infusorien zu finden. Dagegen fand ich zu meiner Überraschung zwischen den Kiemen ziemlich häufig die vorliegende Turbellarie, im Jänner junge, Ende Februar die ersten geschlechtsreifen 
Exemplare. Die daraufhin untersuchten Mytilus edulis von Triest enthielten aber kein einziges Exemplar. Es scheint also Urastoma cyprinae im hohen Norden Mytilus, in der Ostsee Cyprina, im Süden dagegen Solen zu bewohnen, ähnlich wie für Provortex tellinae falls die beiden Formen, welche ich unter diesem Speziesnamen vereinige, sich tatsächlich als identisch erweisen sollten - an der französischen Nordküste Solen, bei Neapel aber Tellina als Wirt dient. 


\section{Die bisher bekannt gewordenen parasitischen Turbellarien.}

In diesem Kapitel will ich zunächst in systematischer Reihenfolge alle Turbellarien aufzählen, welche bisher als Parasiten oder als des Parasitismus verdächtig beschrieben worden sind, unter Anführung der Charaktere, durch welche sie sich von den nichtparasitischen Verwandten unterscheiden. Hierauf soll eine Übersicht der bei Turbellarien vorkommenden Arten des Parasitismus gegeben und untersucht werden, welche anatomischen Merkmale als Folgen der parasitischen Lebensweise anzusehen sind.

\section{Acoela.}

Erst kürzlich ist zum ersten Male von einer parasitischen Acoelen berichtet worden. I. Avagina (nov. gen.) incola Leiper. Leiper $r^{1}$ ) fand bei $5 \%$ der von ihm in Millport untersuchten Exemplare von Echinocardium cordatum Gray im Nebendarm (,accessory canal“) ein blattförmiges, bis $2^{\circ} 5 \mathrm{~mm}$ langes Turbellar, das sich von Haplodiscus bloß durch die seitliche Lage der Hoden unterscheidet. Es soll hier nicht bloß die Bursa seminalis, sondern auch eine Vagina fehlen, so daß die Ablage der Eier nicht durch die, bloß dem männlichen Apparate dienende Geschlechtsöffnung, sondern durch Ruptur einer kurz vor letzterer liegenden Stelle des Integumentes erfolgt.

\section{Rhabdocoela.}

Diese Unterordnung der Rhabdocoelida enthält zwei Familien /Genostomatidae und Fecampiidae) und acht Gattungen (Graffilla, Syndesmis, Collastoma, Didymorchis, Anoplodinm, Genostoma, Urastona und Fecampia), welche durchweg parasitische Spezies umfassen, und im ganzen werden nicht weniger als 27 parasitische Formen genannt, deren mehrere allerdings Species incertae sind, von welchen nicht viel mehr bekannt ist, als ihre parasitische Lebensweise.

\section{Fam. Macrostomidae.}

2. Macrostomum scrobiculariae Graff. ${ }^{2}$ ) Diese in ihrer Gattungszugehörigkeit zweifelhafte Form wurde von Villot im Darm von Scrobicularia tenuis F. u. H. gefunden.

1) R. T. Leiper, On an acoelous Turbellarian inhabiting the common heart urchin. Nature, vol, 66, nr. I721, London 1902, pag. 641 (ergänzt durch briefliche Mitteilungen).

2) Graff, Monogr. Turbell., I., Leipzig 1882, pag. 245 . 


\section{Fam. Microstomidae.}

3. Rhynchoscolex vejdovskýi Selzera. ${ }^{1}$ ) Diese Microstomide soll ein Ektoparasit von Lumbriculus variegatus (Müll.) sein und sich von dessen Blute ernähren.

4. Nemertoscolex parasiticus Grff. ${ }^{2}$ ). Eine wahrscheinlich den Microstomidae zuzurechnende Art, welche in der Leibeshöhle vor Echizms pallasi Guér lebt. Es fehlen ihr, wie der vorgenannten, Statocyste und Augen, dagegen besitzt sie Wimpergrübchen.

\section{Fam. Mesostomatidae.}

5. Mesostoma a selli Kennel $\left.{ }^{3}\right)$. Lebt in den Bruttaschen von Asellus aquaticus L. und unterscheidet sich, soviel bisher bekannt, von den meisten Mesostoma-Arten durch seine Augenlosigkeit. Es bildet hartschalige Dauereier, die wahrscheinlich nach außen gelangen, während die „im Frühling ausschlüpfenden Tierchen sich vor Schluß der Tasche am Bauch der Asseln ansiedeln und dort einsperren lassen".

6. Byrsophlebs nana Laidlaw. ${ }^{4}$ ) Lebt in großen Mengen ektoparasitisch auf der Annelide Nephthys scolopendroides Chiaje und unterscheidet sich von den Gattungsgenossen durch den Mangel der Rhabditen, Hautdrüsen und Augen sowie dadurch, daß ihr, das Gehirn einschließende Vorderende zu einem weit ausstreckbaren Tastapparat umgewandelt, das Hinterende aber mit einer Saugscheibe versehen ist. Diese Spezies saugt wahrscheinlich an den zarten Ruderlappen das Blut ihres Wirtes, wozu sie durch die eigentümliche Gestaltung ihres Pharynx besonders befähigt zu sein scheint (S. 3).

\section{Fam. Vorticidae.}

Aus dieser Familie sind nicht weniger als 17 parasitische Spezies (gegen 58 freilebende) anzufühten und unter ihren Io Gattungen sind 5 durchaus parasitisch. Ich habe die Familie früher ${ }^{5}$ ) in die beiden Subfamilien Euvorticina und Vorticina parasitica eingeteilt, doch hat sich seither diese Einteilung als eine unnatürliche erwiesen, indem die nur durch ihre gleiche Lebensweise zusammengehaltenen Genera der V. parasitica sich von verschiedenen freilebenden Gattungen ableiten lassen, so Graffilla, Syndesmis und Collastoma von Provortex, Didymorchis von Vortex, Anoplodium von Derostoma.

7. Provortex tellinae Graff. Falls sich die von mir oben (S. 8) motivierte Zuweisung dieser Spezies zu Provortex als richtig herausstellen sollte, würde letzteres Genus aus fünf freilebenden Arten und einem parasitischen bestehn. Im Darme von Tellina sp.

1) E. Sekera, Beitr. z. K. d. Turb. d. Süßwassers. Sitzungsber. k. böhm. Ges., Prag ı888, pag. 22. E. Sekera, Studie limnobiologické, Programm d. Gymnasiums Pilsen, I898, pag. 23.

*) R. Greeff, Die Echiuren. Nova Acta Acad, Leop.-Car, vol. 41, Halle 1879, pag. 130, tab. XX (V), fig. $51-53$.

3) J. v. Kennel, Mesostoma aselli n. sp., Zool. Anz., XXI. Bd., r898, pag. 64r.

4) F. F. Laidlaw, Typhlorhynchus nanus: a New Rhabdocoele. Quart. Journ. Micr. Sc., N. Ser. vol. 45, P. 637 , tab. 35. - Dieses Tier gchört in die Gattung Byrsophlibs, wie ich oben (diese Abhandlung, S. 8) auseinandergesetzt habe.

5) Graff, Monogr. Turbell., I., Leipzig 1882, pag. 343 . 
und Solen vagina L. (S. 9) lebend, hat dieser Parasit zwei wohlausgebildete Augen bewahrt und unterscheidet sich von den freilebenden Provortexspezies bloß durch bedeutendere Größe der weiblichen Geschlechtsdrüsen, besonders der hier (im Gegensatze zu den übrigen Arten) verästelten Gestalt der Dotterstöcke sowie die, damit zusammenhängende, Produktion zahlreicher (bis 7) hartschaliger, je 2 Embryonen einschließender Eier, während die freilebenden sämtlich nur je ein $\mathrm{Ei}$ in ihrem Uterus enthalten.

Genus Graffilla. Der Mund liegt subterminal, der Pharynx ist im Verhältnis zum Körper sehr klein; die Geschlechtsöffnung gehört der Bauchfläche an, die beiden Keimstöcke sind enorm lange, im Körper aufgewundene zylindrische Stränge, die Dotterstöcke ebenfalls sehr umfangreich und meist stark verästelt, die Hoden paarig; Gehirn und Augen sind reduziert. Schmarotzen sämtlich in Mollusken.

8. Gr.muricicola Ther. $^{3}$ ) Der bis $5 \mathrm{~mm}$ lange Körper zerfällt in ein dickeres Vorderteil und einen feinen Schwanzanhang, beide oft durch vier kreuzweise gestellte warzige Auftreibungen, ähnlich wie bei manchen Trematoden-Redien, voneinander abgesetzt. Der Pharynxrand ist hier mit einem Kranze von Bohrstacheln besetzt. Die Keimstöcke sind zylindrische Stränge, die Dotterstöcke im Hinterleibe mit reichen Verästlungen den Darm umgebend, die Hoden unverästelte Schläuche. Augen klein, Rhabditen sehr klein und spärlich, Hautdrüsen fehlen, Exkretionskanäle vorhanden. Selır häufig und in großer Zahl in der Niere von Murex brandaris L. und Murex tmuculus L.

9. Gr. parasitica (Czern.). $\left.{ }^{2}\right)$ Mund und Pharynx wie bei der vorhergehenden Art, doch ohne Bohrstacheln. Hoden, Keimstöcke und Dotterstöcke wie bei Gr. muricicola, doch sind letztere noch umfangreicher und erstrecken sich weiter nach vorn als dort. Augen und Rhabditen fehlen, Hautdrüsen sind massenhaft vorhanden, der ExkretionsApparat scheint zu fehlen. Bewohnt häufig und zahlreich das Bindegewebe des Fußes der Tethys leporina L.

10. Gr. buccinicola H. L. Jameson. ${ }^{3}$ ) Mund subterminal, Pharynx klein, oline Bohrstacheln, Keimstöcke gewundene lange Stränge, die enorm entwickelten Dotterstöcke umhüllen den größten Teil des Darmes als einheitliche Masse, sind aber nach vorn und hinten verästelt, ebenso sind die beiden Hoden von exzessiver Größe. Augen klein oder ganz fehlend. Rhabditen und Hautdrüsen, desgleichen der Exkretions-Apparat fehlend. Schmarotzt an der Niere von Buccinum undatum L. und Nepunzea antiqua (L.).

II. Gr. brauni Ferd. Schm. ${ }^{4}$ ) Mund und Pharynx wie bei der vorhergehenden Art. Die Keimstöcke sind zylindrische Strånge von mehr als einem Drittel der Körperlänge, die sich jederseits in einen langen vordern und einen kurzen hintern Ast spalten. Die

1) H. v. Ihering, Graffila muricicola, e. paras, Rhabdocoele. Z. f, wiss. Zool., Bd. XXXII, I880, pag. 147. - Graff, Monogr. Turbell., I., pag. 372. - L. Böhmig, Unters, üb. rhabd. Turbell., I., Z. . wiss. Zool, Bd. XLIII, 1886, pag. 290.

2) Diese Form wurde zuerst von A. Lang beschrieben in: Mittheil. Zool. Stat. Neapel, Bd. II, I880, pag. 7. - V. Czerniavsky, Materialia ad Zoogr. Ponticam comp., Bull. Soc. Imp. Moscou, vol. 55, II., I880 (1S8I), p. 27I, hat sie zuerst als Langia parasitica benamst, so daß der später von mir gewählte Speziesname tcthydicola zurücktreten muß. - Vgl. auch: Graff, Monogr. Turbell., I., pag. 375, und Böhmig, Unters. üb. rhab. Turbell., I, pag. 290.

3) H. L. J ameson, Addit. Notes on the Turbellaria. Trans. Liverpool Biol. Soc., vol. XI, 1897, pag. 169. - Eine eingehendere Darstellung der Anatomie dieser Spezies habe ich in dieser Abhandlung S. ro gegeben.

4) Ferd. Schmidt, Graffilla Brauni n. sp., Arch. f. Naturg., vol. 52, II., i886, pag. 304. 
großen Dotterstöcke umhüllen hinten den Darm vollständig, während sie ihm vorn bloß dorsal aufliegen und bis ins erste Körperdrittel reichen. Die Hoden sind klein, kolbenförmig. Augen klein, doch stets deutlich. Rhabditen fehlen, Hautdrüsen finden sich bloß im Vorderende des Körpers, ein Exkretions-Apparat mit zwei seitlichen Mündungen vorhanden. Häufig und oft in sehr großer Zahl in der Leber von Teredo sp.

I2. Gr. mytili (Levins.). ${ }^{1}$ ) Mund und Pharynx wie bei den übrigen Arten. Die Keimstöcke werden als breite, ausgebuchtete (?) Säcke beschrieben, die sich von der Körpermitte bis zu den (sehr kleinen) Augen erstrecken. Dotterstöcke groß und stark verästelt. Im übrigen nicht genauer untersucht. Lebt an den Kiemen von Mytihus edulis L.

13. Syndesmis echin orum François. ${ }^{2}$ ) Dieses Tier ist der einzige Repräsentant seiner Gattung. Der kleine Pharynx und der Mund liegen nahe dem Vorderende des Körpers, der Darm ist mit seitlichen Divertikeln versehen. Augen fehlen, desgleichen Rhabditen und Hautdrüsen. Die Geschlechtsöffnung liegt am Hinterende des Körpers und sämtliche Geschlechtsdrüsen sind paarig und reich verästelt. Jeder Hode zerfällt in 5 bis ro, oft nochmals sekundär zerschnittene Lappen, jeder Keimstock besteht aus mehreren (meist 3), mit kurzen Nebenzweigen versehenen Ästen, am reichsten verästelt sind aber die beiden baumförmigen seitlichen Dotterstöcke. Am bemerkenswertesten ist jedoch die Komplikation des Begattungs-Apparates durch Ausbildung einer der Kopula dienenden $\mathrm{V}$ ag in a neben dem, der Eiablage dienenden, Ausführungsgange des Uterus. Ein Exkretions-Apparat fehlt. Lebt im Darme verschiedener Echiniden (Echinus sphaera Müll., E. acutus Lam., Sphacrechinus granzlaris A. Ag., Strongylocentrotus drocbacchensis [Müll.] und lividus Brdt.), bisweilen in enormer Anzahl (bis zu I33 Stück in einem Wirte).

14. Collastoma monorchis Dörler. ${ }^{3}$ ) Auch diese Spezies repräsentiert ein besonderes Genus. Der Mund liegt nahe dem Vorderende und der kleine Pharynx hat einen ähnlichen Bohrapparat wie Graffila muricicola. Augen, Rhabditen und Hautdrüsen fehlen. Ein einfacher großer Hodenschlauch, zwei keulenförmige Keimstücke und zwei unverästelte, aber fast durch die ganze Körperlänge sich erstreckende Dotterstöcke sind vorhanden. Der Kopulations-Apparat mit seinem einfachen Uterus, einem Ductus communis der weiblichen Drüsen und einer mächtigen Bursa seminalis, die einerseits mit dem Ductus communis, andrerseits aber durch eine Vag in a mit dem Atrium genitale kommuniziert, schließt sich an die bei Syndesmis echinorum herrschenden Verhältnisse an. Ein Exkretions-Apparat wurde auch hier nicht beobachtet. Lebt im Darme von Phascolosoma vulgare Dies.

15. Didymorchis paranephropis Hasw. ${ }^{4}$ ) Ist die einzige Art dieses Genus. Der dorso-ventral abgeplattete Körper besitzt am Hinterende eine Haftscheibe und ist bloß auf der Ventralfläche bewimpert. Zwei kleine Augen und Rhabditen vorhanden. Pharynx groß, Mund am Ende des ersten Fünftels des Körpers gelegen. Die den Beginn des letzten Viertels einnehmende Geschlechtsöffnung führt in ein weites, als Uterus und Bursa seminalis dienendes Atrium. Ein kleiner Keimstock, zwei den Darm außen umgreifende,

1) G. M. R. Levinsen, Bidrag til kundskab om Grönlands Turbellariefauna. Vidensk. Meddel. naturh. Foren. Kjöbenhavn 1879/80, pag. 180. - Graff, Monogr. Turbell., I., pag. 376.

2) Vgl. d. monographische Bearbeitung dieser Spezies von A. Russo, Sulla Morphologia del Syndesmis echinorum François,, Ric Lab. Anat. Roma, vol. 5, 1895, pag. 43, und diese Abhandlung S. 19.

3) A. Dörler, Neue u. wenig bck, rhabd. Turbellarien. Z. f, wiss, Zool., Bd. LXVlII, r9oo, pag. 33.

4) W. A. Haswell, On Didymorchis. Proc, Linn. Soc. N. S. Wales 1900, pag. 428. 
schwach eingeschnittene Dotterstöcke und zwei ovale, große Hoden vorhanden. Die Eischale besitzt einen schlanken Stiel. Ein Exkretionssystem mit zwei Endblasen vorhanden. Lebt in den Branchialkammern des Paraneplirops neoselandicus.

Genus Anoplodium. Platte Formen mit einem kleinen Pharynx und einem im ersten Körperdrittel gelegenen Munde, während die Geschlechtsöffnung am Hinterende mündet. Ein großer, unregelmäßig gelappter Keimstock, geweihartig verästelte Dotterstöcke und zwei langgestreckte, gelappte Hoden. Mit dem Keimstock ist eine Bursa seminalis („Receptaculum seminis" der Autoren) verbunden, der Uterus ist einfach.

I6. A. parasita Ant. Schn. ${ }^{1}$ ) Ohne Augen und Rhabditen, wahrscheinlich fehlen auch Hautdrüsen. Die Eischale ist in einen langen Stiel ausgezogen. Lebt (oft in großer Anzahl) in der Leibeshöhle von Holothuria tubulosa Gm., woselbst auch die Eier abgelegt werden. Herr Dr. Bruno Wah $1^{2}$ ) fand diesen Parasiten bisweilen auch in Hol. polii Chiaje.

17. A. schneideri C. Semp. ${ }^{3}$ ) Soll "fast in allen Einzelheiten" mit A. parasita übereinstimmen. Im Darm von Stichopus variegatus C. Semp. und Miulleria lecanora Jäger.

I8. A. pusillum Montic. $\left.{ }^{4}\right)$ Kaum I $m m$ lang, gestreckt elliptisch, aber vorn verschmälert und hinten verbreitert, Dotterstöcke weniger und Hoden stärker ausgebildet als bei $A$. parasita, die Eikapseln strohgelb, pyramidenförmig, mit einem kurzen Stiele an der Spitze. In der Leibeshöhle von Holothuria polii Chiaje.

19. A. graffi Montic. ${ }^{5}$ ) Ähnlich dem A. pusillum. In der Leibeshöhle von Holothuria impatiens $\mathrm{Gm}$.

20. A. myriotrochi Graff. ${ }^{6}$ ) Diese kleine rötliche Form wurde von Danielssen im Darme der meisten Exemplare von MIyriotrochus rinki Steenstr. gefunden.

Die vorstehenden vier Spezies sind so wenig bekannt, daß ich sie hauptsächlich mit Rücksicht auf die Wirte provisorisch hieherstelle. So ist Dr. Br. Wahl mit der Untersuchung eines mit zwei Keimstöcken versehenen Anoplodium-ähnlichen Parasiten beschäftigt, der, wenn sich in Neapel die Identität mit A. pussilum herausstellen sollte, die Ausscheidung des letzteren aus dem vorliegenden Genus veranlassen würde.

Für die folgenden, im Anhange zu den Vorticiden anzuführenden Parasiten, fehlt jeglicher Anhalt zur Einreihung in ein bestimmtes Genus.

21. A. chirod ot a e Sabuss. ${ }^{7}$ ) Bis $0.5 \mathrm{~mm}$ lang, drehrund, mit stumpf abgerundetem Vorderende und spitz zugerundetem Hinterende, durchsichtig und schwach gelbrötlich gefärbt. Der wohlausgebildete Pharynx am Vorderende des weiten, rundlichen, gelblichbraunen Darmes, vor dem Pharynx zwei große, schwarze, nierenförmige Augen. In der Leibeshöhle von Chirodota laevis O. Fabr. (Ch. pellucida M. Sars.).

1) Graff, Monogr. Turbell., I., pag. 376 .

2) Nach mündlicher Mitteilung.

3) C. Semper, Reisen im Archipel der Philippinen, I. Bd, Holothurien, Leipzig I868, pag. 100.

4) F. S. Monticelli, Not, prel, int, ad alcuni inquilini degli Holothurioidea del golfo di Napoli.

Monit. Zool. Ital., anno III., Firenze I892, pag. 254.

5) Ebendas. pag. 255.

6) Graff, Monogr. Turbell., I., pag. 379.

7) H. Sabus sow, Beobacht. üb. d. Turbell. d. Inseln von Solowetzk. Trudi d. Ges. d. Naturf. Univ. Kasan, vol. 34, I900, pag. ISS (38). 
22. A. clypeasteris Graff. ${ }^{1}$ ) Von H. N. Moseley in Menge auf der Oberfläche eines bei Suez lebenden Clypeaster sp. gefunden. Die Leibesflüssigkeit soll Hämoglobin enthalten.

23. Vorticide (gen.? sp.?) aus der Leibeshöhle von Cacumaria planci Marenz. In

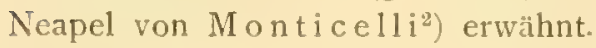

\section{Fam. Genostomatidae. ${ }^{3}$ )}

Diese durchweg aus Parasiten bestehende Familie ist charakterisiert durch die Kombination ihres, am Hinterende des Körpers angebrachten Mundes mit der Geschlechtsöfnung, einen Pharynx doliiformis, paarige männliche und weibliche Geschlechtsdrüsen sowie den Mangel eines Uterus und anderer weiblicher Hilfsapparate. Von ihren beiden Gattungen hat Genostoma Keimdotterstöclse und eine, bloß auf die Kriechsohle beschränkte Bewimperung, Urastoma dagegen getrennte Keim- und Dotterstöcke und ein vollständiges Cilienkleid. Der Exkretions-Apparat ist nicht näher bekannt.

24. Gen. tergestinum (Calandr.). ${ }^{+}$) Entbehrt der Augen und Rhabditen, Hautdrüsen münden bloß in die Haftscheibe, welche am Vorderende der Kriechsohle an. gebracht ist, mit bloß einem Keimlappen im Keim-Dotterstock und chitinösem Penis. Findet sich häufig im Innern des Schalenpanzers von Nebalia bipes M.-E.

25. Gen. marsiliense (Calandr.). . ${ }^{5}$ ) Entbehrt der Augen und Rhabditen, Hautdrüsen und Haftscheibe wie bei der vorigen Art, mit zwei Keimlappen im Keim-Dotterstock, der Penis ist muskulös und nicht mit Chitingebilden ausgestattet. Häufig im Innern des Schalenpanzers von Nebalia bipes M.-E. und einer Nebalia sp.

26. Urastoma cyprinae (Graff). ${ }^{6}$ ) Ganz mit Cilien bekleidet, mit kleinen Pseudorliabditen und großen Hautdrüsen sowie einem Paket Kopfdrüsen versehen. Ein Paar großer Augen vorhanden. Keimstock einfach, Dotterstock netzartig verästelt. Lebt oft in großer Anzahl im Mantelraume und auf den Kiemen von Mytilus edulis L., Cyprina islandica L. und Solen vagina L.

\section{Fam. Fecampiidae.}

Die soeben erschienene eingehende Darstellung des Baues, der Entwicklung und der Biologie dieser merkwürdigen Gruppe durch Caullery und Mesnil ${ }^{7}$ ) hat uns einen Fall von Reduktion durch Parasitismus kennen gelehrt, wie er bisher unter

1) Graff, Monogr. Turbell., I., pag. 379. - Syndesmis? L. Cuénot, Commensaux et Parasites des Echinodermes, II. Revue biol. Nord de la France, tome V, Lille I892, pag. 13. - Monticelli, 1. c. pag. 248.

2) Monticelli, 1. c. pag. 248 .

3) Diese Abhandlung S. 21 .

4) Dörler, Neue u. wenig bek. rhabd. Turb., Z. f. wiss. Zool., Bd. XLVIII, rgoo, pag. 2 I und diese Abh. S. 22 .

5) Dörler, 1. c. pag. 25 und diese Abh. S. 24.

6) Identisch mit Urastoma fausseki Dörler, Enterostoma mytiti Sabuss. und Acmostoma cyprinae Graff. S. oben S. 25 .

7) M. Caullery und F. Mesnil, Recherches sur les „Fecampia“ Giard. Ann. Fac. Sci. Marseille, vol. 13, fasc. IV, เ9o3, pag. I31. 
den Turbellarien noch nicht bekannt war. Die Familie läßt sich folgendermaßen umgrenzen:

Rhabdocoela mit einer Geschlechtsöfnung, mit zwei Zwitterdrüsen, in welchen Keimzellen und Spermatozoen gebildet werden, und einem den Darm ganz einhüllenden Dotterstock. Mund und Pharynx nur bei den Larven vorhanden. Männliche Kopulations-Organe und Exkretionssystem fehlen.

Die einzige Gattung Fecampia ${ }^{1}$ ) enthält zwei, in der Leibeshöhle mariner Crustaceen schmarotzende Arten.

Der zylindrische Körper der ausgewachsenen Tiere ist ganz bewimpert, entbehrt der Rhabditen und Augen und besitzt eine allseits geschlossene zentrale Darmhöhle. Vor ihr findet sich ein ganz rudimentäres Gehirn, das Vorderende ist durch körniges, unter dem Integumente angehäuftes rotgelbes Pigment markiert. Der Leibesraum ist vollständig erfüllt von birnförmigen Bindegewebszellen und langgestreckten, radiär zur Körperoberfläche ziehenden Hautdrüsen, deren Sekret zur Herstellung des Kokons verwendet wird, in welchem der Parasit nach Verlassen des Wirtes seine Eier ablegt. Diese Drüsen bilden sich zuerst im Vorderende des Körpers und erfüllen dieses schon vor erlangter Geschlechtsreife fast vollständig und ausschließlich. ${ }^{2}$ ) Die den Darm in ganzer Länge einscheidende zentrale Partie des Parenchyms wird ausschließlich von Dotterzellen gebildet, welche mit ihren (zumeist den Kern enthaltenden) Enden in das periphe Mesenchym hineinreichen. Der Dotterstock besitzt ebensowenig eine Tunica propria wie die beiden latero-ventral dicht unter dem Integumente der zweiten Körperhälfte gelegenen Zwitterdrüsen. Letztere stellen geschlängelte Schnüre dar, in welchen die Hodenzellen von den, der Hauptmasse nach ventral angehäuften, Keimzellen in keiner Weise scharf abgegrenzt sind. Jederseits des hinteren Darmendes beginnt mit einer becherattigen Erweiterung ein Ausführungsgang, in welchem Keim- und Dotterzellen sowie Spermatozoen zu einem kleinen, kugeligen Uterus geleitet werden, wo die Selbstbefruchtung statthat und immer zwei, je von einem Haufen Dotterzellen umgebene, Keimzellen mit einer gemeinsamen feinen Schale umschlossen und dann durch einen, am Hinterende ausmündenden, Genitalkanal abgesetzt werden.

Die geschlechtsreifen Tiere verlassen den Wirt, indem sie die weichen Stellen seines Hauptpanzers durchbohren, und spinnen dann aus dem Selrete ihrer Hautdrüsen einen birnförmigen (im Stiele mit einer Öffnung versehenen) Kokon, innerhalb dessen die Eier abgelegt werden. Das weitere Anschwellen der Geschlechtsdrüsen während des Verweilens im Kokon hat den völligen Schwund des Darmes zur Folge.

Die beim Ausschlüpfen $0.22 \mathrm{~mm}$ langen Larven sind lebhaft beweglich, besitzen bedeutend längere Cilien als die Erwachsenen, spindelförmige Rhabditen, zwei rotgelbe Pigmentaugen, einen am Vorderende gelegenen Mund und eine rudimentäre PharyngealAnschwellung am Beginne des, von einem großkernigen Epithel ausgelkleideten Darmes. Alle diese Organe, mit Ausnahme der Cilien und des Darmes, gehn nach dem Einbohren

J) A. Giard, Sur un Rhabdocèle nouveau, parasite et nidulant (Fecampia erythrocephala). C.-R. Ac. Sci. Paris, tome 103, 1886, pag. 499.

2) Nach eigenen Untersuchungen an den, mir von den Herren Caullery und Mesni.l freundlichst überlassenen Exemplaren. 
in den Wirt verloren, wenn die Larven $0_{4} 4$ bis $0.5 \mathrm{~mm}$ lang geworden sind, während gleichzeitig die Pigmentierung des vorderen Körperendes anhebt.

27. F. erythrocephala Giard. ${ }^{1}$ ) Erreicht eine Länge von $12 \mathrm{~mm}$, ihr Kokon wird 6 bis $10 \mathrm{~mm}$ lang und bis $2.5 \mathrm{~mm}$ breit. Die Grundfarbe des Körpers ist hell-lachsrot, das Vorderende erscheint in kegelförmiger Ausdehnung karmoisinrot gefärbt, das Augenpigment der Embryonen ist rotorange. Lebt in der Leibeshöhle (meist unter Darm und Leber im (ephalothorax) ${ }^{2}$ ) von Krabben, am häufigsten in 4 bis II $m$ m langen Exemplaren von Carcinus maenas Leach, die bis zu 9 Exemplare des Parasiten enthalten und sich schon äußerlich durch dunkle Verfärbung des Panzers als infiziert erkennen lassen. Auch Platycarcinus pagumis L. und Eupagums bernhardus Brdt. dienen als Wirte.

28. F. xanthocephala Caull.-Mesn. ${ }^{3}$ ) Bis $6 \mathrm{~mm}$ lang, mit Kokons von $3.5 \mathrm{~mm}$ Länge und bis I.5 mm Breite. Weißlichgelb mit orangegelber, minder ausgedehnter Pigmentierung des Vorderendes und gelborangen Larvenaugen. Wohnt in Idotea neglecta G. O. Gars, deren Geschlechtsdrüsen durch den Parasiten in der Entwicklung gehemmt werden. Doch wurde niemals eine vollständige Kastration oder eine Verfärbung des Integumentes an dem Wirte beobachtet.

\section{Alloeocoela.}

Alle aus dieser Unterordnung hier namhaft $\mathrm{zu}$ machenden Formen scheinen, nacl1dem das Acmostoma cyprinae Graff auszuscheiden ist, ${ }^{4}$ ) bloße Kommensalen oder gar nur Raumparasiten zu sein. Den ersteren rechne ich $z u$ das

29. Telostoma mytili Örst. ${ }^{5}$ ) Etwas über I $m m$ lang, oval, mit einem kleinen Schwänzchen versehen, braun marmoriert, Mund nahe dem Hinterende mit weit vorstreckbarem, mit der Spitze nach hinten gerichtetem Pharynx und vier Augen, von denen das vordere Paar kleiner ist als das hintere. Lebt zwischen den Kiemen von Mytilus edulis L.

\section{Fam. Monocelididae.}

Dieselben sind nur durch Raumparasiten vertreten.

30. Monocelis fusca Örst. $\left.{ }^{6}\right)$ Findet sich zwischen den, die Steine überziehenden Balaniden (Balamus balanoides L., u. a.), Chitoniden und Patelliden und zieht sich bei Ebbe in den Mantelraum dieser Tiere zurück, um zwischen den Füßen der ersteren und den Kiemen der letzteren oder auch zwischen den Byssusfäden von Mißmuscheln der Vertrocknung zu entgehn.

3I. M. alba Levins. ${ }^{7}$ ) Heftet ihre gestielten Eier an die Schalenränder, den Sipho

1) Giard, 1. c. pag. 499. - Cáullery-Mesnil, 1. c. pag. 132, Textfig. 1, 3, 4, tab. XII, fig. I u. 3 E.

2) F.W. Gamble (The Cambridge Natural History, vol. II, London I896, pag. 45) nennt ,the acunar spaces and alimentary canal of young shore crabs (Carcines macnas)" als Aufenthaltsort.

3) Caullery-Mesnil, ebendas. pag. 135, textfig. 2-4, tab. XII, fig. 2, 3, tab. X, fig. 4-55.

4) Diese Abhandlung S. 26.

5) Enterostoma mytiti, Graff, Monogr., I., pag. 403.

6) Graff, ebendas, pag. 42 I (sub Monotus).

7) Ebendas. pag. 424 und A, Giard, S. la ponte des Rhabdocoeles de la famille des Monotidae. C.-R, Soc. Biol. Paris, tome IV, I897, pag. IoI2. 
und Mantelrand verschiedener Muscheln (Dona.2 trunculus L., Tellinct tenuis Da Costa, Tellina fabula Gronov.) ab.

32. M. hirudo Levins. ${ }^{1}$ ) Findet sich auf der Oberfläche von Pagumes pubescens, an deren Haaren sie sich mit der Schwanzscheibe festheftet.

\section{Tricladida.}

Diese Ordnung enthält bloß Elktoparasiten oder Kommensalen.

33. Planaria unionicola Woodworth. ${ }^{2}$ ) Eine zweiängige Süßwasserplanarie mit Öhrchen (Tentakelartigen seitlichen Ausbuchtungen in der Höhe der Augen). Sie wurde auf dem Mantel von Unio alatus Say kriechend aufgefunden, doch steht es nicht sicher, ob es sich um ein zufälliges Vorkommnis oder um eine Art von Parasitismus handelt.

34. Gunda sp. C. $\operatorname{Vogt}^{3}$ ) fand auf der Haut der Larve eines Fisches (Muraenide ?) ca. 30 weiße, $0.5 \mathrm{~mm}$ breite Zysten. Ihr Anheftungspunkt war oft blutunterlaufen und sie enthielten je eine, mit zwei runden schwarzen Augen versehene, junge Gunda, so daß es sich also um Eier einer Spezies dieser marinen Tricladengattung handelt.

Bdellouridae. Wheeler ${ }^{4}$ ) hat diese, durchweg ektoparasitische marine Formen umfassende Familie als solche umgrenzt. Die bisher bekannten Arten haben zwei Augen und entbehren der Aurikularfalten des Vorderendes, des Pigments und der Rhabditen, besitzen aber zwei separat auf der Bauchseite mündende Drüsensäcke („Uteri“).5) Die Ductus ejaculatorii öfnen sich getrennt nahe der Penisspitze. Die abgeplatteten elliptischen oder oblongen Eikapseln sind mit einem feinen Stiele an den Kiemenblättern von Limulus polyphemus (L.) angeheftet, an dessen Ventralfäche man diese Parasiten oft in großer Anzahl (über 100 ) vorfindet. ${ }^{6}$ ) Sie durchfressen die Kiemenblätter sowie die weichen Gelenkhäute der Extremitäten des Wirtes. Die beiden Gattungen Bdelloura und Syncoelidium sind durch die Körperform und einige anatomische Merkmale, besonders aber dadurch unterschieden, daß die erstere am Hinterende eine große Haftscheibe trägt, welche der letztgenannten fehlt.

35. Bdelloura parasitica Leidy. ${ }^{7}$ ) Bis 15 mm lang, die elliptischen kurzgestielten Eikapseln $2{ }^{\circ} 4$ bis $6 m m$ lang.

36. B. propinqua Wheeler. $\left.{ }^{8}\right)$ Bis $8 \mathrm{~mm}$ lang, die elliptischen Eikapseln $1 \cdot 25 \mathrm{~mm}$ lang.

37. Syncoelidium pellucidum Wheeler. ${ }^{9}$ ) Bis $3 \mathrm{~mm}$ lang, die oblongen, langgestielten Eikapseln 0.75 mm lang.

1) Graff, 1. c.pag. 424 .

2) W. McM. Woodworth, Contrib. to the Morphol. of the Turbellaria, II. On some Turbellaria of Illinois. Bull. Mus. comp. Zool., vol. XXXI, no. I, Cambridge, Mass., 1897, pag. Io.

3) C. Vogt, S. le parasitisme transitoire d'une Turbellarié triclade (Gunda sp.). C.-R. Assoc. franç. adv. sc. $20^{\mathrm{e}}$ sess. Marseille 1891, pag. 239. pag. 188 ,

4) W. M. Wheeler, Syncoelidium parasiticum. Journal of Morphology, vol. IX, Boston 1894,

5) Graff, Monogr. Turbell., II., Leipzig 1899, pag. 182.

6) Graff, Üb. ein. interess. Thiere d. Zool. u. d. Palmengartens zu Frankfurt a. M., Der Zool. Garten I879, pag. I 96.

7) J. Leidy, Helminthol. Contrib. n. 3, Proc. Acad. Nat. Sci, vol, V., Philadelphia I \$5 I, p. 242.

8) Wheeler, 1. c. pag. I89.

9) Ebendas. pag. 189. 
38. Micropharynx parasitica Jägersk. ${ }^{1}$ ) Eine blattähnliche, sehr breite Form ohne Augen, Tentakel und Haftscheibe. Indessen sind auf der Ventralseite des Hinterendes wahrscheinlich Klebzellen vorhanden, mittels deren sich das Tier festheftet. Ganz bewimpert und reichlich mit Rhabditen versehen. Pharynx sehr klein, Mund im Ende des zweiten Körperdrittels. L.ebt auf der Rückenhaut von Rrija clavata L. und Raja batis L.

\section{Polycladida.}

Die Angaben über Parasiten sind aus dieser Ordnung noch spärlicher als aus der vorigen. Ich ordne sie nach der von $\mathrm{Lang}^{2}$ ) gegebenen systematischen Reihenfolge der Wirte.

39. Planocera inquilina Wheeler ${ }^{3}$ ) lebt in der Kiemenkammer einer Schnecke, Sycotypus camaliculatus Gill, mit welcher sie zweifellos enge vergesellschaftet ist, da von ïber 100 Exemplaren derselben fast jedes $I$ bis 6 Individuen der Planocera enthielt. Diese weist keine andere Anpassung auf, als den vollständigen Pigmentmangel, dagegen besitzt sie Tentakel und Augen und weicht auch sonst in ihrer Organisation nicht wesentlich von den freilebenden Gattungsgenossen ab.

40. Planocera insignis Lang. Seit langem besitze ich eine Polyclade, welche H. v. I hering im Jahre 1876 bei Triest in der Kiemenhöhle von Murex brandaris L. gefunden hat. Dieselbe ist nun von Herrn Dr. Rud. R. v. Stummer-Traunfels einer Untersuchung unterzogen worden, über welche ich dem Genannten folgenden Bericht verdanke:

„Auf Grund eingehender Untersuchung habe ich diese kleine Polyclade als Plano. c'ra insignis Lang*) bestimmen können. Da Lang seinerzeit die betreffende Speziesbeschreibung nur an der Hand eines einzigen Exemplares verfaßt hat, so seien hiemit noch jene wenigen, an dem mir vorgelegenen Exemplare gemachten Befunde erwähnt, welche zur Ergänzung der Lang schen Angaben dienen.

„Vor allem sei bemerkt, daß ich bei der Bestimmung lediglich von anatomischen Merkmalen ausgehn mußte, weil sowohl die Zeichnung als auch die Färbung des mir als Quetsch-Apparat zugekommenen Exemplares durch die Karmintinlition vollständig unkenntlich geworden war. Als Hauptmerkmale leiteten mich hiebei vor allem die Form des männlichen Geschlechts-Apparates, das ganz charakteristisch gestaltete Penisstilet, der Mangel einer akzessorischen Blase bei den weiblichen Leitungswegen, ferner die Form, Größe und Verteilung der Darmäste sowie die Anordnung der Augen. Die von Lang erwähnten, gelblichweißen Punkte; welche der Rückseite ein ,körniges Aussehen' verleihen, dürften den relativ sehr großen, noch in den Ovarialfollikeln befindlichen reifen Eiern entsprechen. Ebenso erschien bei dem mir vorgelegenen Exemplare derjenige Teil der Rückseite, welcher oberhalb des prall gefüllten, sich beiderseits von der Pharyngealtasche hinziehenden Uterus gelegen ist, durch die in dem letzteren befindlichen Eier körnig und höckerig. Die Größe des mir vorgelegenen Individuums

1) L. A. Jägerskiöld, Üb. MIicropharynx parasitica n. g., n. sp., Öfvers. Kongl. Vet. Ak. Förh., Stockholm x896, pag. 707 .

2) A. Lang, Die Polycladen (Seeplanarien) des Golfes von Neapel. Leipzig 1884.

3) Wheeler, Planocera inquilina. Journ. of Morphol, vol. IX, Boston I894, pag. 195.

4) Lang, 1. c. pag. 442-443, tab. I, fig. 6, tab. 10, fig. 8 und 9, tab. 30, fig. 16. 
betrug an Länge $3 \mathrm{~mm}$, an Breite $2 \mathrm{~mm}$, gegenüber den Angaben Langs eine Reduktion der Maße, welche an und für sich unbedeutend ist und sich möglicherweise auf die, bei der Konservierung des Tieres erfolgte Kontralktion des Körpers zurüclführen lassen wird.

"Planocera insignis ist von Lang, soweit aus seinen spärlichen Angaben über das Vorkommen dieser Polyclade hervorgeht, nur in einem, und zwar freilebenden Exemplare beobachtet worden. Das Vorkommen des mir vorliegenden zweiten Exemplares gestattet natürlich keinen sicheren Schluß auf ein parasitisches Verhältnis der Polyclade zur Schnecke. Allein der von mir untersuchte Inhalt des GastrovaskularApparates der Polyclade spricht für die Wahrscheinlichkeit, daß sich Planoccra insignis von den Geweben des Mhurex ernährt. Die Darmäste der ersteren enthielten nämlich eine große Menge von, mit Kernen versehenen Zellen, welche zum Teile schon in Auflösung begriffen waren, zum Teile aber noch die ganz charakteristische Form von epithelialen Zylinderzellen erkennen ließen. Der Grund, weshalb das Langsche Exemplar freilebend erbeutet wurde, dürfte möglicherweise darin zu suchen sein, daß es seinen gewohnten Aufenthalt in der Kiemenhöhle von Murex brandaris behufs Absatzes des Laiches verlassen hatte."

4I. Sty lochus zebra (Verrill). ${ }^{1}$ ) Findet sich stets in, von Einsiedlerkrebsen bewohnten Schneckenschalen (Lunatia heros, Fulgur), bietet aber nichts in ihrer Organisation, was als Folge ihrer eigentümlichen Lebensweise zu deuten wäre. Wenn diese Polyclade nicht von den Fraßabfällen des Einsiedlerkrebses profitiert, so wäre zunächst daran zu denken, daß vielleicht der hier abgesetzte Laich besser geschützt sei, als in anderen Lokalitäten.

42. Prostheceraeus giesbrechti Lang. ${ }^{2}$ ) Eine auffallend bunt gefärbte Art, welche bisher nur in einem, aus dem Grunde des Kiemensacks von Ciona intestinalis (L.) stammenden Exemplare gefunden wurde. Lang meint, daß sie zufällig daselbst hineingekrochen sei, was übrigens erst durch Untersuchung einer größeren Anzahl von Exemplaren dieser Ascidie zu erweisen wäre.

Die folgenden fünf Formen sind so ungenügend beschrieben, daß ihre Gattungszugehörigkeit ebenso zweifelhaft ist wie ihr Parasitismus.

43. Planaria schlosseri Giard. ${ }^{3}$ ) Eine 10 bis $12 \mathrm{~mm}$ lange und 4 bis $5 \mathrm{~mm}$ breite, wahrscheinlich zur Familie der Euryleptiden gehörige Form. ${ }^{4}$ ) Sie lebt auf der zusammengesetzten Ascidie Botrylhes schlosseri ara adonis Giard und gleicht ihrem Wirte so sehr in Färbung und Zeichnung, daß sie auf demselben nur durch ihre Bewegungen wahrgenommen werden kann. "Jedenfalls geht aus der Übereinstimmung in Färbung und Zeichnung hervor, daß die Planarie auf Botryllus angewiesen ist." ${ }^{5}$ )

44. Planaria velellae Lesson. ${ }^{6}$ ) Diese, möglicherweise mit Planaria pellucida

1) A. E. Verrill, Marine Planarians of New England. Trans. Conn. Ac., vol.VIII, Newhaven 1893 , pag. 463. - Vgl. auch Wheeler, Plan. inqu., pag. 195, Anm. 4.

2) Lang, 1. c. pag. 559 u. 630 .

3) A. Giard, Hist. nat. des Synascidies. Arch.Zool, expér., vol. II, Paris 1873, pag. 488, tab. XIX, fig. I.

4) Lang, 1, c. pag. 590 .

5) M. Braun, Über parasitische Strudelwürmer. Centralbl. f. Bakt. u. Parasitenkunde, I. Jahrg. II. Bd., Jena 1887 , pag. 484 .

6) Lang, 1, c. pag. 607 u. 630 . 
(Mert.)') identische Polyclade ist von Lesson und später auch von Ed. Graeffe ${ }^{2}$ ) an Telellen gefunden worden. Sie verzehrt, wie schon der erste Entdecker angegeben, die Weichteile dieser pelagisch lebenden Siphonophore, verhält sich demnach zu ihr mehr als Räuber denn als Parasit.

45. Typlilolepta acuta Giard. ${ }^{3}$ ) Wurde von Giard in großer Anzahl auf Chirodata laevis O. Fabr. kriechend gefunden. Verril1*) hat zahlreiche Exemplare an der gleichen Lokalität und auf derselben Holothurioide gesammelt, vermutet aber in diesem Tiere eine Acoele oder Rhabdocoele.

46. Typhlocolax acuminatus Stps. ${ }^{5}$ ) Von Stimpson auf Chirodote sp. gefunden.

47. Cryptocoelum opacum Stps."i) Von Stimpson auf einem großen SeeIgel (Echinarachinizs sp.) gefunden.

1) Graff, Pelagische Polycladen, Z. f, wiss Zool., LV. Bd., 1892, pag. 195.

2) Nach mündlicher Mitteilung.

3) Lang, 1. c. pag. 6 Ir u. 629.

4) Verrill, l. c. pag. 514

5) Lang, l. c. pag. 612 u. 629 .

6) Ebendas, pag. 612 u. 629 . 


\section{Der Einfluf. des Parasitismus auf den Bau der Turbellarien.}

Überblicken wir die unter den Turbellarien vertretenen Kategorien von Parasitismus, so können wir sie - von dem Räuber Planaria velellae absehend - in folgende Gruppen bringen:

I. Gelegentliche Raumparasiten, welche

a) bloß ihre Eier an andere Tiere anheften:

Monocelis albo an Schale, Mantelrand und Sipho verschiedener Muscheln,

Gunda sp. auf der Haut von Muraenidenlarven;

b) im Mantelraume Schutz vor Vertrocknung suchen:

Monocelis fusca in Balanen, Muscheln, Chitonen und Patellen.

2. Ständige Vergesellschaftung unbekannter Bedeutung:

Stylochus sebra mit Einsiedlerkrebsen.

3. Ektoparasiten:

Rhynchoscolex vejdovsky i ${ }^{1}$ ) auf Lumbriculus variegatus,

Byrsophleos nana auf Nephthys scolopendroides,

Anoplodizm clypeasteris auf Clypeaster sp.,

H Monocelis himido auf Pagurus pubescens,

Bdellonra parasitica auf Limulus polyphemus,

- propinqua auf Limulus polyphemus,

Syncoelidium pellucidum auf Limulus polyphemus,

Micropharynx parasitica auf Raja clavata und Raja batis,

i Planaria schlosseri auf Botryllus schlosseri var. adonis,

T Typlalolepta acuta auf Chirodota laevis,

i Typhlocolax acuminatus auf Chirodota sp.,

iCryptocoelum opaczm auf Echinarachnius sp.

4. Bewohner von Körperhöhlen, welche mit der Außenwelt in offener

Kommunikation stehn (Schleimfresser oder Kommensalen?):

a) in Bruttaschen:

Mesostoma aselli bei Asellus aquaticus;

b) in Respirationstäumen von Crustaceen:

Didymorchis paranephropis in den Branchialkammern von Paranephrops neozelandicus,

Genostona tergestimum innerhalb der Schale von Nebalia bipes,

- marsiliense innerhalb der Schale von Nebalia bipes und Nebalia sp.;

1) Mit ? sind diejenigen bezeichnet, bei welchen es noch zweifelhaft ist, ob es sich nicht etwa bloß um eine zufällige Vergesellschaftung handelt.

v. Graff, Turbellatien als Parasiten. 
c) im Kiemsack von Ascidien:

i Prostheceracus giesbrechti bei Ciona intestinalis;

d) im Mantelraume und auf den Kiemen von Mollusken:

? Graffilla mytili bei Mytilus edulis,

Unastoma cyprinae bei Mytilus edulis, Cyprina islandica und Solen vagina,

? Tolostoma mytili bei Mytilus edulis,

?Planaria unionicola bei Unio alatus,

Planocera inquilina in der Kiemenkammer von Sycotypus canaliculatus,

i Plenocera insignis in der Kiemenkammer von Murex brandaris.

5. Entoparasiten, u. zw.:

a) im Darme:

Avagina incola (im Nebendarm) bei Echinocardium cordatum,

Macrostomum scrobicularine bei Scrobicularia tenuis,

Provortex tellinae bei Tellina sp. und Solen vagina,

Syndesmis Echinonum bei Echinus sphaera, E. acutus, Sphaerechinus granularis, Strongy-

locentrotus dröbacchensis und Str. lividus,

Collastoma monorchis bei Phascolosoma vulgare,

Anoplodium schneideri bei Stichopus variegatus und Mülleria lecanora,

- myriotrochi bei Myriotrochus rinki;

b) in oder an der Niere:

Graffilla maricicola bei Murex trunculus und M. brandaris,

- buccinicola bei Buccinum undatum und Neptunea antiqua;

c) in der Leber:

Graffilla brauni bei Teredo sp.;

d) in der Leibeshöhle:

Nemertoscolex parasiticis bei Echiurus pallasi,

Graffilla parasitica im Fuße von Tethys leporina,

Fecampia erythrocephala bei Carcinus maenas, Platycarcinus pagurus und Eupagurus bernhardus,

- xanthocephala bei Idotea neglecta,

Anoplodium parasitc bei Holothuria tubulosa und H. polii,

- pusillum bei Holothuria polii,

- graffi bei Holothuria impatiens,

- chirodotae bei Chirodota laevis,

Unbestimmte Vorticide bei Cucumaria planci.

Wenn wir nun die Anpassungen an die parasitische Lebensweise betrachten, so können nur jene Formen herangezogen werden, deren Organisation hinreichend bekannt und deren Parasitismus sichergestellt ist. Auch müssen die sub 3 u. 4 genannten vor den Entoparasiten behandelt werden.

Für die Ektoparasiten und die Bewohner von, mit der Außenwelt offen kommunizierenden Körperhöhlen ist von vornherein zunächst die Ausbildung von Haftapparaten zu erwarten. Klebzellen auf der Ventralfäche, besonders des Hinterendes des Körpers, sind ja auch bei freilebenden Formen weit verbreitet als Schutz gegen 
Strömung und Brandung und ebenso Saugscheiben als Hilfsmittel bei der Kopula und zur Feststellung des Körpers behufs Bewältigung der Beute, Es hat also nichts Verwunderliches, daß die Ektoparasiten Byrsophlebs nana, Bdelloum parasitica, Bd. propinqua und wahrscheinlich auch Micropharynz parasitica das Hinterende ihres Körpers zu einer Haftscheibe umgewandelt haben, wobei für die letztgenannte Spezies noch die, im Verhältnisse zu ihren Verwandten sehr auffallende Verbreiterung und Abflachung des Körpers als ein weiteres Adhäsionsmittel in Betracht kommt. Genostoma tergestinzım und G. marsiliense tragen die Haftscheibe an der Ventralfläche des vorderen Körperendes und sind durch die Verlagerung des, zum Ansaugen geschickten, Pharynx an das Hinterende befähigt, die so charakteristischen spannenden Bewegungen zu vollführen. Die Kombination von Mund- und Geschlechtsöffnung (durch Ausmündung des Genitalkanals in die Pharyngealtasche), wie sie bei den Gattungen Genostoma und Urastoma vorkommt, hat nichts zu tun mit dem Parasitismus, da wir dieser Organisations-Eigentümlichleit auch bei vielen freilebenden Formen ${ }^{1}$ ) begegnen.

Dagegen darf das Fehlen von Rhabditen, die ja jetzt in erster Linie als Mittel zum Fange der Beute betrachtet werden, $^{2}$ ) als Folge der parasitisclien Lebensweise anzusehen sein. Und wenn dieselben bei Byrsophlebs nana und den Arten der Genera Genostoma, Bdelloura und Syncoelidium gänzlich fehlen, dagegen bei Didymorchis, Urastoma und Aicropharynx - wenngleich (wie bei Urastoma) bisweilen nur in kümmerlicher Form - vorhanden sind, so darf man annehmen, daß die ersteren sich bloß von Teilen ihrer Wirte ernähren (Bdelloura und Syncoelidinm nähren sich von den Kiemenblättern und Gelenkhäuten des Limulus, Byrsophlebs nana wahrscheinlich vom Blute der Nephthys), während bei letzteren dies noch nicht oder doch nicht ausschließlich der Fall ist.

Schleim sezernierende Hautdrüsen fehlen bei Byrsophlebs nana, sind aber massenhaft vorhanden bei Bdelloura, Syncoelidium und Urastoma (hier außer den über den Körper zerstreuten Drüsen auch noch ein großes Paket Kopfdrüsen), bloß auf die Ventralseite beschränkt bei Micropharynx, wogegen bei Genostoma solche nur in die Saugscheibe einmünden. In den letzten beiden Fällen sind sie zweifellos der Adhäsion an dem Wirte dienstbar, während im übrigen das gegensätzliche Verhalten in Bezug auf diese Drüsen, wahrscheinlich ebenso wie bei den unten zu besprechenden Entoparasiten, auf biologische Verhältnisse zurückzuführen ist.

Die merkwürdigste und zweifellos mit dem Elitoparasitismus zusammenhängende Erscheinung ist aber das, unter allen Rhabdocoeliden bloß bei drei ektoparasitischen Arten mit Sicherheit ${ }^{3}$ ) konstatierte, Fehlen der Cilien auf der Dorsalfläche. Didymorchis hat noch die ganze Bauchfläche bewimpert, während die beiden Genostona-

1) Bei allen Prorkynchidae, bei Arten der Gattungen Cylindrostoma, Monoophorum und Enterostomum und bei Mesostoma mutabile Böhmig.

2) Vgl. Graff, Monogr. Turbell., II., pag. 54

3) Von Monocelis circinnak (Calandr.) und $1 \%$. sicala (Calandr.) wird behauptet, daß sic bloß ventral bewimpert seien. Im übrigen erwähne ich hier mit Rücksicht auf das folgende Kapitel, daß aus der Gruppe der Thabdecoitida ein teilweises Fehlen der Cilien anch für Aonocelis chapuisi Graff (nom. nov.) - an der vorderen Spitze der Dorsalfläche -, auf dem Rüssel von Alaurina, der Psendorhynchinu und Acrorlynichina sowie am Hinterende von Bothrioplana bohemica Vejd, angegeben wird. Eine Vorstufe des Verlustes der Cilien bildet deren Unbeweglichkeit am Vorderende von Monocelis fusca Örst., Mon. longiceps (Ant, Dug.) und Bothrioplana semperi M. Braun sowie an den Tentakelspitzen von Vorticerus. 
Arten nur auf einem kleinen ovalen Felde derselben Cilien tragen. Dies weist auf die Gewöhnung des Kriechens auf fester Unterlage hin, mit welcher der Verlust der dorsalen Cilien und der Fähigkeit, im freien Wasser zu schwimmen, einherging. ${ }^{1}$ )

Die Augen sind bei der in Rede stehenden Kategorie von Parasiten bald wohlentwickelt (Bdelloura, Syncoclidinu, Urastoma, Planocera), bald klein (Didymorchis), bald gar nicht vorhanden (ATesostoma aselli, Byrsophlebs nana, Genostoma, Micropharyinx). Von den augenlosen besitzen Byrsopllebs nana und die Genostona-Arten, welche bei der raschen Beweglichkeit ihrer Wirte leicht abgeworfen werden, einen den Augenmangel kompensierenden und die Wiederauffindung des Wirtes erleichternden Tastapparat: erstere in dem merkwürdigen rüsselartigen Vorderende (s. oben S. I), letztere im Rande des vorderen Körperendes (s. oben S. 23).

Der $\mathrm{Ph}$ ary $\mathrm{nx}$ ist verschieden entwickelt und scheint bloß bei Byrsophlebs nana der Lebensweise besonders angepaßt zu sein (s. oben S. 3); auffallend klein ist er bloß bei Micropharynx und Urastoma; bei letzterer Gattung und bei Genostoma findet sich der Mund an das Hinterende verlagert.

Der Darm ist bei Genostona und Urastoma durch seitliche divertikelartige Ausbuchtungen, bei Bdelloura parasitica und Syncoelidinm durch Anastomosierung, resp. Verwachsung der hinteren Hauptdärme von den meisten freilebenden Verwandten verschieden, doch sind analoge Bildungen auch bei letzteren nicht selten zu beobachten.

In der Ausbildung der Geschlechts-Organe sind hier ebenfalls nur wenige Andeutungen der - bei Entoparasiten so auffallenden - relativen Vergrößerung der Drüsen zu konstatieren. So an den Dotterstöcken, welche bei Genostoma verästelt, bei Urastoma netzartig gestaltet erscheinen, und in dem auffallenden Umfange der Hoden von Genostoma tergestinum und Didymorchis.

Die Entoparasiten weisen viel weitergehende Anpassungen und Reduktionen auf.

Denselben fehlen Haftscheiben oder Saugnäpfe und wo eine Festheftung stattfindet, erfolgt dieselbe durch den, alsdann an das Vorderende verlagerten Pharynx (Graffilla, Collastoma, Fecampia), welcher bei Gr. muricicola und Coll. monorchis mit Stacheln oder Häkchen zum Anbohren und Festheften ausgestattet ist.

Alle bisher genauer untersuchten Entoparasiten sind am ganzen Körper mit Cilien belkleidet, doch ist für Fecampia konstatiert, daß die Cilien der freilebenden Larven eine bedeutendere Länge besitzen als jene der ausgewachsenen Tiere.

Wohlausgebildete Rhabditen sind nur in der Haut der Larven von Fecampia vorhanden, von ausgewachsenen Formen enthält nur Graffilla muricicold kleine stäbchenförmige Körper in spärlicher Anzahl.

Hautdrüsen fehlen den meisten gänzlich, bei Grafflla branmi sind bloß die (vielleicht der Anheftung dienenden) Kopfdrüsen vorhanden, während massenhafte Hautdrüsen nur Fecampia und Graffilla parasitica zukommen. Den Arten des erstgenannten Genus dienen sie zur Erzeugung des Kokons; welche Funktion sie bei der zuletzt genannten Form haben, ist bisher unbekannt.

1) Auf die gleiche Ursache dürfte der Cilienverlust auf der Rückenfläche vieler Landplanarien und der Süßwassertrikade Planaria polychroa O. Schm. zurückzuführen sein (vgl. Graff, Monogr. Turbell., II., pag. $39-40$ ). 
Die Reduktion der Augen ist hier unverkennbar als eine Folge des Parasitismus verbreitet. Wohlausgebildete Augen sind bei Macrostomum scrobiculariae, Anoplodium chirodotae und Provortex tellinae beobachtet, wobei zu bemerken ist, daß der zuletzt genannte Darmschmarotzer überhaupt noch so wenige Anpassungen an den Parasitismus aufweist, daß diese Lebensweise bei ihm erst jüngeren Datums zu sein scheint. Bei einigen Graffilla-Arten (muricicala, branni, mytili) sind die Augen sehr klein, bei Gr. buccinicola gibt es Individuen mit kleinen Augen neben solchen, welchen die Augen ganz fehlen, Fecampia weist nur bei den Larven kleine Pigmentaugen auf, während die geschlechtsreifen Individuen dieser, wie aller übrigen entoparasitischen Turbellarien, der Augen gänzlich entbehren. Dementsprechend finden wir auch das Gehirn reduziert. Wenn auch der Grad der Reduktion im einzelnen noch nicht genau studiert ist, so spricht sich dieselbe doch, namentlich bei Graffilla und Fecampia, unverkennbar sowohl in der geringen Größe als auch in der mangelhaften histologischen Differenzierung aus. Der Phary $n x$ ist bei den, die Mehrzahl der Entoparasiten bildenden Gattungen Graffilla, Anoplodium und Fecampio sehr klein und verkümmert, bei letzterem Genus geht er mit Mund und Darm im Laufe der zunelımenden Geschlechtsreife vollständig zu Grunde. Im übrigen zeigt der Darm oft, wie bei Ektoparasiten, unregelmäßige Ausbuchtungen oder Divertikel (Syndesmis).

Am auffallendsten sind aber die, auf eine größere Eiprodultion hinzielenden, Veränderungen der Geschlechts-Organe. Schon Provortex tellinae unterscheidet sich von den freilebenden Gattungsgenossen durch bedeutenderen Umfang der Keimstöcke, Verästelung der Dotterstöcke und größere Zahıl der Uterus-Eier. Bei den übrigen sehen wir die kleinen keulen- oder birnförmigen Keimstöclie der freilebenden Turbellarien zu langen, gewundenen Schnüren (Graffilla), ausgebuchteten großen Säcken (Anoplodium) oder baumförmig verzweigten Drüsen (Symdesmis) werden. Die Dotterstöcke, bei Collastoma noch als, die Seiten des Körpers einnelimende, schwach eingeschnittene Stränge repräsentiert, werden geweih- oder baumförmig verästelte, neben dem Darme liegende (Anoplodizm, Syndesmis) oder denselben zum Teile umspinnende Gebilde (Graffilla muricicola, parasitica, brami), deren einzelne Äste dann miteinander derart verschmelzen, daß sie im reifen Zustande als kontinuierliche Rinde einen 'Teil des Darmes (Graffilla buccinicola) oder dessen ganzen Umfang (Fecampia) einscheiden. Die ursprünglich parige Entstehung dieses Organs ist bei solchen Formen nur noch in der Duplizität der Ausführungsgänge zu erkennen. Bei Syndesmis und Graffilla muricicola greift dieser Wucherungsprozeß auch auf die Hoden über, während bei Fecampia die Reduktion so weit geht, daß ein, bei dem ausgebildeten Zustande keiner einzigen freilebenden Turbellarie mehr erhaltener ursprünglicher Zustand der Geschlechtsanlage zu stande kommt, indem hier der keimbereitende Teil des weiblichen Apparates mit den, Spermatozoen bildenden Zellen jederseits zu einer $\mathrm{Zwitterdrüse} \mathrm{vereinigt} \mathrm{ist.} \mathrm{Hand}$ in Hand mit dieser, die Selbstbefruchtung ermöglichenden Einrichtung geht hier einerseits die enorme Fruchtbarkeit sowie andrerseits der Mangel irgendwelcher Kopulations-Organe - Erscheinungen, die bei den übrigen Turbellarien ohne Analogie dastehn. In ganz entgegengesetzter Richtung hat sich der Geschlechts-Apparat bei Collastoma und Syndesmis entwickelt. Die kompliziertere Gestaltung der Geschlechtsdrüsen hat hier eine schärfere Scheidung der ausführenden Kanäle (langer Ductus communis der weiblichen Drüsen) vom Uterusstiele herbeigeführt und die, dadurch bedingte 
größere Schwierigkeit der Begattung und Befruchtung der Eier durch Ausbildung einer, bloß der Begattung dienenden "Vagina" kompensiert, ähnlich wie wir dies bei Trematoden und Cestoden beobachten.

Sehr merkwürdig ist die Gestaltung des Mesenchyms vieler entoparasitischer Turbellarien: Die fast lückenlose Ausfüllung des Leibesraumes durch rundliche oder birnförmige Zellen, wie sie für die Gattungen Graffilla, Collastoma, Syndesmis, Anoplodinm und Fecampia beschrieben worden ist. Ich habe eben (S. I 8 ) auseinandergesetzt, daß ich in diesem „blasigen Bindegewebe", welches entweder den ganzen Leibesraum oder nur einen Teil desselben (Graffilla buccinicola) erfüllt, einen Ersatz des Nephridialsystems sehe, wie es den freilebenden Formen zukommt. Diese Anschauung, nach welcher demnach das ursprüngliche Exkretionssystem der Turbellarien durch ein, den entoparasitischen Formen eigentümliches Exkretophoren-Gewebe ersetzt sein soll, findet ihre Stütze in mehrweniger bestimmt lautenden Angaben von dem Fehlen des „Exkretionssystems" bei solchen Parasiten, wie: Graffilla parasitica und buccinicola, Syndesmis cchinomun, Collastoma monorchis, Anoplodinm parasita, Fecampia erythrocephala und xanthocephala. Bei Graffilla muricicola scheinen noch Reste des ursprünglichen Exkretionssystems vorhanden zu sein, bei Gr. brauni ist dessen Existenz durch den Nachweis der Exkretionsbecher außer Zweifel gestellt. Wenn ich auch weiß, daß in Bezug auf dieses Organsystem bloß negativen Angaben mit größter Vorsicht begegnet werden muß, so glaube ich doch zu dem Ausspruche berechtigt zu sein, daß mit der parasitischen Lebensweise bei den Turbellarien - im Gegensatze zu Trematoden und Cestoden - eine Reduktion des Nephridialsystems einhergeht.

Fecampia bietet eines der schönsten Schulbeispiele dafür, wie wälırend der Ontogenie durch den Parasitismus und die infolge desselben auftretende, vermehrte Eiprodultion eine Reduktion der Bewegungs-Organe (Cilien), der Augen und des gesamten Stoffwechsel- und Kopulations-Apparates, ja selbst eine Vereinfachung der Geschlechtsdrüsen vor sich geht, und ich zweifle nicht daran, daß ein eingehenderes Studium der Entwicklungsgeschichte parasitischer Turbellarien noch zahlreiche, gleich instrulstive derartige Beispiele zu Tage fördern werde.

Schließlich seien nech einige Worte der Form und Größe sowie der Art.der Bewegung entoparasitischer Turbellarien gewidmet. Im Vergleiche mit ihren freilebender. Verwandten sind sie von bedeutender Größe. Die freilebenden Arten von Prowortex erreichen höchstens $0.75 \mathrm{~mm}$ Länge, Prov. tellinae mißt schon $2 \mathrm{~mm}$, Collastoma $\mathrm{I}^{\circ} 5 \mathrm{~mm}$, die sicheren Spezies von Graffilla 2.5, 3.2, 4, 4.5 und 5 mm, Syndesmis 6 mm, Fecampia 6 - I2 mm. Alle die Genannten sind durch auffallende Vergrößerung der weiblichen Geschlechtsdrüsen und Produktion vieler Eier ausgezeichnet und daß hierin die Ursache der Körpergrößen-Zunahme zu suchen sei, lehrt der Vergleich mit Didymorchis und Anoplodium, welche, immer nur ein Ei erzeugend, die durchschnittliche Größe der nächstverwandten freilebenden Genera (Vortex und Derostoma) nicht überschreiten. Mit der Größenzunahme nimmt die Lokomotionsfähigkeit der Entoparasiten ab. Auch gehn die Körperkontraktionen sehr träge vor sich, bedingen aber höchst eigentümliche Gestaltsveränderungen, die namentlich bei den Graffilla-Arten an die Sporocysten und Redien von Trematoden erinnern. 


\section{Freilebende und parasitische Plathelminthen.}

Die Erkenntnis der einheitlichen Organisation der Plattwürmer und der innigen verwandtschaftlichen Beziehungen zwischen den drei großen Gruppen der Turbellarien, Trematoden und Cestoden hat ihren prägnantesten Ausdruck darin gefunden, daß Lang ${ }^{1}$ ) dieselben als Phylum Plathelminthes den übrigen "Vermes" gegenüberstellte. Und wenn dabei in der üblichen Weise die Turbellaria als "freilebende Platlelminthen mit wimperndem Körperepithel" charakterisiert wurden, so blieb nach Abzug des, keinen systematischen Wert besitzenden, von der Lebensweise genommenen Merkmales ${ }^{2}$ ) für die Turbellarien bloß das Vorhandensein des Cilienkleides charakteristisch, wie für die Trematoda das Fehlen eines solchen, während sich für die Cestoda als Differentialdiagnose gegenüber den beiden genannten Gruppen das Fehlen sowohl des Cilienkleides als des Darmes ergab.

Das Bekanntwerden zahlreicher parasitischer Turbellarien und die im vorangehenden zusammengestellten Eigentümlichleiten des Baues derselben sowie manche der, seither àn freilebenden Turbellarien beobachteten Tatsachen haben aber den Wert dieser, olnehin sehr spärlichen systematischen Grenzmarken noch weiter herabgedrückt. Wir wissen heute, daß es freilebende und parasitische Turbellarien mit einer nur teilwe isen Bew imperung der Körperoberfläche gibt (s. oben S. 43) und in Fecampia ist uns eine Form bekannt geworden, die mit Beginn der Geschlechtsentwicklung Mund und Pharynx, im Höhepunkte der Geschlechtsreife aber selbst den Darm einbüßt und damit den für die Cestoden bedeutungsvollsten systematischen Charakter erlangt.

Dazu kommt, daß es sich bei genanerer Untersuchung der ektoparasitischen Plathelminthen-Gattung Temnocephala herausgestellt hat, daß diese mit den Trematoden bloß den Mangel eines Cilienkleides teile, im übrigen aber eine "Übergangsform von den rhabdocoelen Turbellarien zu den monogenetischen Trematoden" darstelle, "die jedoch mehr zu ersteren, als zu letzteren hinneige" ${ }^{3}{ }^{3}$ ) In der Diskussion der systematischen Stellung des Genus Temnocephala sind -- nanientlich von Weber ${ }^{4}$, Braun ${ }^{5}$ ) und $\mathrm{Wacke}^{6}$ ) die Grenzen zwischen Turbellarien und Trematoden erörtert worden und es sei mir ge-

1) A. Lang, Lehrbuch der vergleichenden Anatomie, I. Abth., Jena I889, pag. 132.

2) M. Braun, Bronns Klassen u. Ordnungen d. Thierreichs, IV. Bd., Vermes, Abth. Ir, Leipzig 1879 bis 1893, pag. 521 .

3) R. Wacke, Beiträge zur Kenntnis der Temnocephalen. Zool. Jahrb., Suppl. VI (PIate, Fauna Chilensis, III. Bd.), H. I, Jena I903, pag. 87.

4) M. Weber, Über Temnocephala Blanchard. Zool. Ergebnisse e. Reise in Niederländisch-Ostindien, I. Bd., Leiden I890/91, pag. 24.

5) Braun, 1. c. pag. 52 I.

6) Wacke, l. c., woselbst die bisherige Literatur vollständig angeführt ist. 
stattet, hier vom Standpunkte des uns heute von den Turbellarien Bekannten, einige Worte zu dieser Erörterung hinzuzufügen.

Neben den Cilien könnten die stäbchenförmigen Körper des TurbellarienEpithels hier in Betracht kommen, wenn nicht gerade bei parasitischen Formen (s. oben S. 43 u. 44) diese für freilebende Turbellarien charakteristischen ') Gebilde so häufig fehlten. Auch hat der durch Blochmann²) geführte Nachweis, daß die Subcuticularzellen der Trematoden und Cestoden das eingesenkte Epithel dieser Plattwürmer darstellen, zwar die lang erörterte Epithelfrage in befriedigender Weise gelöst, aber doch die Hoffnung getäuscht, hierin einen Differentialcharakter gegenüber den Turbellarien gefunden zu haben. Denn es sind doch eine Anzahl von Trematoden ${ }^{3}$ ) und Cestoden ${ }^{4}$ ) ubrig geblieben, bei denen eine kernführende Epithelialschicht mit verschmolzenen Zellgrenzen vorliegt, wie sie nicht selten auch bei Turbellarien ${ }^{5}$ ) beobachtet wird, und wo gar keine Epithelzellen oder doch nur ein Teil derselben sich drüsenartig in die Tiefe versenkt haben. Andrerseits ist nicht bloßs an der Außenfläche des Pharynx, sondern auch im Integumente der Turbellarien die, wenigstens partielle, Versenkung des Epithels als weitverbreitete Erscheinung nachgewiesen worden, wie in der Kriechleiste, Sinneskante und den Kopulations-Organen der Landplanarien.") Und bei der parasitischen Triclade Syntcoelidium liegt wahrscheinlich eine Versenkung der gesamten Epithelzellen unter den Hautmuskelschlauch vor, die hier nur mit ihren kernlosen Epithelialplatten die Grenzschicht des Integumentes herstellen. ${ }^{7}$ )

Hautmuskelschlauch, Nervensystem und Sinnes-Organe bieten ebensowenig Anhaltspunkte zur Unterscheidung wie der Exkretions-Apparat ${ }^{8}$ ) und das Parenchym namentlich der parasitischen Turbellarien zeigt unverkennbare Übereinstimmung mit jenem der Trematoden und Cestoden (s. oben S. 46).

Pharynx und Darm sind bei den verschiedenen Abteilungen der Turbellarien so verschiedenartig gestaltet, daß der Gabeldarm der Trematoden nur eine untergeordnete Modifikation der, schon bei jenen gegebenen Verhältnisse darstellt. Er ist, wie die Darmform der Tricladen und Polycladen, selbständig aus dem unverästelten Darmsacke der

1) Mit Braun (1. c.) betrachte ich das von Wacke (pag. 24 , tab. II, fig. 22) beschriebene ,stäbchenartige, Kommabacillen vergleichbare Sekret" der zwei großen Drüsen von Temnoc, nowae-zelandiae nicht als den stäbchenförmigen Körpern der Turbellarien vergleichbar. Es handelt sich hier um kleinste Sekretgranula, die ebenso, wie dies bei Pigmentkörnchen so oft vorkommt, nicht rund, sondern stäbchenartig gestreckt sind.

2) F. Blochmann, Die Epithelfrage bei Cestoden und Trematoden. Hamburg I 896.

3) Braun, 1. c. pag. 422. - N. Maclaren, Über die Haut der Trematoden. Zool. Anz., XXVI. Bd., I903, pag. 5 I6.

4) W. Salensky, Üb. d. Bau u. d. Entwicklungsgeschichte der Amphilina Wagn. Zeitschr. fo wiss. Zool., XXIV. Bd., 1874, pag. 300. - Braun, 1. c., Abt. Ih, pag. II $46 \mathrm{ff}$.

5) Bei manchen Acoila und Rluabiocola, u. a. auch bei Byrsophlebs nana (s. o. S. 2).

6) Graff, Monogr. Turbell., II,, pag. 42, 104, 172.

7) Whe eler, Syncoelidium pellucidum, pag.170, fig. 6 u. 10, hy.

8) Mit Bezug auf den Exkretions-Apparat von Temnocephala sei hier erwähnt, daß dorsale Exkretionsporen auch bei Turbellarien vorhanden sind, u. zw. bei Stinostomum bicaudatum (Ke nnel, Zool. Jahrb., Abt. f. Anat., Bd. III, I $88 S$, pag. 480), Anocelís coeca (Vej dovský, Sitzungsber. kgl. böhm. Ges. d. Wiss., 1882, pag. 275, fig. 4 u. 5), Dendrocoelum lackum (I jima, Zeitschr. f. wiss. Zool., XL. Bd., I884, pag. 398), Gunde segmentata (Lang, Mitth. Zool. Station Neapel, III. Bd., I8SI, pag. 2II) und Thysarozoon brocchii (L a ng, Polycladen, pag. 165). 
Rhabdocoela abzuleiten und kann ebensowenig als ein Klassencharakter betrachtet werden wie die, übrigens auch bei freilebenden und parasitischen Turbellarien vorkommenden, Haftscheiben und Saugnäpfe.

Im Geschlechts-Apparat stimmen Turbellarien, Trematoden und Cestoden so sehr überein und die verschiedenen Typen desselben sind durch vermittelnde Übergänge so gut miteinander verbunden, daß es nur wundernehmen muß, weshalb es bis heute keine einheitliche Terminologie für die Teile des Geschlechts-Apparates der Plattwürmer gibt. Seit wir auch Turbellarien kennen, bei welchen der weibliche Genitalkanal in einen, der Eiablage dienenden Eiergang (Ootyp, Uterus) und eine, die Aufnahme des Sperma bei der Kopula vermittelnde Vagina (Laurerscher Kanal) gespalten ist ${ }^{1}$ ) und diese Kanäle bisweilen sogar durch gesonderte Öffnungen nach außen münden ${ }^{2}$ ), kann dieses Organsystem keinen Differentialcharakter mehr darbieten.

Unter diesen Umständen bleibt es dem persönlichen Ermessen anheimgestellt, ob man die Gattung Temnoceplaala den Trematoden oder den Turbellarien zuteilen will. Bei letzteren würde sie als eine, durch den gänzlichen Mangel der Cilienbekleidung und den Besitz frontaler Randtentakel charakterisierte Gattung, am besten in der Familie Vorticidae, und zwar bei dem Genus Derostoma einzureihen sein, dessen Diagnose, von den erwähnten Gattungsmerkmalen abgesehen vollständig auf Temnocephala paßt.

Je mehr sich die Kenntnis der Plathelminthen vertieft hat, desto schwieriger wurde die Abgrenzung der Klassen derselben. Und wie die "schlechten Spezies" bedeutungsvoll für die Deszendenztheorie geworden, so liefern derselben die „schlechten Klassen" der Plattwürmer Argumente, die umso überzeugender wirken, als sie auf dem festen Grunde vergleichend-morphologischer Tatsachen beruhen.

1) Syndesmis echinom (s. oben S. 20) und Artiocotylus speciosus (Graff, Monogr. Turbell, II., pag. 208).

2) MToroophortm durum und Gyrator hermaphroditus (Graff, Zool. Anz., XXVI. Bd., I902, pag. 39). 


\section{Verzeichnis der Turbellarien-Wirte}

nebst Angabe der Lokalität, an welcher dieselben mit Turbellarien behaftet gefunden wurden.

\section{Echinodermata.}

Echinoidea.

Strongylocentrotus droebacchensis (Müll.), Darmparasit: Syndesmis echinorum François (Alexandrozusk).

- lividus Brdt., Darmparasit: Syndesmis echinorum François (Banyıls-sur-mer).

Sphaerechinus granularis A. Ag., Darmparasit: Syndesmis echinorum François (Plymouth Sound, Sartorö, Triest, Unago, Neapel).

Echinus sphaera Müll., Darmparasit: Syndesmis echinorum François (Roscoff).

- acutus Lam., Darmparasit: Syndesmis echinorum François (Banyuls-sur-mer).

Clypeaster sp., Elstoparasit?: Anoplodium clypeasteris Graff (Sues).

Echinarachnius sp., Ektoparasit?: Cryptocoelum opacum Stps. (Hongkong).

Echinocardium cordatum Gray, Nebendarm-Parasit: Aragina incola Leiper (Millport).

\section{Holothurioidea.}

Stychopus variegatus C. Semp., Darmparasit: Anoplodium schneideri C. Semp. (Plilippinen).

Holothuria impatiens Gm., Leibeshöhlen-Parasit: Anoplodium graffi Montic. (Neapel).

- tubulosa Gm., Leibeshöhlen-Parasit: Anoplodium parasita Ant. Schn. (Triest, Korfu, Nizza, Neapel).

- polii Chiaje, Leibeshöhlen-Parasiten: Anoplodium parasita Ant. Schn. (Triest); A. pusillum Montic. (Neapcl).

Mílleria lecanora Jäger, Darmparasit: Anoplodium schneideri C. Semp. (Phi leppinill).

Cucumaria planci Marenz., Leibeshöhlen-Parasit: eine Vorticide unbestimmter Gattung (Neapel).

Chirodota laevis O. Fabr., Leibeshöhlen-Parasit: Anoplodium chirodotae Sabuss. (Solowetak); Ektoparasit?: Typhlolepta acuta Girard (Grand Manan).

- sp., Ektoparasit?: Typhlocolax acuminatus Stps. (Belringstraße).

Myriotrochus rinki Steenstr., Damparasit: Anoplodium myriotrochi Graff (Neapel). 


\section{Vermes.}

Nephthys scolopendroides Chiaje, Ektoparasit: Byrsophlebs nana (Laidlaw) (Neapel).

Lumbriculus variegatus (Müll.), Ektoparasit?: Rhynchoscolex vejdovskýi Selkera (Böhmen).

Phascolosoma vulgare Dies., Darmparasit: Collastoma monorchis Dörler (Roscoff).

Echiurus pallasi Guér., Leibeshöhlen-Parasit: Nemertoscolex parasiticus Grff. (Nordsee).

\section{Arthropoda.}

Crustacea.

Balan us balanoides L. und andere Species, Gelegentlicher Raumparasit zwischen den Füßen: Monocelis fusca Örst. (Port-Erin anf Han, Plymouth Somnd, Millport, Ostende, (Vimmerenti).

Nebalia bipes M.-E., Ektoparasiten: Genostoma tergestinum (Calandr.) (Triest, Neapel); Genostoma marsiliense (Calandr.) (Triest).

- sp., Ektoparasit: Genostoma marsiliense (Calandr.) (Harscille).

Id otea neglecta G. O. Sars, Leibeshöhlen-Parasit: Fecampia xanthocephala Caull.Mesn. (Saint-illartin im Armelkanal).

Asellus aquaticus L., Bruttaschen-Parasit: Mesostoma aselli Kennel (Dorpat).

Paranephrops neozelandicus, Branchialkammer-Parasit: Didymorchis paranephropis Hasw. (Otago in Nenseeland).

Einsiedlerkrebse sp., vergesellschaftet mit Stylochus zebra (Verrill) (Woods-Holl Mass, Vineyard Sound, Long Island Sound).

Eupagurus bernhardus Brdt., Leibeshöhlen-Parasit: Fecampia erythrocephala Giard (Fécamp, Iport, St.-Vaast-la-Hogne, Tatihon, Saint-Martin).

Pagurus pubescens, Ektoparasit?: Monocelis hirudo Levins. (Egedesminde).

Platycarcinus pagurus L., Leibeshöhlen-Parasit: Fecampia erythrocephala Giard (F'camp, Yport, St.-Vaast-la-Hogue, Tatihou, Saint-Hartin).

Carcinus maenas Leach, Leibeshöhlen- und ? Darmparasit: Fecampia erythrocephala Giard (Port-Erin auf Han, Plymouth Sound, Fécamp, Yport, St.Vaast-laHogne, Tatihou, Saint-Mlartin).

Limulus polyphemus (L.), Ektoparasiten: Bdelloura parasitica Leidy und Bdelloura propinqua Wheeler (amerikanische Kiiste und in Aquarien); Syncoelidium pellucidum Wheeler (Woods-Holl Mass).

\section{Mollusca.}

Lamellibranchiata.

Muscheln verschiedener Art (Donax truncullus L., Tellina tenuis Da Costa und besonders T. fabula Gronov.), Gelegentlicher Raumparasit: Monocelis alba Levins., welche ihre Eier an Schale, Mantelwand und Sipho ablegt (Bonlogne). 
Mytilus edulis L., Mantelhöhlen-Parasiten: Urastoma cyprinae (Graff) (Solozvetsk. Alexandrazesk); Graffilla mytili (Levins.) (Egedesminde); Telostoma mytili Örst. (Kopenhagent).

Unio alatus Say, Mantelhöhlen-Parasit?: Planaria unionicola Woodworth (Illinois river near Havana).

Cyprina islandica L., Mantelhöhlen-Parasit: Urastoma cyprinae (Graff) (Kiel).

Solen vagina L., Mantelhöhlen-Parasit: Urastoma cyprinae (Graff) (Triest); Darmparasit: Provortex tellinae Graff (Armelkanal).

Teredo sp., Leberparasit: Graffilla branni Ferd. Schm. (Lesina).

Tellina sp., Darmparasit: Provortex tellinae Graff (Neapel).

Scrobicularia tenuis F.u. H., Darmparasit: Macrostomum scrobiculariae Graff (s Mittelneer).

\section{Gastropoda.}

Chitoniden sp., Gelegentlicher Raumparasit (zwischen den Kiemen): Monocelis fusca Örst. (Port-Erin auf Man, Plymouth Sound, Millport, Ostende).

Patelliden sp., Gelegentlicher Raumparasit (zwischen den Kiemen): Monocelis fusca Örst. (Port-Erin auf Man, Plymonth Sound, Millport, Ostende).

Murex brandaris L., Kiemenhöhlen-Parasit?: Planocera insignis Lang (Triest); Nierenparasit: Graffilla muricicola Iher. (Triest, Neapel).

- trunculus L., Nierenparasit: Graffilla muricicola Iher. (Triest, Neapel).

Buccinum undatum L., Nierenparasit: Graffilla buccinicola H. L. Jameson (PortErin auf MTan).

Neptunea antiqua (L.), Nierenparasit: Graffilla buccinicola H. L. Jameson (Alexandrozesk, Port-Erin auf Man).

Sycotypus canaliculatus Gill, Kiemenhöhlen-Parasit: Planocera inquilina Wheeler (Woods-Holl Mlass).

Tethys leporina L., Leibeshöhlen-Parasit (im Fuß): Graffilla parasitica (Czern.) (Neapel).

\section{Tunicata.}

Ciona intestinalis (L.), Kiemensack-Parasit?: Prostheceraeus giesbrechti Lang (Neapel).

Botryllus schlosseri Sav. var, adonis Giard, Elstoparasit?: Planaria schlosseri Giard (Roscoff).

\section{Vertebrata.}

Raja clavata L., Elstoparasit: Micropharynx parasitica Jägersk. (Bohusläit). Raja batis L., Ektoparasit: Micropharynx parasitica Jägersk. (Bohuslän).

Muraenidenlarve sp., Gelegentlicher Ektoparasit (Eier auf die Haut ablegend):

Gunda sp. (Nizza). 


\section{Die Parasiten der Turbellarien.}

Wie die intensivere Beschäftigung mit den Turbellarien eine ansehnliche Zahl von solchen kennen lehrte, welche eine parasitische Lebensweise führen, so ist auch eine Menge von Organismen bekannt geworden, die auf und in Turbellarien leben. Algen, Bakterien, Protozoen und Würmer wählen sich Turbellarien als Wirte. Doch sind die meisten von ihnen nur als gelegentliche Funde registriert worden, ohne daß wir eine genauere Kenntnis ihres Baues und ihrer Entwicklungsgeschichte besäßen oder uns darüber klar wären, in welche der mannigfaltigen Kategorien der als „Parasitismus" zusammengefaßten Arten der Vergesellschaftung sie einzureihen seien.

Als erste Vorarbeit zu dahinzielenden Untersuchungen sei die folgende Zusammenstellung betrachtet, welche hoffentlich Spezialforschern Veranlassung sein wird, sich mehr als dies bisher geschehen konnte, der Turbellarien-Parasiten anzunehmen.

\section{Symbiotische Algen.}

Solche sind bisher nur in der Turbellarien-Ordnung der Rhabdocoelida bekannt, wo sie als Zooxanthellen und Zoochlorellen beschrieben worden sind, erstere bloß in marinen Formen, letztere in Meeres- und Süßwasser-Rhabdocoeliden vorkommend.

Seit ich zum ersten Mal die diesbezüglich bekannten Tatsachen zusammengestellt habe und der Frage näher getreten bin, welche biologische Bedeutung diesen Einschlüssen des Turbellarienkörpers zukommt, ${ }^{1}$ ) sind nicht bloß viele neue algenführende Rhabdocoeliden bekannt geworden, sondern es ist jetzt auch für mehrere Formen sichergestellt, daß in ihren Eiern und ausschlüpfenden Embryonen noch keine Algen wahrgenommen werden können. Überdies hat $\mathrm{G}$. Haberlandt für Convoluta roscoffensis Graff den Nachweis erbracht, daß in derselben tatsächlich ein „Phytozoon" im Sinne Brandts²) vorliegt, indem die grünen Körper der genannten Acoele ,ihren Charakter als selbständige Algenorganismen aufgegeben haben und so zu einem integrierenden histologischen Bestandteil des Wurmes geworden sind, daß sie nunmehr sein Assimilationsgewebe vorstellen ${ }^{\text {". }}{ }^{3}$ ) Dadurch haben alle diese Symbiosen ein erhöhtes Interesse gewonnen, indem zu erwarten steht, daß unter den mit Zoochlorellen und Zooxanthellen ausgestatteten Turbellarien auch noch die Vorstadien dieses extremsten Falles von Anpassung erhalten

1) L. v. Graff, Monogr. d. Turbell., I., Leipzig I882, pag. 74 U. I82. -- Zur Kenntnis d. physiol. Function d. Chlorophylls im Thierreich. Zool. Anz., VII. Jahrg., Leipzig 1884, pag. 520.

2) K. Brandt, Üb.d. morphol, u. physiol. Bedeutung d. Chlorophylls bei Tieren, I. im Arch, f. Phys. v. Dubois-Reymond, Jahrg. I8\$2; II. in Mitth. d. Zool. Station zu Neapel, IV. Bd., Leipzig 1883.

3) G. Haberlandt, Üb. d. Bau. u. d. Bedeutung d. Chlorophyllzellen von Convoluta roscoffensis, in: L. v. Graff, D. Organisation d. Turbellaria Acoela. Leipzig I89 I, pag. 75. 
geblieben seien. Ich beschränke mich hier auf den Hinweis, daß zwar Cont' roscoffensis den selbstätigen Nahrungserwerb gänzlich aufgegeben zu haben scheint, während dagegen Conw. convoluta und Amph. langerhansi, obgleich beide Massen von Zooxanthellen enthalten, äußerst gefräßige Räuber sind. ${ }^{1}$ )

Manche Beobachter geben an, die Färbung ihrer Objekte sei "durch Algen" hervorgebracht, olne die Algen näher zu beschreiben und ohne das Organ näher zu bezeichnen, in welchem sich dieselben befinden. Bei den darmlosen Acoelen, deren Leibesraum von verdauendem Parenchym erfüllt ist, wird die (stets tierische) Nahrung in letzteres hineingepreßt, wo sie dann in den sich mit wässeriger Flüssigkeit erfüllenden "Nahrungsvakuolen“ zur Verarbeitung gelangt. Algen, die zufällig in letztere hineinkommen, werden ebenfalls hier eingeschlossen bleiben und nicht in das plasmatische Parenchym übertreten. Solche Einschlüsse dürfen nach unseren bisherigen Kenntnissen ebensowenig auf Symbiose bezogen werden, wie die Algen, welche bei den übrigen wasserbewohnenden Turbellarien ja so leicht mit dem Wasser und mit den Fraßobjekten in das Lumen des Darmes aufgenommen werden. Alle wahrscheinlich in diese Kategorie gehörenden Angaben ${ }^{2}$ ) werde ich daher unberücksichtigt lassen.

Um wirkliche Symbiose handelt es sich voraussichtlich nur bei den in folgendem anzuführenden Formen.

Acoela. Eine verhältnismäßig große Anzahı dieser, durchweg marinen, niedersten Turbellarien enthält symbiotische Algen. Gelbe oder braune Zooxanthellen finden sich bei allen Arten des pelagisch lebenden Genus Haplodiscus, ${ }^{3}$ ) bei Convoluta convoluta (Abbildg.) $)^{4}$, C. bimaculata Graff ${ }^{5}$ ) und Amplichoems langerhansi (Graff) ${ }^{6}$ ); grüne Zoochlorellen bei Conv. schultzii O. Schm. ${ }^{7}$ ) und C. roscoffensis Graff ${ }^{8}$ ). Auch sind die orangeroten Fleckchen des Aphanostoma aurantiacum Verrill ${ }^{9}$ ) und die „violettroten Flecken" der Conv. grönlandica Levins. ${ }^{10}$ ) wahrscheinlich nichts anderes als Algen.

Bei allen sind die Algen im Parenchym, besonders in dessen peripheren Partien, enthalten und stellen in ausgewachsenen Exemplaren ein ständiges Vorkommnis dar.

1) Es wird freilich notwendig sein, jeden einzelnen Fall genau zu untersuchen. Sonst gelangt man $2 u$ so wenig begründeten Konjekturen, wie es die von W. A. Silliman (Beobacht. üb. d. Süßwasserturbellaricn Nordamerikas. Z. f. wiss. Zool., 41. Bd., I885, pag. 63) hinsichtlich seines Mesostoma viziparmu ( $=M$. viridatım [Müll.]) aufgestellten sind. Silliman spricht die Überzeugung aus, daß dieses Tier von seinen Zoochlorellen ernährt werde und fügt dann die Meinung hinzu, daß auch die vermeintliche! - Abwesenheit der Dotterstöcke, die Viviparität und der Mangel der Augen bei dieser Turbellarie „durch das Vorhandensein des Chlorophylls der Algen bedingt werden"!

2) Sic beziehen sich auf Mesostoma lanciola M. Brn., Vortex coronarius O. Schm., V. cuspidafus O. Schm., $V$. infundibuliformis Fuhrm., $V$. triquetrus Fuhrm. und $V$. pictus O. Schm.

3) Die Zooxanthellen der Haplodiscus-Arten sind genauer beschrieben bei L. Böhmig, Die Turbellaria acoela d. Plankton-Expedition. Kiel und Leipzig 1895, pag. 31.

$\left.{ }^{4}\right)=$ C. paradoxa Örst. Graff, Monogr. Turbell., I., pag. 228. - Organ. Turb. Acoela, pag. 62.

5) Graff, Monogr. Turbell., I., pag. 234.

$\left.{ }^{6}\right)$ Graff, Vorl. Mitth. üb. Rhabdocoeliden, II., Zool. Anz., XXVI. Jahrg., Leipzig 1902, pag. 12 I.

7) Graff, Organ. Turb. Acoela, pag. 63.

8) Y. Delage, Etudes histol. s. 1. Planaires Rhabdocoeles Acoeles (Conv. Schultzii O. Sch.). Arch. Zool. expér. (2), tome IV, Paris 1886, pag. ro9. - Graff, Organ. Turb. Acoela, pag. 66.

9) A. E. Verril1, Marine Planarians of New England. Trans. Conn. Ac., vol. VIII, 1893, pag. 509.

10) G. M. R. Levinsen, Bidrag til kundskab om Grönlands Turbellarie-fauna. Vidensk. Meddel. naturh. Foren. in Kjöbenhavn $1879 / 80$, pag. 168, fig. I. - Graff, Monogr. Turbell, I., pag. 232. 
Bei den Haplodiscus-Arten und Conv, convoluta dringen sie auch in die Ovarien, bei Amph. langerhansi überdies in das Gehirn und die Wandungen des Pénis und Pharynx ein.

Schließlich sind hier zu verzeichnen die eigentümlichen gelben Körper (Zooxanthellen?), welche während der Furchung in den Eiern von Polychoenus condatus Mark ${ }^{\text {b }}$ ) und Aphanostoma sp. Gardiner ${ }^{2}$ ) auftreten und von welchen für die erstgenannte Spezies sichergestellt ist, daß sie den ausgebildeten Tieren fehlen.

Rhabdocoela. Aus dieser Unterordnung sind bisher bloß mit Zoochlorellen behaftete Süßwasserbewohner bekannt. Die Zoochlorellen erfüllen in mehr oder weniger großer Anzahl die Lücken des Mesenchyms, und zwar vornehmlich der, dem Integumente anliegenden Partien desselben und dringen bei einer Spezies (Derostoma anophthalmam) auch in die Dotterstöcke ein. Letztere sind hier ,ganz mit Zoochlorellen vollgepfropft, wogegen im Körperparenchym nur wenige grünc Körnchen verteilt sind" (D orner). In folgenden Gattungen und Arten sind bisher Zoochlorellen konstatiert:

Mesostoma viridatum (Müll.) ${ }^{3}$ ), MI. stimulosum n. sp. mihi $\left.{ }^{4}\right)$, M. minimum Fuhrm.5);

Castrada hofmanni M. Brn. $\left.{ }^{6}\right)$, C. neocomensis $\mathrm{Volz}^{7}$ ), C. viridis Volz $)^{8}$, C. intermedic Volz $\left.{ }^{9}\right)$, C. chlorea M. Brn. $\left.{ }^{10}\right)$, C. tripeti $\left.(\mathrm{Volz})^{11}\right)$;

Vortex viridis (G. Shaw) ${ }^{12}$ ), V. scoparius $\mathrm{O} . \mathrm{Schm}^{13}{ }^{3}$, V. graffi Hallez ${ }^{14}$ ), V. penicillus M. Brn. $\left.{ }^{15}\right)$, V.triquetrus Fuhrm. $\left.{ }^{16}\right)$;

Derostoma unipunctatum Örst. $\left.{ }^{17}\right)$, D. galizianum O. Schm. $\left.{ }^{18}\right), \quad D$. anophthahmum Vejd. $\left.{ }^{19}\right)$, D. typhlops Vejd. $\left.{ }^{20}\right)$, D. balticum M. Brn. ${ }^{21}$ )

1) E. G. Gardiner, Early Development of Polychoerus caudatus Mark. Journ. of Morphol., vol. II, Boston 1895, pag. I59.

2) Gardiner, 1. c. pag. 161. - Diese Form ist wahrscheinlich identisch mit dem von Verrill (1. c. pag. 510 ) beschriebenen Aphanostoma olizaccum.

3) Graff, Monogr. Turbell, I., pag. 304. - M. Braun, Rhabd. Turb. Livlands, Arch f. d. Naturk. Liv.-, Ehst- u. Kurlands (2), Bd. X, Dorpat 1885, pag. 58. - Silliman, 1. c. pag. 59 (Mles. viviparzm). O. Fuhrmann, Turbell. d. Umg. v. Basel, Revue Suisse Zool., vol. II, Genève I894, pag. 24 I.

4) = Typhloplana viridata in: P. Hallez, Contrib. à l'hist. nat. des Turbellariés, Trav. Inst. Zool. Lille, vol. II, 1879 .

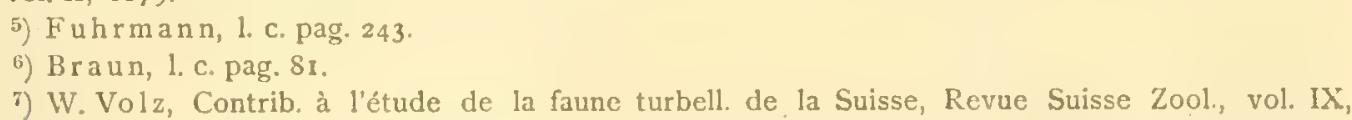
Genève 1901, p. 173.

8) Volz, ebendas, pag. 170

9) Volz, ebendas. pag. 179.

10) Braun, 1. c. pag. 83 .

II) Volz, 1. c. pag. 175

12) Graff, Monogr. Turbell., I., pag. 351.

13) Graff, ebendas. pag. 355 .

14) Graff, ebendas. pag. 36r.

15) Braun, 1. c. pag. 93 .

16) Fuhrmann, 1. c. pag. 265. - G. Dorner, Darst. d. Turbellarienfauna Ostpreußens. Schr. phys.ökon. Ges. Königsberg, Jahrg. 43, 1902, pag. 41.

$\left.{ }^{17}\right)$ Graff, Monogr. Turbell., I., pag. 367. -- Braun, 1. c. pag. 96.

18) Graff, Monogr. Turbell., I., pag. 269. - Hallez, Catalogue des Rhabd., Tricl. et Polyclades du Nord de la France, $2^{e}$ éd., Lille 1894, pag. 98.

19) Dorner, 1. c. pag. 46

${ }^{20)}$ E. Sekera, Erg. m. Stud. an D. typhlops, Zool. Anz., vol. IX, 1886, pag. 566.

21) Braun, 1. c. pag. Ioo. 
Bei einer Anzahl dieser Rhabdocoelen wurden auch ausgewachsene Exemplare gefunden, die ganz frei von Zoochlorellen waren, und zwar sind solche bald sehr selten ( $V$. viridis), bald häufig ${ }^{1}$ ), bald die Regel (V.triquetrus und $D$. unipunctatum), ohne daß es bis heute festgestellt wäre, ob das Fellen oder Vorhandensein der Zoochlorellen von der Lokalität, der Jahreszeit ${ }^{2}$ ) oder irgend welchen anderen Umständen abliänge.

Alloeocoela. Von solchen sind bloß zwei marine Formen hier anzuführen. Die eine, Monocelis vividirostris Sabuss., ${ }^{3}$ ) enthält bloß im Mesenchym des Vorderendes Zoochlorellen, die andere, Enterostomum zooxanthella Graff $^{4}$ ), ist dadurch interessant, daß sie die einzige mit einem Darm versehene Turbellarie darstellt, bei welcher die symbiotischen Algen ähnlich wie bei Hydra und den Altinien im Plasmaleibe der Zellen des Darmepithels wohnen.

In den Ordnungen der Tricladida und Polycladida sind bisher symbiotische Algen unbekannt.

\section{Krystalloide.}

Als Krystalloide hat $\mathrm{Halle} \mathrm{z}^{5}$ ) eigentümliche rundliche Körperchen bezeichnet, welche sich nicht selten in der Leibeshöhle, den Muslieln, Speichel- und Schleimdrüsen des Mesostoma elwenbergi ansammeln und sich daselbst, namentlich im Herbste, so sehr vermehren, daß das Tier seine Durchsichtigkeit einbüßt und eine matt-weiße Farbe annimmt. Hallez schrieb ihnen die Gestalt eines pentagonalen Dodelaeders zu und hielt sie für Reservestoffe für die Zeit der Überwinterung. Indessen hatte schon vorher Schneider ${ }^{6}$ ) dieselben als kugelrunde Körper dargestellt, die sich später mit einer Cyste umgeben, „welche von polyedrischen sich treffenden Leisten besetzt ist", und sie für Parasiten erklärt. Mit Schneiders Beschreibung stimmen auch meine Befunde bei M. elivenbergi ${ }^{7}$ ) und Derostoma anipunctatum ${ }^{8}$ ) besser überein als mit jener von Hallez

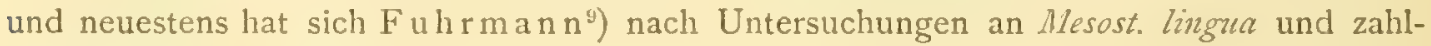
reichen anderen Arten nicht bloß in Bezug auf die Form, sondern auch hinsichtlich der biologischen Bedeutung dieser Körper den Ansichten Schneiders angeschlossen. Auch ich darf hier berichten, daß der gegenwärtig im hiesigen zoologischen Institute arbeitende Herr Mag. A. Luther bei Mesost. rostratum den Bau und die Entwicklung der Kry-

1) Mesost. viridatum, Castrada chlorea, C. tripeti, Vortex scoparius, V. graffi, Derostoma galizianum, D. anophthalmum, D. typhlops.

2) Nur von $D$.typhlops gibt Sekera an, daß es ,im Sommer immer von Zoochlorella behaftet" sei und K. Parádi (Orvos.-Természett. Ért. Klausenburg, Jahrg. I881, pag. 168-169) hat die der Zoochlorellen entbehrenden Individuen als $D$. anophthalmon, die mit solchen versehenen als $D$. claudipolitamum beschrieben.

a) H. Sabussow, Beobacht. üb. d. Turbellarien d. Inseln von Solowetzk. Arb. (Trudi) d. Naturf. Ges. b. d. Univ. Kasan, Bd. XXXIV, H. 4, Kasan 1900 (russisch mit deutschem Auszuge), pag. 190.

4) Graff, Turbellarien von Lesina. Zool. Anz., IX. Jahrg., I886, pag. 34 .

5) Hallez, Contrib., pag. 79.

6) A. Schneider, Unters, üb. Plathelminthen, 14. Jahresber. Oberhess, Ges., Giessen 1873, pag. 36.

7) Graff, Monogr. Turbell, I., pag. 77 .

8) Graff, in: K. Lip pits ch, Beitr. z. Anat. d. Derostoma unipunctatum Oe., Zeitschr. f. wiss. Zool,, Bd. XLIX, 1889, pag. I48 nota.

y) Fuhrmann, 1. c. p. 223 . 
stalloide studiert und den unzweifelhaften Nachweis erbracht hat, daß dieselben parasitische Protozoen darstellen. ${ }^{1}$ )

Man wird nicht fehlgehn, wenn man die in verschiedenen Beschreibungen von Rhabdocoelen des süßen Wassers (vergl. besonders Dorner, l.c.) enthaltenen Angaben, daß die Leibeshöhle „von lichtbrechenden Kügelchen erfüllt" sei, sämtlich auf solche „Krystalloide“ bezieht. Damit erweitert sich der Kreis der Wirte dieser Kategorie von Parasiten, und es erscheinen folgende Rhabdocoela des süßen Wassers mit denselben behaftet:

Mesostoma elurenbergi (Focke), M. lingua (Mül1.), MI. masovicum Dorner, M. exignumn Dorner, M. rostratum (Müll.), M. oscari n. cp. mihi (= tetragomm Hallez), M. cylcloposthe Dorner; Castrada radiatı (Müll.), C. hofmanni M. Brn.; Bothromesostoma personatun (O. Schm.); Gyrator hermapluroditus Ehrbg. ${ }^{2}$ ); Vortex triquetnes Fuhrm., V. armiger O.Schm.; Dorostoma unipunctatum Örst., D. typhlops Vejd.

Wie die angeführten Süßwasserturbellarien durch die Anhäufung der „Krystalloide“ ihre Durchsichtigkeit verlieren und im durchfallenden Lichte opak, im auffallenden Lichte dagegen weiß erscheinen, so ist es für Convoluta convoluta seit langem bekannt, daß sie bisweilen weißglänzende Flecken und Querbinden aufweist, welche sogar zur Aufstellung besonderer Spezies Veranlassung geworden sind. Ich habe gezeigt, ${ }^{3}$ ) daß diese bei mehreren Acoelen vorkommenden, im auffallenden Lichte weißen Zeichnungen außerordentlich variabel seien und von eigentümlichen, wie es scheint, stets dem Integumente eingelagerten Körperchen herrühren, welche ich den eben erwähnten Krystalloiden zurechnen zu dürfen glaubte. Ihre Form wechselt, bald sind sie rundlich, bald langgestreckt, bald verästelt, jedes Körperchen erweist sich wieder aus feinsten Kügelchen zusammengesetzt. Im durchfallenden Lichte erscheinen sie mehrweniger opak, in toto grau oder bräunlich, bei starker Vergrößerung irisierend. Gegen Säuren sind sie unempfindlich, auch nehmen sie keine Tinktion an. Bei Amplichoerns langerhansi, ${ }^{4}$ ) wo sie ganz konstant schon bei I mm langen Individuen auftreten und mit zunehmender Größe eine immer reichere und vielfach wechselnde weiße Zeichnung hervorbringen, fand ich sie auf Schnitten in den basalen Teil der Epithelzellen eingebettet als krümelige, rundliche oder längliche Körper, deren größte einen Durchmesser von $0.003-0.005 \mathrm{~mm}$ erreichen.

Diese Körper sind bisher bloß bei den Acoela ${ }^{5}$ ) und der Polyclade Planocera in-

1) A. Labbé, Sporozoa (Das Tierreich, 5. Lief., Berlin 1899, pag. 127) hat die Krystalloide des Mes. ehrenbergi nach Schneiders Darstellung bei den Sporozoa incerla eingereiht.

2) Ich habe von dieser Spezies schon in meiner Monographie (I., tab. XI, fig. 20, d) die, die ganze Leibeshöhle erfüllenden Krystalloide abgebildet, sie aber damals für Darmzellen gehalten, welche durch den Zerfall des Darmes isoliert wurden. Neuerliche Untersuchungen haben mich belehrt, daß die so bezeichneten Zellen nichts sind als Krystalloide, die vollkommen jenen des Mes. elurubergi gleichen. Ihr Durchmesser beträgt 0.002 bis $0.003 \mathrm{~mm}$.

3) Graff, Monogr. Turbell., I., pag. 78, tab. II, fig. 5, ma. - Organ. Acoela, tab. I, fig. I (die braunen Flecken), tab. VII, fig. I2.

4) Graff, Vorl. Mitth. üb. Rhabdocoeliden, II, Zool. Anz., Bd. XXVI, 1902, pag. I22.

5) u. zW. bei: Aphanosioma pulchellum (Ulj.); Convoluta sabtilis (Graff); Co albomaculata (Pereyasl.); C. variabilis (Pereyasl.); C. schultzei O. Schm., Co convoluta (Abbildg.), Co festiva Ulj., C. sordida Graff, C. lacazei Graff, C. elegans Pereyasl., C. bimaculata Graff; Amphichoerus cinerizes (Graff), A. langerhansi (Graff); Polychourus caudatus Mark. 
quilim Wheeler ${ }^{1}$ ) vorgefunden worden und ich zweifle heute nicht daran, daß dieselben eine andere Bedeutung haben als die sogenannten Krystalloide der Süßwasserturbellarien. Wheeler spricht für seine Polyclade die Ansicht aus, daß es sich um Urate handle.

\section{Bakterien und fragliche Protozoen.}

Bakterien und bakterienähnliche Organismen hat Laidlaw im Darmepithel zweier neuer tropischer Polycladen gefunden. Dieselben waren stäbchenförmig bei P'anoccra armata, ${ }^{2}$ ) hantelförmig bei Prosthiostomm elegans. ${ }^{3}$ ) Während es sich hier wahrscheinlich um Parasiten handelt, fallen die durch die verletzte Schale in Eier von Leptoplana tromellaris Örst. eindringenden Baliterien, welche Francotte ${ }^{4}$ ) beschrieben hat, unter einen andern Gesichtspunkt.

Fragliche Protozoen. Hieher gehören vor allem die Gebilde aus Convoluta roscoffensis Graff, welche zuerst von Geddes beschrieben und dann genauer durch Delage ${ }^{5}$ ) dargestellt wurden. Diese, als Pulsatella convolutae bezeichneten zelligen Einschlüsse finden sich zu 3 bis 40 im Körper der genannten Acoelen unregelmäßßig in den Parenchymlücken verteilt, mit Vorliebe im Vorderende und in der Mundgegend, und können auch aus dem Körper ausgestoßen werden, ohne ihre, dann mit Lokomotion verbundenen charaliteristischen Kontraktionen einzustellen. Delage charakterisiert sie als „cellule caliciforme, sans noyaux, dont la cavité est occupée par une touffe de cils vibratiles animés ensemble d'un mouvement rhythmique", ohne jedoch zu einer Entscheidung darüber zu kommen, ob es sich um Parasiten, um Exkretions- oder um primitive Zirkulations-Organe handelt. Repiachoff ${ }^{6}$ ) hat dieselben Gebilde in einer, allem Anscheine nach mit Otocelis mbropunctata (O.Schm.) identischen Acoelen von Neapel beobachtet.

$\mathrm{Ob}$ die eigentümlichen „Drüsen“, welche ich") von Convoluta convoluta (Abbildg.) und C. flavibacillum Jens. beschrieben habe, Beziehungen zu Pulsatella haben oder einer andern Gruppe parasitischer Protozocn (? Sporozoa) zuzurechnen seien, muß einstweilen dahingestellt bleiben.

1) W. M. Wheeler, Planocera inquilina. Journal of Morphology, vol. IX, Boston 1894, pag. 196, findet in der Randpartie des Körpers, eingebettet in die Basilarmembran des dorsalen Integumentes, Körperchen, welche eine im auffallenden Lichte weiße, im durchfallenden schwarze Farbe bedingen. Dieselben sind nicht gleichmäßig verteilt, sondern in netzartigen Zügen dichter angehäuft als außerhalb dieser. Bisweilen umhüllen dieselben auch die im Uterus liegenden Eier. - Die Natur der Pigmente der Polycladen ist, obgleich gerade diese Gruppe durch mitunter prachtvolle Färbungen ausgezeichnet erscheint, noch sehr wenig studiert. Ob die, namentlich am Rande des Körpers so häufig auftretende weiße Zeichnung nicht auch bei anderen Formen durch ähnliche Einlagerungen hervorgebracht wird wie bei Planocerr intulilina, wäre erst noch zu untersuchen.

2) F. F. Laidlaw, Marine Turbellaria. Fauna and Geogr. of the Maldive and Laccadive Archipelagos, vol. I, pt. 3, 1892 , pag. 283 , tab. XV, Fig. 10, $\mathbf{r}$.

3) Ebendas. pag. 300, textfig. 7 r.

4) G. Francotte, Quelques essais d'embryol. pathol. expér., Bull. Acad. Belg. (3.), tome XXVII, Bruxelles I894, pag. 382 . - A. Giard, A propos d'une note de M. Francotte etc., Compte rendu Soc. Biol., Paris (10.), tome I, I894, pag. 385 .

5) Delage, 1. c. pag. 150, tab. V, fig. 26 u. 27.

6) W. Repiachoff, Nachtrag, Zool. Anz., VIII. Jahrg., I885, pag. 273.

7) Graff, Monogr. Turbell, I., pag. 60, tab. III, fig. 10, hd-hdiur. - Organ. Acoela, pag. Ir. 
Die von Böhmig') bei Haplodiscus scutiformis, H. obtusus, H. acuminatus, H. ovatus und von Sabussow ${ }^{2}$ ) bei $H$. ussozei in und zwischen den Ovarialzellen gefundenen fadenförmigen Körper hat der erstgenannte für Coccidiensporen erklärt, wogegen Montice $11 \mathbf{i}^{3}$ ) sie für, durch den Mund eingedrungene, Spermatozoen hält. Mit Rüclisicht auf die Tatsachen der "hypodermic impregnation" bin auch ich geneigt, in den fraglichen Gebilden Spermatozoen zu vermuten.

Amoeboide Körper in lebhafter Bewegung hat Hallez $z^{4}$ in Plan. fusca vorgefunden, doch vermutet er in denselben das Entwiclilungsstadium einer Sporozoe.

Flagellaten ähnliche Organismen mit lebhaft schwindenden Geißeln sind bisher bloß in den Nebentaschen der Bursa seminalis von Honocelis fusca Örst. gefunden worden. ${ }^{5}$ )

\section{Sporozoa.}

Diese kommen in Arten aller Ordnungen der Turbellarien, besonders häufig aber in der Abteilung der Tricladida vor. Leider betreffen die Literatur-Ausgaben bloß gelegentlich gefundene Formen, von denen bisher keine einzige auf ihre Entwicklung untersucht wurde. Doch scheint es sich durchweg um Gregarinida Acephalina (Labbé) zu handeln, die ich mangels anderer Einteilungskriterien in der systematischen Reihenfolge der Wirte und innerhalb dieser nach den befallenen Organen aufzählen werde.

Acoela. In Convoluta sp. soll nach Labbéb) die bei Nemertinen verbreitete Urospora nemertis (Köll.) vorkommen. Diese Angabe scheint mir indes schon mit Rücksicht auf die verschiedene Organisation und Lebensweise der Wirte noch der Bestätigung zu bedürfen.

Rhabdocoela. Schultze $\mathrm{e}^{7}$ ) fand ,im Darm eines neuen Mesostomu aus der Ostsee zwei bewegungslose, kleine Gregarinen von etwa birnförmiger Gestalt, mit dunkelkörnigem Inhalt und großem Kern und Kernkörperchen".

In der Leibeshöhle von Mesost. rostratum (Müll.) fand Fuhrmann ${ }^{8}$ ) mehrere unbewegliche, von starker Zellhaut umgebene und von ihm für Gregarinen angesehene Gebilde und $\mathrm{ich}^{9}$ ) habe in einem Exemplare des marinen Proxenetes cochlear Graff sieben Gregarinen abgebildet, die mit ihrem zähflüssigen, nur geringe Kontraktions-Erscheinungen aufweisenden Körper sich den verschiedensten Organen anschmiegten. Dazu kommt die oben (S. 23, Taf. III, Fig. 27, G) aus dem Darmlumen von Genostona tergestinum (Calandr.) beschriebene Gregarine.

Siißroasser-Tricladen. Dorne $\mathrm{r}^{10}$ ) spricht von, im Darm und in der Leibeshöhle der "Planarien" gẹfundenen Gregarinen. Die folgenden Angaben beziehen sich wahrscheinlich såmtlich auf Darm-Schmarotzer, obgleich $\mathrm{Hallez}$ das Organ nicht näher

1) Böhmig, Turb. Acoela Plankton-Exp., pag. 32, tab. I, fig. 19-21, x, tab. II, fig. 30-34.

2) H. Sabussow, Haplodiscus Ussowii, Mitth. Zool. Stat. Neapel, XII. Bd., I896, pag. 377. pag. 36 .

3) F. S. Monticelli, A proposito del Haplodiscus Ussowii. Atti Soc. Nat. Mat. Modena 1899,

4) H allez, 1. c. pag. 86, tab. V, fig. 36 .

5) Graff, Monogr., I., pag. 182, tab. XX, fig. 10.

6) A. Labbé, Sporozoa (Das Thierreich, 5. Lief.), Berlin, 1899, pag. 44.

7) M. Schultze, Beitr. z. Naturg. d. Turbellarien, Greifswald 1851, pag. 67

8) Fuhrmann, I. c. pag. 223 u. 24 I.

9) Graff, Monogr. Turbell,, 1., pag. 182, tab. VIII, fig. I, x.

10) Dorner, l. c. pag. 50. 
angibt (es heißt: „dans le corps"). Aus dem Darm der l'lan. torva (Müll.) beschreibt $\mathrm{Schultze}$ zunächst ${ }^{1}$ ) Gregarinen von gestrecktem, vorn breit abgerundetem und hinten rasch zugespitztem Körper und dazu eine kugelig gestaltete. Er vermutet, daß zu dieser Form auch die bisweilen gefundenen Sporenbehälter mit Tausenden ovaler Sporen von ca. 0.005 mm Länge gehören. Weiter erwähnt Schultze von derselben Planaria zwei Zysten von $0.55 \mathrm{~mm}$ Durclimesser mit Tausenden von gestreckt eiförmigen, $0^{\circ} \mathrm{O} 2 \mathrm{~mm}$ langen Sporen, ${ }^{2}$ ) deren jede ein Paar spindelförmiger Hohlräume enthält, welche an die Polkapseln der Myxosporidien-Sporen erinnern und demnach jedenfalls zu einer andern Spezies gehören als die zuerst beschriebenen.

In Plan. fusca. (Pall.) treten nach $\mathrm{Hallez}$ sehr häufig und zahlreich birnförmige Gregarinen $^{3}$ ) auf, deren Konjugation beobachtet wurde. Viel seltener fand $\mathrm{Hallez}$ in demselben Wirte große, schon mit freiem Auge erkennbare Zysten (drei- bis viermal so groß als die Gregarinen), die von ovalen Sporen erfüllt waren. ${ }^{4}$ )

Mingazzini5) rechnet die von Schultze und Hallez bei Süßwasserplanarien gefundenen Gregarinen zu seinem nov. gen. Pleurozyga, während Labbéb) sie unter Mingazzinis Genus Lankesteria als L. planariae einreiht.

Land-Tricladen. Noch viel häufiger als die Süßwasserplanarien sind die landbewohnenden von Sporozoen befallen. Schon Moseley ${ }^{7}$ ) berichtet über im Darme und im Bindegewebe von Bipalizm und Rhynchodemus lebende Gregarinen, doch sind erst durch mich und meine Schüler solche Parasiten genauer beschrieben und abgebildet worden.

Im Lumen des Darmes fanden sie sich bei Geoplana nasuta Loman ${ }^{8}$ ); Choeradoplana langi $\left.\mathrm{Graff}^{9}\right)$; Bipalium haberlandti $\mathrm{Graff}^{10}$ ), B. marginatum Loman ${ }^{11}$ ), B. virile Jos. Müll. $\left.{ }^{12}\right)$;

im Darmlumen, aber überdies auch in den Epithelzellen des Darmes fanden sich die Sporozoen bei G. ladislavii Graff ${ }^{13}$ ) und G. micholitzi Graff, ${ }^{14}$ ) ausschließlich intra-

1) Schultze, 1. c. pag. 70, tab. VII, fig. 18-22.

2) Ebendas. pag. 6, tab. VII, fig. 7, a-c.

3) Hallez, 1. c. pag. 85, tab. V, fig. $26-33$.

4) Ebendas. fig. 34 u. 35 .

5) P. Mingazzini, Contributo alla conoscenza degli Sporozoi. Ric. Labor. Anat. Roma, vol. III, 1893, pag. 67, Anm. 2.

6) A. Labbé, 1. c. pag. 46. Hier werden aber von Schultzes Abbildungen bloß fig. I8, von Hallez bloß fig. 3 I -35 einbezogen. Es sei Spezialisten überlassen, ob diese Auswahl gerechtfertigt ist. Dagegen muß die Einbeziehung der von $\mathrm{K}$ eferstein aus Leptaplana tremellaris (Müll.) beschriebenen Gregarine schon deshalb als verfehlt bezeichnet werden, weil es nicht wahrscheinlich ist, daß eine ausschließlich marine Polyclade und eine ausschließlich im Süßwasser lebende Triclade dieselbe Spezies eines Entoparasiten beherbergen soliten.

7) H. N. Moseley, On the Anat. and Histol, of the Land-Planarians of Ceylon. Phil. Trans. R. S. London 1874 , pag. 132.

s) Graff, Monogr. Turbell., II., Leipzig 1899, pag. 250, tab. XXVII, fig. II, G.

y) Ebendas. pag. 25I, tab. XXX, fig. I, G-Gir.

10) Ebendas. pag. 250.

11) Ebendas. pag. 250.

12) Jos. Müller, Ein Beitr. z. K. d. Bipaliiden. Z. f. wiss. Zool., LXXIII. Bd., I902, pag. I I I, tab. V, fig. $2-2 \mathrm{~b}$.

13) Graff, Monogr. Turbell., II., pag. 250.

14) Ebendas, pag. 250, tab. XXVI, fig. 8, G. 
zellulär bei G. munda Fletch. Ham. ${ }^{1}$ ), G. korotneffi Graff $\left.{ }^{2}\right)$; P'rocephalus sikorai Graff ${ }^{3}$ ), B. proserpina Humbert ${ }^{4}$ ), B. eplippinm Loman ${ }^{5}$ );

im Mesenchym lagen sie bei G. stecistrupi $\mathrm{Krsm}^{6}{ }^{6}$ ), G. olivacca Fr. Müll. ${ }^{7}$ ) und Platydemus laterolineatus (Graff) ${ }^{8}$ );

im Hoden bei B. ephippium Loman, doch handelt es sich hier um die gleichen Parasiten, welche bei dieser Spezies auch im Darmepithel leben.

$\mathrm{Zu}$ den Sporozoa gehört schließlich auch die von mir $^{9}$ ) im Mesenchym unterhalb des dorsalen Integumentes von Polycladus gayi Blanch. gefundene große Zyste, welche ich damals für ein Arthropoden-Ei gehalten habe. Nachdem ich später eine zweite,

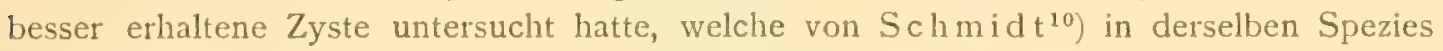
gefunden worden war, kam ich zu der Überzeugung, daß es sich um eine GregarinenZyste handle.

Die Herren F. Schaudinn und S. Prowazek, denen ich die betreffenden Präparate zur Prüfung übersandte, bestätigten meine Ansicht und der erstere war so freundlich, mir folgendes darüber zu schreiben: „Es sind ohne Zweifel Gregarinen-Zysten. Bei der einen waren sogar schon die Sporodukte ausgebildet. Im Inneren sieht man die weiblichen Gameten umschwärmt von zahlreichen männlichen Mikrogameten; einzelne befruchtete Gameten haben sich bereits durch Abscheidung einer zarten Hülle zu Sporozysten umzubilden angefangen. Die weitere Entwicklung dieser Gregarine zu verfolgen, wäre höchst interessant; die Bildung von Sporodukten bei einer Coelomgregarine ist meines Wissens neu. Klassifizieren kann man sie natürlich nicht, solange keine reife Sporozyste da ist. Möglich wäre es auch, daß, wie bei Aggregaten (Frenzel), die Sporozoiten direkt durch Zerfall der Sporoblasten gebildet werden, doch ist mir dies bei dem Vorhandensein der Sporodukt-Anlagen nicht wahrscheinlich. Die Sporodukte entstehn hier ganz ebenso wie bei Clepsidrina und ähnlichen Formen."

Polycladen. Im Darme von Leptoplana tremellaris (Müll.) hat Keferstein ${ }^{11}$ ) schlanke, bis $0.3 \mathrm{~mm}$ lange Gregarinen gefunden und Mingazzin i beschrieb unter dem Namen Ophiodina discocelidis ${ }^{12}$ ) solche aus dem Darme von Discocelis tigrink.

1) Graff, Monogr. Turbell., II., pag. 250.

2) Ebendas. pag. 250 .

3) Ebendas. pag. 250.

4) Ebendas. pag. 250 .

5) Ebendas. pag. 250.

6) K. Krsmanović, Beitr. z. Anat. d. Landplanarien. Z. f, wiss. Zool., LXV. Bd., 1898, pag. 208, tab. 8, fig. I4.

7) Br. Busson, Üb. einige Landplanarien. Sitzungsber. Ak. Wiss. Wien, math.-natw. Kl., Bd. CXII, Abt. I, 1903 , pag. 52 .

8) Graff, Monogr. Turbell., II., pag. 250, tab. L, fig. 14 u. I5.

9) Ebendas. pag. 252, tab. XXX, fig. 9.

10) A. Th. Schmidt, Z. K. d. Tricladenaugen u. d. Anatomie. v. Polycladus gayi. Z. f. wiss. Zool., LXXII. Bd, I 902 , pag. 536 .

11) W. Keferstein, Beitr. z. Anat. u. Entw. e. Seeplanarien v. St. Malo. Abh. königl. Ges. d. Wiss. zu Göttingen, XIV. Bd. 1868, pag. 22, tab. II, fig. Io u. 11. - Vgl. oben S. 60, Anm. 6.

12) Mingazzini, 1. c. pag. 56, tab. II, fig. 43. - Labbé (1. c. pag. 49) hat die Gattung Ophioidina unter die "Genres incertains des Acephalina" eingereiht. 
Im Parenchym des Körpers von Cestoplana mbrocincta (Gr.) regellos zerstreut, finden sich nach $\mathrm{Lang}^{1}$ ) Gregarinen ,als absolut konstante Schmarotzer, und zwar stets in Kopulation".

\section{Ciliata.}

Die parasitischen Ciliaten der Turbellarien rekrutieren sich aus den beiden Gruppen der Holotricha und Peritricha, und zwar stellt letztere bloß Ektolommensalen, während die erstere teils solche, teils Entoparasiten abgibt.

Am längsten bekannt sind die im Darmlumen der Süßwasser-Tricladen lebenden Formen, welche jetzt in zwei Gattungen untergebracht werden.

Discophrya planariarum (Sieb.) ${ }^{2}$ ) wurde in der Pharyngealtasche sowie in den Darmästen von Planaria toria (Müll.), Pl. gonocepliala Ant. Dug., Pl. fusca (Pall.), Dendrocoelum lacteum (Müll.) und Polycelis nigra (Müll.) von zahlreichen Autoren vorgefunden.

Hoplitophrya uncinata (MI. Schultze) ${ }^{3}$ ) wird aus dem Darme mariner Turbellarien, und zwar der Gunda ulvae (Örst.), sowie einer Polycladen-Art (Proceros sp.) beschrieben. ${ }^{4}$ )

In den Darmdivertikeln von Pol. nigra (Müll.) hat $\mathrm{Hallez}^{5}$ ) ein nicht näher bestimmbares holotriches Infusorium beschrieben und was es mit den von Örsted ${ }^{\text {(5) }}$ im Darm von Rhabdocoelen vorgefundenen, in Ketten oder Haufen von drei bis zehn beisammenliegenden bewimperten Infusionstieren für eine Bewandtnis habe, wird ebenfalls schwer festzustellen sein.

Eine im Epithel des Darmes selbst lebende Ciliate habe ich bei einer australischen Landplanarie, Artioposthic fletcheri (Dendy), gefunden ${ }^{\top}$ ) und im Mesenchym von Stenostomum lencops (Ant. Dug.) ist das Vorkommen eines holotrichen Infusoriums durch Fuhrmann ${ }^{8}$ ) bekannt geworden.

Als Epizoen leben: Coleps hirtus (Müll.) auf Vorter sexdentatus Graff ${ }^{9}$ ) und

1) A. Lang, Die Polycladen (Seeplanarien) des Golfes von Neapel, Leipzig 1884, pag. 518 u. 64 I, tab. XVI, fig. I 5 .

9) Abbildungen dieses Parasiten finden sich bei O. Bütschli (Bronns Klass. u. Ordn., Protozoa, tab. LXV, fig. 3) und A. W. Schweyer (D. paras. bewimperten Infus., Trudi d. St. Petersb. Ges. d. Naturf., 1901, vol. 27, pag. 49, tab. I, fig. 19). Zu der von letzterem zitierten Literatur gehören wahrscheinlich folgende, die Wirte betreffenden Angaben: Schultze, l. c. pag. 67 , tab. VII, fig. 1-5 (Opalina folymorpha); Hallez, 1. c. pag. 85 ; Fuhrmann, l. c. pag. 225-226, tab. X, fig. 3; Dorner, l.c. pag. 50.

3) Abbildungen haben Schultze (1. c. pag. 68, tab. VII, fig. 7-9, vielleicht gehört auch fig. 6 dazu?), Büt schli (1. c. tab. LXV, fig. 3) und Schweyer (1. c. pag. 48, tab. I, fig. 18) gegeben.

4) Nach Claparède und Lachmann (Études s. les Infusoires et les Rhizopodes, I., Genève 1858, pag. 374) führt Schweyer diesen Proceros sp. als Wirt der Hoplit. uncinata an und dazu auch noch die Pianaria limacina O. Fabr., obgleich aus Claparèdes Abbildung (tab. XXI, fig. 9) die Identität mit dem Schultzeschen Infusor nicht erschlossen werden kann und zudem auch deshalb nicht wahrscheinlich erscheint, weil die Planaria limacinu O. Fabr, zweifellos eine Nacktschnecke (Pontolimaxt) ist.

5) Hallez, 1. c. pag. 84, tab. V, fig. 20 U. 2 I.

6) A.S.Örsted, Entwurf ein. syst. Einth. u. spez. Beschr. d. Plattwürmer, Kopenhagen 1844, pag. 14, textfig. $4-9$.

i) Graff, Monogr. Turbell., II., pag. 25I, tab. XXX, fig. 10, tab. XXXI, fig. 7, Pa.

๖) Fuhrmann, 1. c. pag. 223, tab. X, fig. 2.

9) Graff, Monogr. Turbell., I., pag. I\$2. 
Trichodinen auf verschiedenen Turbellarien. Die letzteren sollen den Süßwassertricladen die Cilien abfressen. ${ }^{1}$ ) Ohne nähere Angabe der Spezies werden Trichodinen angeführt als Parasiten von Bothrioplana alacris Sekera²), Polycelis nigra (Müll.) ${ }^{3}$ ) und Thysinowoon brocchii (Risso) ${ }^{4}$ ); Tr. mitra Sieb. und Tr. pediculus Ehrbg. von Plan. polyclurou O. Schm. ${ }^{5}$ ), Tr. stein i Clap. Lachm. von Plan. gonoceplarla Ant. Dug. ${ }^{6}$ ) und Mesostoma tetragonum O. Schm. ${ }^{\top}$ ).

\section{Orthonectida.}

Keferstein ${ }^{8}$ ) bildet ab ein ,räthselhaftes Thier, das in den Magentaschen von Leptoplanu tremellavis (Müll.) oft in großer Menge vorkommt, $0.135 \mathrm{~mm}$ lang, $0.03 \mathrm{~mm}$ breit". Giard") hat dasselbe später als Intoshia Leptoplanae bezeichnet, ohne jedoch eine nähere Beschreibung desselben zu geben.

\section{Trematodes.}

Solche sind bisher aus Turbellarien der Gruppen Rhabdocoela, Alloeocoela, Süßwasser-Tricladida und Polycladida gefunden, teils eingekapselt, teils frei, bald im Mesenchym (Leibeshöhle), bald im Darm. Sie scheinen sämtlich der Familic der Distomidae anzugehören.

Rhabdocoela. Ein im Mesenchym eingekapseltes Distomum bei Microstomum lineare (Müll.) ${ }^{10}$ ), eine im Bindegewebe des Vorderkörpers von Derostoma umipunctatum Örst. freilebende „Holostomidenlarve"، ${ }^{11}$ )

Alloeocoela. Ein junges geschlechtsloses Distomum frei im Mesenchym von Enterostommm zooxanthella Graff ${ }^{12}$ ) und wahrscheinlich ein ebensolches eingekapselt bei Plagiostomm koreni Jens. ${ }^{13}$ )

Tricladida des süßen Wassers enthalten nach Dorner ${ }^{14}$ ) "gar nicht selten ein-

1) I. Ijima, Unters. üb. d. Bau u. d. Entw. d. Süßwasser-Dendrocoelen (Tricladen). Zeitschr, f. wiss. Zool., XL. Bd., pag. 366.

2) E. Sekera, Üb. e. interess. Turbellarien-Fundort. Zool. Anz, XIX. Bd., I896, pag. 377.

3) Fuhrmann, 1. c. pag. 225.

4) Lang, l. c. pag. 64I.

5) Hallez, Contrib., pag. 84, tab.V, fig. 22-25. - Ijima, l. c. pag. 366 Anm. - F. Vejdovský, Sitzungsber. königl. böhm. Ges. Prag, Jahrg. 1881, pag. 116. Vejdovský erklärt hier die von Hallez abgebildete Trichodina als Tr. milra, wogegen der letztere (Catalogue, 2. éd., pag. 74) sie mit Tr. steini identifiziert.

6) Vejdovský, l. c. pag. Iı6.

7) Hallez, Catalogue, 2. éd,, pag. 74. Die von O. Schmidt, M. Schultze, P. Hallez und mir unter diesem Namen beschriebene Form ist verschieden von der gleichnamigen Art O. F. Müllers, weshalb ich für sie den neuen Namen $M$. oscari vorschlage.

$\left.{ }^{8}\right)$ Keferstein, 1. c. pag. 37, tab. II, fig. 8.

9) A. Giard, Sur les Orthonectida. Compte rendu Acad. Paris, vol. 85, 1877, pag. 814.

10) Sekera, Beitrag z. K. d. Süßw.-Turbell., Sitzungsber. kgl, böhm. Ges. 1888, pag. 16, tab. I, fig. I3.

11) Dorner, 1. c. pag. 43, tab. II, fig. 7 .

12) Graff, Turbell. v. Lesina, pag. 342.

13) O. Jensen, Turbellaria ad litora Norvegiae occid., Bergen 5878 , pag. 93, tab. V, fig. 3, m. Vgl. Gratf, Monogr. Turbell., I., pag. I82, Anm. I.

14) Dorner, l. c. pag. 50. 
gekapselte Distomen, die sich hauptsächlich am Vorderende im Bindegewebe festgesełzt haben und häufig in bedeutender Zahl vorkommen". Indessen finde ich nirgends speziellere Angaben. Dagegen liegen solche für die Polycladida vor. So erwähnt Keferstein ${ }^{1}$ ) eingekapselte Distomen (in den Magentaschen?) von Leptoplana tremellaris (Müll.), während ich zahlreiche eingekapselte Distomen im Mesenchym von Planoccra pellucida (Mert.) ${ }^{2}$ ) und einige Exemplare eines geschlechtsreifen Distomum im Darm von Planocera simrotha $\mathrm{Graff}^{3}$ ) vorgefunden habe.

\section{Nematodes.}

Vereinzelt bei den Allococoela und Süßwasser-Tricladida vorkommend, sind dieselben bei den Landplanarien außerordentlich häufig, und zwar in den verschiedensten Organen anzutreffen.

Bothrioplana alacris Sekera ${ }^{4}$ ) beherbergt im Pharynx und im Mesenchym des Körpers enzystierte wie freie Nematoden.

Der erste bei Turbellarien überhaupt bekannt gewordene Rundwurm ist der von Metschnik off ${ }^{5}$ ) frei im Pharynx von Dendrocoelum lacteum (Müll.) gefundene und nachher von Leuckart ${ }^{6}$ ) als Jugendzustand von Mermis nigrescens Duj. erkannte Parasit, welcher wahrscheinlich identisch ist mit dem, von $\mathrm{Hallez}^{7}$ ) bei Polycelis nigra (Müll.) und von Bergendal ${ }^{8}$ ) bei Pol. tenuis Ij. unter den gleichen Umständen, von Fuhrmann ${ }^{y}$ ) dagegen eingekapselt im Pharynx von Plan. gonocephala Ant. Dug. gefundenen Nematoden.

Die zahlreichen Nematodenvorkommnisse bei Landplanarien seien hiemit in der systematischen Reihenfolge der Wirte aufgezählt.

Geoplana mfiventris Fr. Müll. ${ }^{10}$ ) enthält bis zu 5 mm lange und $0.3 \mathrm{~mm}$ breite, noch nicht mit Geschlechts-Organen versehene Nematoden zu Dutzenden im Darmtraktus. In den Hauptdarmästen liegen sie mehr gestreckt, in den Divertikeln spiralig aufgerollt, die von den Parasiten besetzten Divertikel sind stark ausgeweitet und des Epithels fast ganz beraubt.

G. ladislavii Graff ${ }^{11}$ ) enthält sehr kleine Nematoden (von $0.15-0.2 m m$ Länge und 0.008 -0.016 mm Breite) zwischen den Muskeln des Bulbus penis.

G. micholitis Graff ${ }^{12}$ ) mit kleinen Nematoden (Breite $0.02 \mathrm{~mm}$ ) im vorderen Ha u p d a rm.

1) Keferstein, 1. c. pag. 22, tab. II, fig. 9.

2) Graff, Pelagische Polycladen. Z. f. wiss. Zool., LV. Bd., 1892, pag. I98.

3) Ebendas. pag. 204 .

4) Sekera, Turbellarien-Fundort, pag. 377 .

5) E. Metschnikoff, Üb. Geodesmus bilineatus Nob., Bull. Acad. Sc. St. Pétersbourg, 1866, tome IX, pag. 558, Anm.

6) R. Leuckart, Bericht nied. Thiere, Arch. f. Naturg., 33. Jahrg., II., Berlin, x867, pag. 26r.

7) Hallez, Contrib., pag. 83 .

8) D. Bergenda 1, Studien üb. Turbellarien, I., Kongl. Sv. Vet. Acad. Handl., B. 25, Stockholm 1892, pag. 39

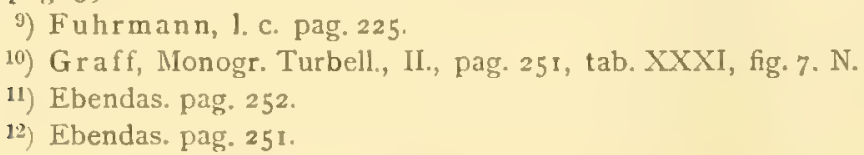


G. spenceri Dendy') mit kleinen Nematoden im Mesenchym unterhalb des Darmes.

G. hoggi Dendy²) beherbergt sehr kleine Nematoden, die dorsal und ventral mit einem Teile ihres Körpers in den Hautmuskelschlauch eingebohrt sind, mit dem Reste im Bindegewebe stecken.

G. steenstmipi Krsm. ${ }^{3}$ ) mit einem kleinen Nematoden, der zum Teile im Längsnervenstamme, zum Teile im umgebenden Mesenchym lag.

Artioposthia fletcheri (Dendy) ${ }^{4}$ ) mit sehr kleinen Nematoden innerhalb des ventralen Hautmuskelschlauches.

A. diemenensis (Dendy) ${ }^{5}$ ) enthält sehr kleine Nematoden im Bindegewebe zwischen der Drüsenzone und dem dorsalen Integumente.

Bipalium proserpina Humb.") mit sehr kleinen Nematoden in den Längsnervenstämmen und im Darmlumen.

B. diana Humb. ${ }^{\top}$ ) mit „einem gewissermaßen eingekapselten Nematoden. Derselbe lag von einer auffallend dicken faserigen Hülse umschlossen im Körperg ewebe, ungefähr 25 mm vor der Mundöffnung über und zwischen den äußeren Enden von zwei Darmzweigen".

B. mivittatum $\mathrm{Gr}^{8}$ ) hatte in einem $\mathrm{Hodenfollikel}$ einen ca. $0.6 \mathrm{~mm}$ langen und bis 0.016 mm breiten Nematoden.

B. woodworthi Graff ${ }^{9}$ ) beherbergt im Mesenchym unterhalb des Darmes ca. $0.12 \mathrm{~mm}$ lange und $0.026 m$ breite Nematoden, deren eines Ende in den Darm hineinreicht. In der Umgebung des Parasiten ist das Darm-Epithel zerstört, das Mesenchym verdichtet.

Placoceplualus javanus (Loman). Herr Dr. Loman isolierte aus dem Darme einen ca. $2.7 m m$ langen und bis $0.17 m m$ breiten Nematoden der bereits die Anlage der Geschlechts-Organe enthielt. Ich habe denselben genauer beschrieben und abgebildet. ${ }^{10}$ )

In Cotyloplana zuliteleggei W. B. Sp., C. punctata W. B. Sp. und Platydemus laterolineatus (W. B. Sp.) fand ich ${ }^{11}$ ) sehr kleine Nematoden im Mesenchym und in den Längsnervenstämmen verteilt.

Rhynchodemus terrestris (Müll.) enthält nach $\mathrm{De} \mathrm{Man}^{12}$ ) in seinem $\mathrm{Phary \textrm {nx }}$ bisweilen kleine Nematoden (Myorictes?) und in

Rlyynchodemus $s p$. aus Ceylon fand Bergendal ${ }^{13}$ ) einen in leichten Schlingen innerhalb des Längsnervenstammes liegenden Nematoden.

1) A. Dendy, The Anatomy of an Australian Land Planarian. Trans. R. S. Victoria, 1889; Melbourne I890, pag. 53 .

2) Graff, Monogr. Turbell., II., pag. 252, tab, XXVI, fig. 6, N.

3) K. Krsmanović, 1. c. pag. 208.

4) Graff, Monogr. Turbell., II., pag. 252.

5) Ebendas. pag. 252.

6) Ebendas. pag. 252.

7) Bergendal, 1. c. pag. 39 .

8) Graff, Monogr. Turbell., II., pag. 25i, tab. XLII, fig. 6, N.

9) Das von C. Mell (D. Landplanarien d. Madagass. Subregion. Abh. Senckenb. naturf. Ges., Bd. XXVII, Frankfurt a. M. 1903, pag. 209) beschriebene Exemplar enthielt diesen Parasiten, wie ich einer nachträglichen mündlichen Mitteilung des Herrn Mell entnehme.

10) Graff, Monogr. Turbell., II., pag. 25I, tab. XXXVII, fig. 7 u. 8.

11) Ebendas. pag. 252.

12) J. G. De Man, De gewone Europeesche Landplanarie, Geodesmus terrestris O. F. M., Tijdschr.

Nederl. Dierk. Vereen., Deel. II., Afl. 4, s'Gravenhage 1876, pag. 240.

13) Bergendal, 1. c. pag. 39.

v. Graff, Turbellarien als Parasicen. 


\section{Rotatoria.}

Von der durch Vejdovský beschriebenen Drilophaga bucephalus ${ }^{1}$ ) berichtet Sekera ${ }^{2}$, daß dieses auf der Haut von Lumbriculus variegatus L. lebende Rotator auf Bothrioplana alacris Sek. übergeht, wenn letztere alloeocoele Turbellarie mit Lumbriculus gefüttert wird. Die Bothrioplana soll durch diesen Ektoparasiten eine, schließlich zum Tode führende, Schrumpfung des Körpers erfahren.

1) Vej dovský, Üb. Drilophaga Bucephalus n. g. n. sp., ein parasit. Räderthier. Sitzungsber, königl. böhm. Ges. d. Wiss. 1882, pag. 391 .

2) Sekera, Turbellarien-Fundort, pag. 377 . 
TAFEL-ERKLÄRUNGEN. 



\section{Erklärung der Tafel I.}

Fig. I-I4. Graffilla buccinicola Ja mes.

Fig. I. Zweimal vergr. Exemplare nach dem Leben gezeichnet in ihren verschiedenen wechselnden Formen. $a$ die größten, weiblich reifen, $b$ die kleinsten, männlich reifen Individuen.

Fig. I'. Reifes Spermatozoon.

Fig. 2-12. Querschnitte durch ein weiblich reifes Exemplar. Dasselbe hatte konserviert eine Länge von $2: 3$ mm und wurde in 307 Schnitte (von je $7.5 \mu$ Dicke) zerlegt und diese in Hämatoxylin-Eosin gefärbt. Der Tinktionseffekt ist möglichst getreu wiedergegeben und bloß der Darm schematisch gefärbt. Vergr. 85 mal.

Fig. 2. Der II. Schnitt mit dem Pharynx und den, in kleine Ballen zerteilten, cyanophilen Exkretionsstoffen.

Figg. 3. Der 19. Schnitt mit dem Pharynx, den großen, dorsal von Exkretionsstoffen erfüllten Parenchymzellen und einem, in die Pharyngealtasche mündenden Exkretionskanal (ex).

Fig. 4. Der 3I. Schnitt, Gehirn und Darm treffend.

Fig. 5. Der 50. Schnitt mit den vorderen Enden des Dotterstockes (tiefrot) und der von Sperma erfüllten Samenblase.

Fig. 6. Der 68. Schnitt mit Geschlechtsporus und Bursa seminalis, Dotterstock, Schalendrüsen, Samenblase und spärlichen cyanophilen Exkretionszellen.

Fig. 7. Ventraler Teil des 83 . Schnittes mit den in das Atrium femininum mündenden Ovidukten.

Fig. S. Der 100. Schnitt mit Dotterstock, Keimstöcken, Schalendrüsen und Hodenresten (te) sowie den hintersten Exkretionskapillaren.

Fig. 9. Der I54. Schnitt mit dem rings vom Dotterstock und den beiden Keimstöcken umgebenen Darme.

Fig. 10. Der halbe 197. Schnitt, ebenso.

Fig. II. Der 250. Schnitt mit dem hintersten Ausläufer des linken Keimstockes (ks).

Fig. 12. Der 28I. Schnitt durch das Hinterende des Darmes.

Fig. I 3. Blasiges Parenchym, die verschiedenen Tinktionszustände der Zellen aus mehreren Schnitten kombiniert. Vergr. 500mal.

Fig. 14. Querschnitt durch Integument und Randparenchym. Vergr. 50omal. 


\section{Buchstaben-Bezeichnung.}

af Atrium femininum.

ag Atrium genitale commune.

$b$ Bulbi der Cilien.

$b g$ Peripheres, retikuläres Bindegewebe.

$b g f$ Fasergerüst desselben.

$b g k$ Kerne der, die Zellen des blasigen

Bindegewebes umhüllenden Membran.

bgl Lücken zwischen diesen Membranen, von erythropilen Körnchen erfüllt.

$b g l_{l}, \quad b g l_{I I}$ Ebensolche mit cyanophilen Körnchen.

$b g m$ Membranen des blasigen Bindegewebes. $b g \%, b g{ }^{\prime}$ Zellen des retilkulären Bindegewebes.

bs Bursa seminalis.

bsa Ausführungsgang derselben.

$c$ Cuticularschicht der Epithelzellen.

$c i, c i$, Cilien.

cy Cyanophile Körnchen.

$c y b$ Ballen von solchen.

d Mittelschicht der Epithelzellen.

$d a$ Darm.

$d m$ Muskularis desselben.

do Dotterstock.

do, Unreife Dotterstocksfollikel.

ep Äußeres Epithel.

er Erythrophile Körnchen.

$e x$ Vermutliche Exkretionsöffnung.

$f$ Basalteil der Epithelzellen. $f a, f a_{I}$ Faltungen des blasigen Bindegewebes. $g$ Gehirn.

ga Ganglienzellen.

gö Geschlechtsporus.

hm Hautmuskelschlauch.

$k s, k s_{T,} k s_{I I}$ Keimstöcke.

lm Längsfasern des Hautmuskelschlauches. $m, m_{I}$ Muskelfasern.

ma Muskeln des Atrium genitale.

$m p$ Muskelgeflecht des retikulären Bindegewebes.

mple Muskeln des Pharynx.

od Ovidukt.

ph Pharynx.

pht Pharyngealtasche.

$r$ Randschicht der Epithelzellen.

$m$ Ringmuskeln des Hautmuskelschlauches.

$s d r$, sdr, Schalendrüsen.

sl Schleimpfröpfe.

$s p$ Sperma-Massen.

te Hodenfollikel.

v Hohlräume des Epithels.

is Vesicula seminalis.

$Z$ Amöboide Bindegewebszellen.

$\approx-z_{6}$ Verschieden tingierte Zellen des blasigen Bindegewebes.

$z k, z k$, Kerne desselben.

zz Peripherer Teil des blasigen Bindegewebes. 


\section{D00180.0.}
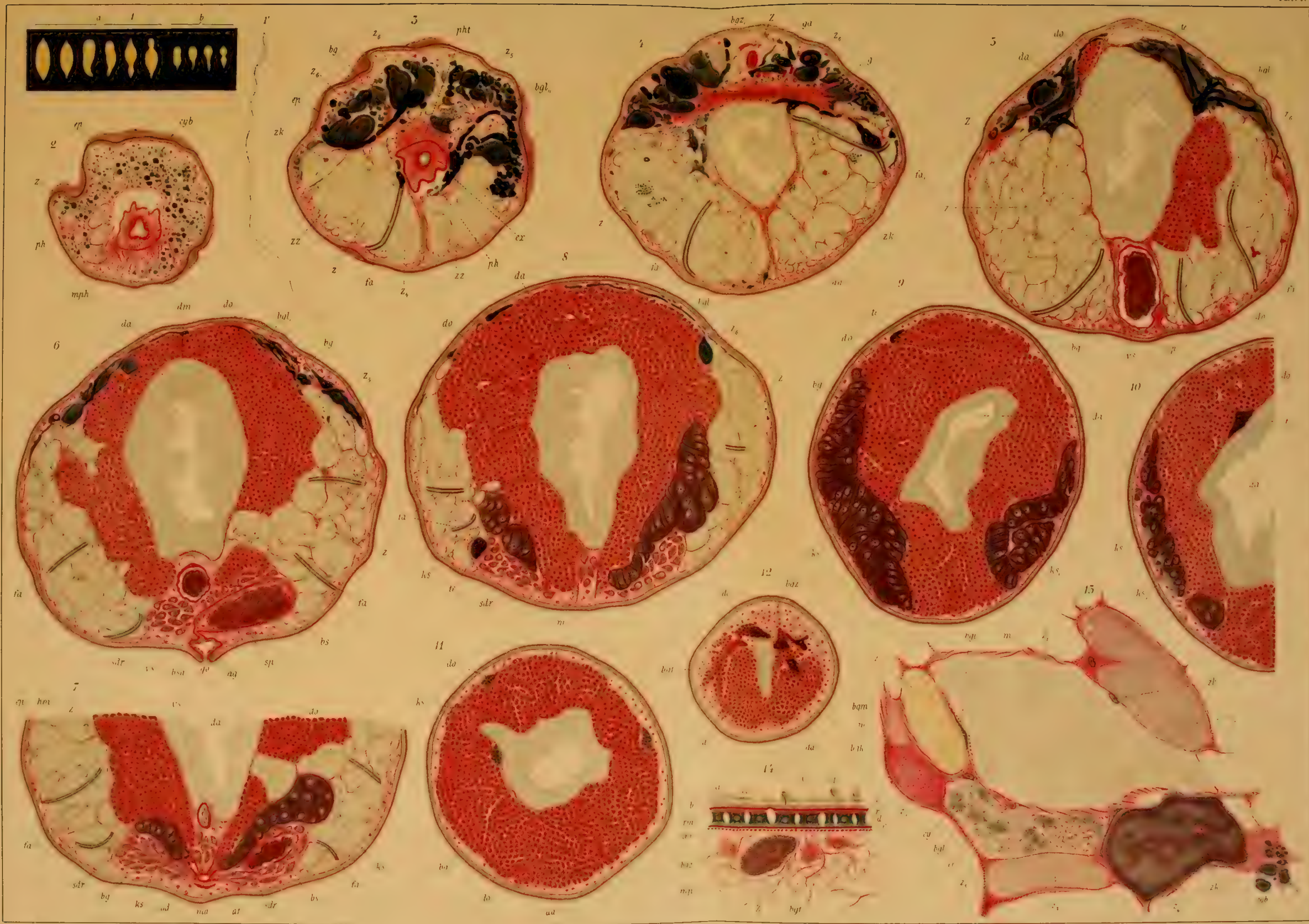



\section{Erklärung der Tafel II.}

Fig. I-II. Graffilla buccinicola James.

Fig. I -6. Querschnitte durch ein männlich reifes Exemplar. Dasselbe hatte konserviert eine Länge von fast I $m m$ und wurde in 196 Schnitte (von je $5 \mu$ Dicke) zerlegt. Tinktion und Vergr. wie bei der Taf. I dargestellten Serie.

Fig. I. Der 38. Schnitt mit der Samenblase und dorsalen, von Exkretionsstoffen erfüllten Parenchymzellen.

Fig. 2. Ventrale Hälfte des 49. Schnittes mit dem Penis.

Fig. 3. Der 57. Schnitt mit der Geschlechtsöffnung und den Körnerdrüsen des männlichen Apparates.

Fig. 4. Der 78. Schnitt mit den Hoden, dem weiblichen Atrium und den Schalendrüsen.

Fig. 5. Der 93. Schnitt mit den, hinter dem Atrium liegenden Schalendrüsen und der hinteren Partie der Samenblase, den beiden Hoden und Anlagen der Keim- und Dotterstöcke.

Fig. 6. Der I23. Schnitt, durch die hintere Partie des Darmes und der Hoden gehend, mit Dotter- und Keimstocksfollikeln.

Fig. 7. Horizontalschnitt durch ein $0.9 m m$ langes Individuum, in der Höhe des Gehirnes geführt, den Darm und die Hoden fast in ganzer Länge treffend.

Fig. 8. Horizontalschnitt aus derselben Serie (Vergr. der Fig. 7 u. 8 wie oben), in der Höhe der Samenblase geführt, den Pharynx, eine ventrale Kommissur der beiden Hoden sowie den Ausführungsgang der Bursa seminalis treffend.

Fig. 9. Wandung der Samenblase aus einem Querschnitte, 28omal vergr.

Fig. 10. Wandung der Bursa seminalis, 280 mal vergr.

Fig. II. Längsschnitt durch Pharynx, Ösophagus und Darmwandung, 28omal vergr.

Fig. I2-13. Urastoma cyprinae (Graff).

Fig. I2. Das schwimmende Tier, 20 mal vergr.

Fig. I3. Dasselbe, leicht gequetscht, ca. I20mal vergr., mit Weglassung des Dotterstockes gezeichnet.

Fig. 14. Syndesmis echinorum François.

Nach dem Leben bei 2 mal Vergr. gezeichnet. $a$ ein flach ausgebreitetes, langsam kriechendes Exemplar, $b$ ein anderes, langgestreckt, mit fein ausgezogenem Hinterende. 


\section{Buchstaben-Bezeichnung.}

$a g$ Atrium genitale commune.

au Augen.

bg Peripheres, retikuläres Bindegewebe.

$b g l_{I}$ Von cyanophilen Körnchen erfüllte

Bindegewebslücken.

$b g \approx, \quad b g z_{I}$ Zellen des retikulären Bindegewebes.

bsa Ausführungsgang der Bursa seminalis.

bse Epithel derselben.

$c y b$ Ballen cyanophiler Körnchen.

da Darm.

dm Muskularis des Darmes.

do Dotterstock.

do, Unreife Dotterstocksfollikel.

$d_{s}$ Vakuolisierte Darmzellen.

cp Äußeres Epithel.

$g$ Gehirn.

gc Genitalkanal.

gö Geschlechtsporus.

$h d r$ Hautdrüsen.

hin Hautmuskelschlauch.

$k$ Zellkerne.

$k d r, k d r_{7}$ Körnerdrüsen des männlichen Apparates. $k s, k s_{I}$ Keimstöcke.

$k \approx$ Körnerzellen des Darmes.

lm Längsmuskeln.

o Mund.

oe Ösophagus.

pe Penis.

pi Pigmentzellen.

phe Pharynx.

phe Epithel desselben.

phs Pharyngealzellen.

rdmn Radiärmuskeln des Pharynx.

rm Ringmuskeln.

$s, s_{l}, s_{I I}$ Selkret-Massen.

sd Stirndrüsen.

$s d r$ Schalendrüsen.

$s p$ Sperma-Massen.

te, te I Hoden.

tel Lückenräume derselben.

ad Vasa deferentia.

is Vesicula seminalis.

$Z$ Amöboide Bindegewebszellen.

$\approx-z_{6}$ Verschieden tingierte Zellen des blasigen Bindegewebes.

$\approx k, \approx k_{I}$ Kerne derselben. 

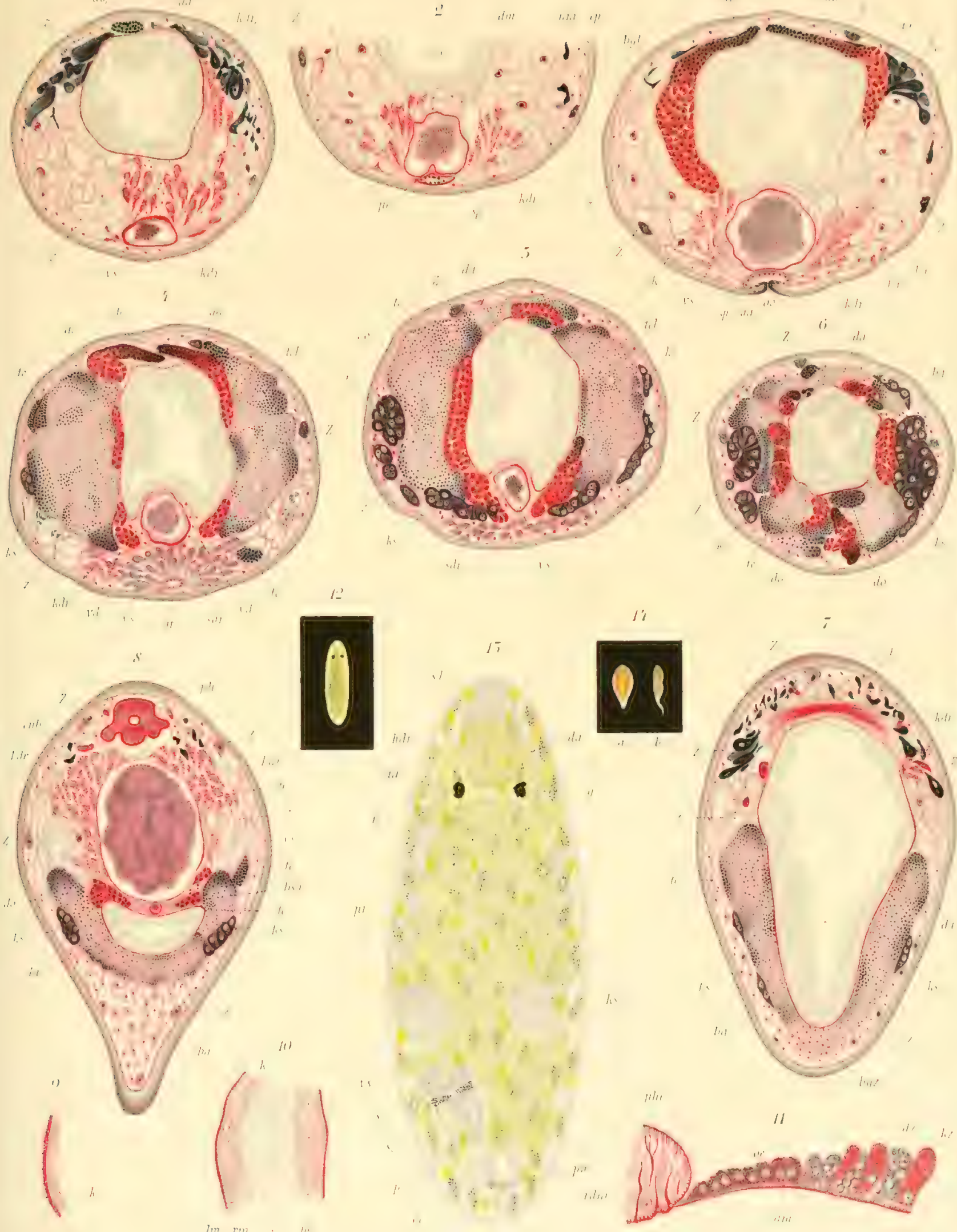



\section{Erklärung der Tafel III.}

\section{Fig. I-24. Byrsophlebs nana (L a id law).}

Fig. 1. Das kriechende Tier nach dem Leben gezeichnet, ca. $200 \mathrm{mal}$ vergr.

Fig. 2. Hinterende desselben bei Festheftung mit dem Schwanz-Anhange (ca).

Fig. 3-7. Verschiedene Formen des letzteren.

Fig. 8. Das festgeheftete Tier mit dem Rüssel ( $R$ ) umhertastend.

Fig. 9, a-c. Verschiedene Formen des Chitin-Anhanges der Bursa copulatrix.

Fig. 10. Eine Klebzelle (klz) des Schwanz-Anhanges, stark vergr.

Fig. I I-22. Querschnitte aus einer Serie von 126 Schnitten (Länge des konservierten Objektes $0.63 \mathrm{~mm}$ ), tingiert mit Hämatoxylin-Eosin, Vergr. $300 \mathrm{mal}$.

Fig. I I. Der 6. Schnitt, die vier Rüsselnerven treffend.

Fig. I 2. Der I I. Schnitt, durch das Gehirn gehend.

Fig. 13. Der 20. Schnitt mit den beiden Hoden.

Fig. I4. Der 33. Schnitt, den Pharynx etwas schief von vorn und oben nach hinten und unten treffend, mit einem Flächenschnitte durch das dorsale Integument des Rüssels.

Fig. 15. Der 40. Schnitt mit dem Pharyngealzellensack.

Fig. 16. Der 51. Schnitt mit Pharyngealzellensack, Ösophagus und Speicheldrüsen.

Fig. 17. Der 67. Schnitt, Darm und Dotterstöcke darstellend.

Fig. IS. Der So. Schnitt, den proximalen Teil des Penis und dessen Drüsen sowie die Vasa deferentia treffend.

Fig. 19. Penisquerschnitt aus dem 86. Schnitte.

Fig. 20. Desgl. aus dem 90. Schnitte.

Fig. 21. Desgl. aus dem 93. Schnitte.

Fig. 22. Männliche Geschlechtsöffnung, Antrum masculinum, Chitinteile des Penis und Drüsen, aus dem 99.-102. Schnitte kombiniert.

Fig. 23. Medianschnitt durch Mund und Pharynx (der Rüssel R ist hier fast rechtwinklig abgeknickt), Vergr. $300 \mathrm{mal}$.

Fig. 24. Medianschnitt durch das Hinterende mit den beiden Geschlechtsöfnungen, Keimstock, Receptaculum seminis, Bursa copulatrix und Penis. Die Zeichnung ist aus mehreren Schnitten kombiniert und viele Details (namentlich des männlichen Apparates) weggelassen. Vergr. 30omal.

\section{Fig. 25-30. Genostoma tergestinum (C a la n d r.).}

Fig. 25. Das ungequetschte, kriechende Tier v. d. Bauchseite betrachtet, ca. 200 mal vergr.

Figs. 26. Quetschpräparat, das Vas deferens (vd) nur links, der Dotterstock (do) nur rechts eingezeichnet, die Drüsen weggelassen.

Fig. 27. Querschnitt aus der Mitte der Körperlänge (aus einer von Prof. L. Böhmig angefertigten Schnittserie), zoomal vergr.

Fig. 28. Formen der chitinösen Penisspitze, a Trichterform, b dieselbe im Profil, um die der Ventralfläche angehörige Mündung $\left(b_{I}\right)$ zu zeigen, c Spießform.

Fig. 20. Zwei "rätselhafte Organe", a mit zahlıeichen Drüsen, b mit einem feinkörnigen Tropfen an dem distalen Trichter.

Irig. 30. Ein ebensolches, di distales, pr proximales Ende, e blasige Erweiterung des Rolires. 


\title{
Fig. 31. Genostoma marsiliense ( $\mathrm{C}$ a landr.).
}

Das ungequetschte, kriechende Tier, ca. 250 mal vergr., die akzessorischen Drüsen des Geschlechts-Apparates sowie die Speicheldrüsen weggelassen.

\section{Buchstaben-Bezeichnung}

\author{
(exklusive a, b, c, di, e, pr).
}

$a d r$ Drüsen des Antrum masculinum.

$a d_{r_{I}}$ Ausführungsgänge von solchen.

bc Bursa copulatrix.

$b g, b g_{1}$ Bindegewebe.

$b g k$ Kerne desselben.

ca Schwanz-Anhang.

cad Schwanzdrüsen.

$c d$ r Drüsen (versenkte Matrixzellen?) der

Chitinteile des Penis.

$c d r_{I}$ Ausführungsgänge von solchen.

ch Chitinteile des Penis.

$c h_{I}$ Chitin-Anlaange der Bursa copulatrix.

ci Cilien.

cif Cilienfeld.

$d a, d a_{I}$ Darm

dak Kerne des Darmepithels.

do, do $o_{T_{1}}$ do ${ }_{I I}$ Dotterstock.

dr Akzessorische (Schleim-)Drüsen d. Penis.

dre Sekretkanal.

dvm Dorsoventrale Muskeln.

$e d r$ Erythrophile Körnerdrüsen des Penis.

cp Epithel des Integumentes.

$e p k, e p k_{l}$ Kerne desselben.

$G$ Gregarine.

gc Männlicher Genitalkanal.

$g$ Gehirn.

hm Hautmuskelschlauch.

le Kern.

klz Klebzelle.

kr Körnersekret.

$k s, k s_{I}$ Keimstock.

lm Längsmuskeln.

mdi, mdi $i_{I}$ Muskulöses Diaphragma.

mg Muskel- und Drüsengeflecht.

mm Muskularis.

mme Äußere Muskularis.

mmi Innere Muskularis.

mr Retraktor-Muskeln. $m r / 2$ Muskeln, von den sogen. „stäbchenförmigen Gebilden" ( $($ h $)$ entspringend.

ms Muskeln der Saugscheibe.

mu Muskelfasern und Muskularis.

nd Dorsale vordere Nerven.

$n l$ Seitliche Längsnerven.

$n v$ Ventrale vordere Nerven.

o Mund.

oe Ösophagus.

pe Penis.

ph Pharynx.

phep Pharyngealepithel.

pht Pharyngealtasche.

phz Pharyngealzellen.

phas Pharyngealzellensack.

$R$ Rüssel.

$r d m, r d m_{I}$ Radiärmuskeln.

rhe sieh sub $m r h$.

$R m$ Rüssel-Retralitoren.

rm Ringmuskeln.

$r p h$ Retralstoren des Pharynx.

rs Receptaculum seminis.

$s, s_{I}$ Drüsensekrete.

sad Drüsen der Saugplatte.

spd Speicheldrüsen.

$s p / 2$ Sphinkter-Muskeln.

$s p p$ Sekretpfröpfe der Speicheldrüsen.

$s s_{\text {, }} s s_{I}$ Saugplatte oder Vorderrand derselben.

te Hoden.

tuk Kerne der Tunica propria desselben.

"Vakuolen.

ad Vas deferens.

$v d_{I}$ Anschwellung desselben.

vs Samenblase.

$x$ Rätselhafte Organe.

* Beginn des Schwanz-Anhanges.

ơ Männliche Geschlechtsöffnung.

\& Weibliche Geschlechtsöffnung. 


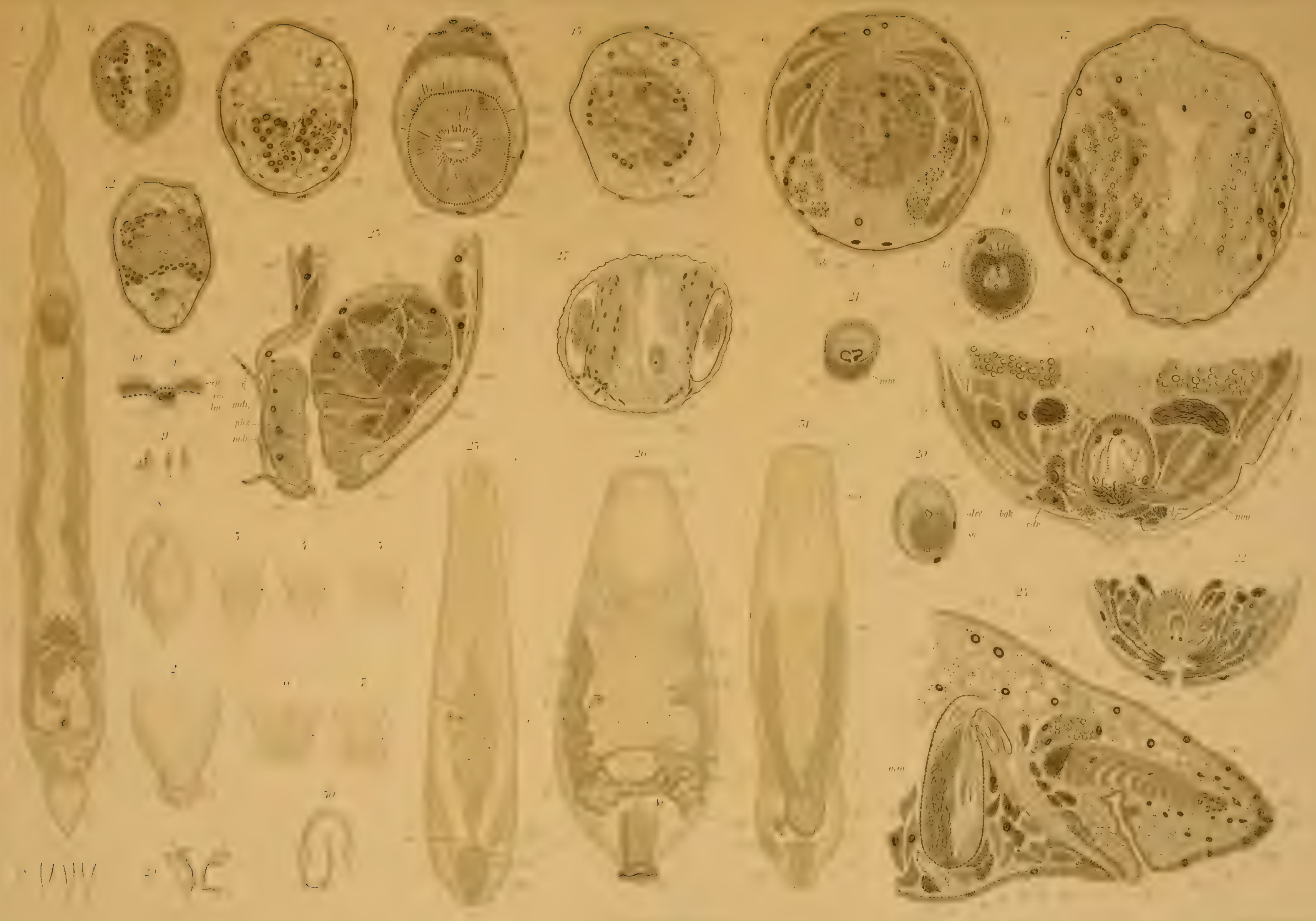








